\title{
A Liquid Density Standard Over Wide Ranges of Temperature and Pressure Based on Toluene
}

\begin{tabular}{l}
\hline Volume 113 \\
\hline Mark O. McLinden \\
Physical and Chemical Properties \\
Division \\
National Institute of Standards \\
and Technology, \\
Boulder, CO 80305-3328
\end{tabular}

\section{Jolene D. Splett}

Statistical Engineering Division National Institute of Standards and Technology,

Boulder, CO 80305-3328

markm@boulder.nist.gov jsplett@boulder.nist.gov

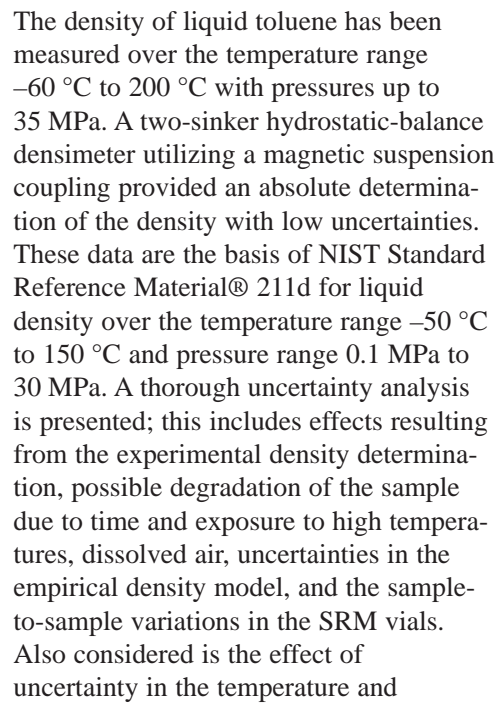

The density of liquid toluene has been measured over the temperature range $-60{ }^{\circ} \mathrm{C}$ to $200^{\circ} \mathrm{C}$ with pressures up to $35 \mathrm{MPa}$. A two-sinker hydrostatic-balance densimeter utilizing a magnetic suspension coupling provided an absolute determination of the density with low uncertainties. These data are the basis of NIST Standard Reference Material ${ }^{\circledR}$ 211d for liquid density over the temperature range $-50^{\circ} \mathrm{C}$ to $150^{\circ} \mathrm{C}$ and pressure range $0.1 \mathrm{MPa}$ to $30 \mathrm{MPa}$. A thorough uncertainty analysis is presented; this includes effects resulting from the experimental density determination, possible degradation of the sample due to time and exposure to high temperatures, dissolved air, uncertainties in the empirical density model, and the sampleto-sample variations in the SRM vials.

Also considered is the effect of uncertainty in the temperature and

January-February 2008

pressure measurements. This SRM is intended for the calibration of industrial densimeters.

Key words: calibration; density; standard reference material; toluene; uncertainty.

Accepted: February 19, 2008

\section{Introduction}

The property of fluid density is a vital parameter in a multitude of industrial processes. These include the control of chemical processes and the metering of fuels and other commodity chemicals. Often, the process stream is sampled through an industrial densimeter for continuous, real-time determination of the density. Such densimeters are not absolute instruments-they must be regularly calibrated at the conditions of use with fluids of known density.

The work presented here utilizes an absolute fluid densimeter to establish the density of toluene as a function of temperature and pressure for use as a calibration standard. The measured density data are presented, but of more relevance for calibration purposes, the density data are also represented in terms of an empirical function relating temperature, pressure, and density.
Toluene has a number of advantages as a density standard: it is a stable chemical of relatively low toxicity; its density of $865 \mathrm{~kg} / \mathrm{m}^{3}$ at ambient conditions is well matched to many applications; its freezing point of $-95{ }^{\circ} \mathrm{C}$ and boiling point of $111^{\circ} \mathrm{C}$ cover the range of many industrial processes. Toluene has a low surface tension compared to that of water, and it is relatively inexpensive. The National Institute of Standards and Technology (NIST) has sold a density Standard Reference Material $\left(\mathrm{SRM}^{\circledR}\right)$ based on toluene for many years, but the previous SRM was certified only at ambient conditions: $15^{\circ} \mathrm{C}$ to $25^{\circ} \mathrm{C}$ and normal atmospheric pressure.

This SRM certifies the density of a particular batch of toluene. This approach is preferred for high-accuracy calibrations over the alternative approach of measuring the density of "very pure" toluene for at least two reasons. First, a batch certification is directly traceable 
to NIST, and this is often a requirement for high-level calibration laboratories. Second, toluene in very high purities is difficult to obtain. High-quality commercial toluene (e.g., reagent grade or HPLC grade) is usually intended for use as a chemical precursor or as a solvent in various chemical analyses; it is certified to be free of contaminants (such as sulfur compounds) that would affect the analysis, but other impurities, such as closely related organic compounds, are often present. The use of "pure" toluene would greatly complicate the traceability of density and shift the problem to one of determining purity and/or the effects of impurities on the density.

This work describes the development of an extended-range SRM (designated as SRM 211d) for fluid density over wide ranges of temperature and pressure. First, the experimental principle, apparatus, and procedures are described. A description of the calibration procedures establishes traceability to SI quantities. The most significant uncertainties in the experimental determination of the fluid density are shown to arise from uncertainties in the sinker volumes, and the calibration of the sinker volumes is described in detail. Sections 4 and 5 present the results and a thorough analysis of the uncertainties.

\section{Experimental Determination of Density}

\subsection{Experimental Principle}

The two-sinker densimeter used in this work is described in detail by McLinden and Lösch-Will [1], and this general type of instrument is described by Wagner and Kleinrahm [2]. In the present densimeter two sinkers of nearly the same mass, surface area, and surface material, but very different volumes, are weighed separately with a high-precision balance while immersed in a fluid of unknown density. The fluid density $\rho$ is given by

$$
\rho=\frac{\left(m_{1}-m_{2}\right)-\left(W_{1}-W_{2}\right)}{\left(V_{1}-V_{2}\right)},
$$

where $m$ and $V$ are the sinker mass and volume, $W$ is the balance reading, and the subscripts refer to the two sinkers. The main advantage of the two-sinker method is that adsorption onto the surface of the sinkers, systematic errors in the weighing, and other effects that reduce the accuracy of most buoyancy techniques cancel.

A magnetic suspension coupling transmits the gravity and buoyancy forces on the sinkers to the balance, thus isolating the fluid sample (which may be at high pressure and/or extremes of temperature) from the balance. The central elements of the coupling are two magnets, one on each side of a nonmagnetic pressureseparating wall. The top magnet, which is an electromagnet with a ferrite core, is hung from the balance. The bottom (permanent) magnet is held in stable suspension with respect to the top magnet by means of a feedback control circuit making fine adjustments in the electromagnet current. The permanent magnet is linked with a lifting device to pick up a sinker for weighing. A mass comparator with a resolution of $1 \mu \mathrm{g}$ and a capacity of $111 \mathrm{~g}$ is used for the weighings. Each sinker has a mass of $60 \mathrm{~g}$; they are fabricated of tantalum and titanium and are both gold plated.

Equation (1) must be corrected for magnetic effects; this is described by McLinden et al. [3]. In addition to the sinkers, two calibration masses are also weighed. Figure 1 shows a schematic of the density measuring cell and the four weighings. The weighings yield a set of four equations that are solved to yield, first, a balance calibration factor $\alpha$ and a parameter $\beta$ related to the balance tare (i.e., those elements of the system that are always weighed):

$$
\begin{aligned}
& \alpha=\frac{W_{\text {cal }}-W_{\text {tare }}}{\left(m_{\text {cal }}-m_{\text {tare }}\right)-\rho_{\text {air }}\left(V_{\text {cal }}-V_{\text {tare }}\right)} \text { and } \\
& \beta=\frac{W_{\text {cal }}}{\alpha}-\left(m_{\text {cal }}-\rho_{\text {air }} V_{\text {cal }}\right) .
\end{aligned}
$$

where the subscripts cal and tare refer to the calibration weights; $\rho_{\text {air }}$ is the density of the air (or purge gas) surrounding the balance and is calculated from the ambient temperature, pressure, and humidity measured in the balance chamber. In all the measurements reported here, the balance chamber was continuously purged with nitrogen. The "coupling factor" $\phi$, which is the efficiency of the force transmission of the magnetic suspension coupling, is given by

$$
\phi=\frac{\left(W_{1} / \alpha\right)-\beta}{m_{1}-\rho_{\text {fluid }} V_{1}} .
$$

Finally, the fluid density $\rho_{\text {fluid }}$ is given by

$$
\rho_{\text {fluid }}=\frac{\left[\left(m_{1}-m_{2}\right)-\frac{\left(W_{1}-W_{2}\right) m_{1}}{W_{1}-\alpha \beta}\right]}{\left[\left(V_{1}-V_{2}\right)-\frac{\left(W_{1}-W_{2}\right) V_{1}}{W_{1}-\alpha \beta}\right]}-\rho_{0},
$$

where $\rho_{0}$ is the indicated density when measuring in vacuum. In other words $\rho_{0}$ is an "apparatus zero," 


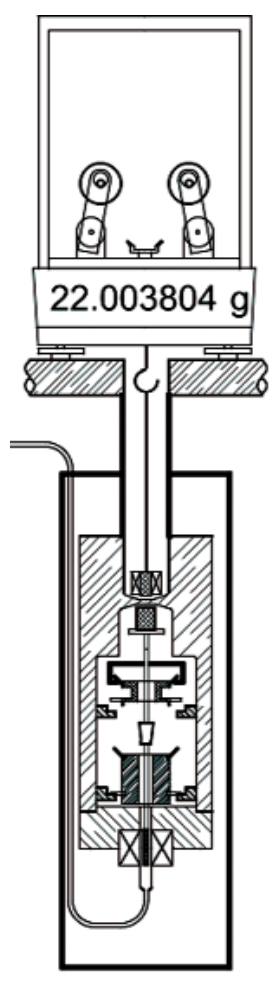

(a)

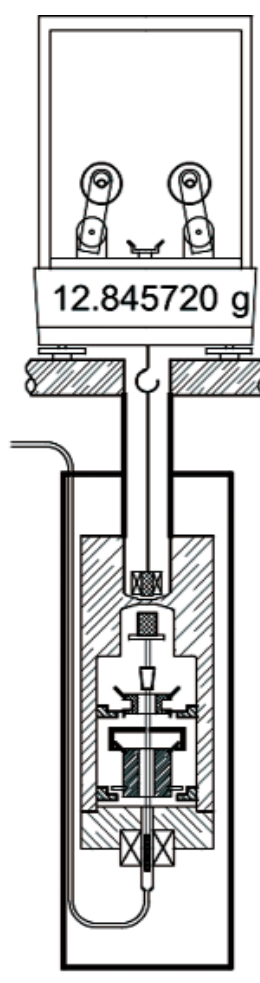

(b)

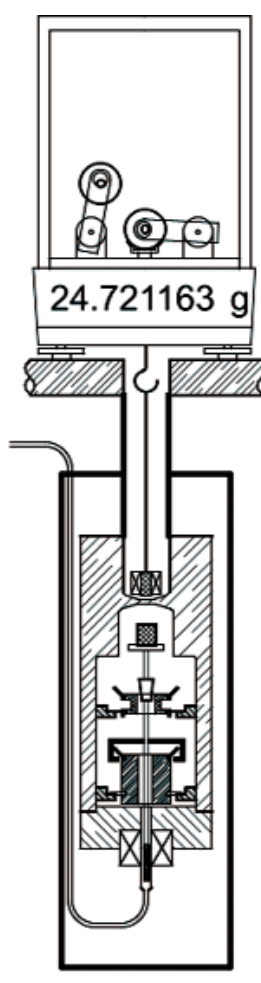

(c)

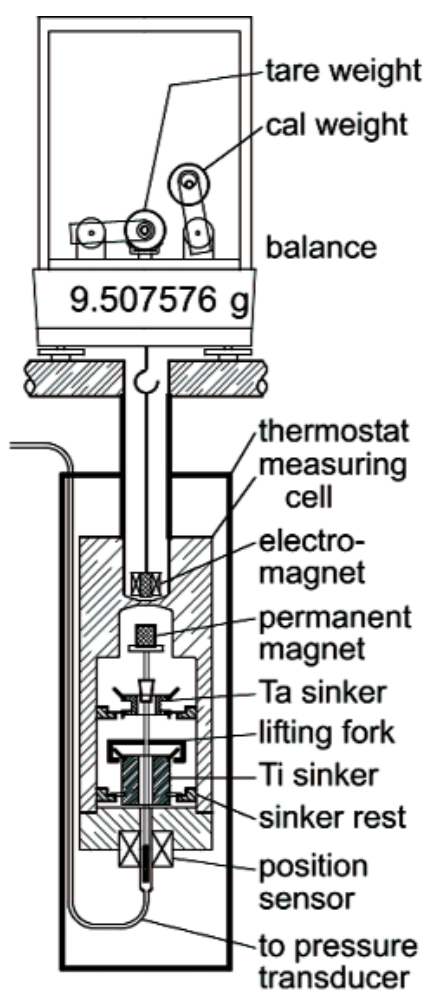

(d)

Fig. 1. Schematic of the two-sinker densimeter showing the four weighings; (a) weighing of the tantalum sinker, (b) weighing of the titanium sinker, (c) weighing of the balance calibration weight, and (d) weighing of the balance tare weight; in (c) and (d) both sinkers are on their rests. Balance displays are typical for a fluid density of $941 \mathrm{~kg} / \mathrm{m}^{3}$. Figure is not to scale.

which compensates for any changes in alignment or sinker masses. (The sinker masses were observed to change on the order of a few $\mu$ g due to surface contamination and physical wear where they were picked up. Any shift in the alignment of the magnetic suspension coupling will result in a slight change in the apparent sinker masses.) The key point of the analysis by McLinden et al. [3] is that the density given by Eq. (5) compensates for the magnetic effects of both the apparatus and fluid being measured. With this apparatus, the coupling factor is nearly unity; for the present results it varied from 1.000020 for vacuum to 0.999975 for toluene at the highest density measured.

\subsection{Apparatus Description}

In addition to the sinkers, suspension coupling, and balance that make up the density measuring system, the apparatus includes a thermostat, pressure instrumentation, and a sample handling system. A schematic diagram of the densimeter is shown as Fig. 2.
The temperature is measured with a standard-reference-quality platinum resistance thermometer (SPRT) and resistance bridge referenced to a thermostatted standard resistor. The signal from the SPRT is used directly in a digital control circuit to maintain the cell temperature constant within $\pm 0.001 \mathrm{~K}$. The pressures are measured with state-of-the-art transducers combined with careful calibration. The transducers (as well as the pressure manifold) are thermostatted to minimize the effects of variations in laboratory temperature.

The thermostat serves to isolate the measuring cell from ambient. It is a vacuum-insulated, cryostat-type design. The measuring cell is surrounded by an isothermal shield, which thermally isolates it from variations in ambient temperature; this shield was maintained at a constant $( \pm 0.01 \mathrm{~K})$ temperature $1 \mathrm{~K}$ below the cell temperature. Electric heaters compensate for the small heat flow from the cell to the shield and allow millikelvin-level control of the cell temperature. Operation at sub-ambient temperatures is effected by circulating ethanol from a chiller through channels in the shield. 


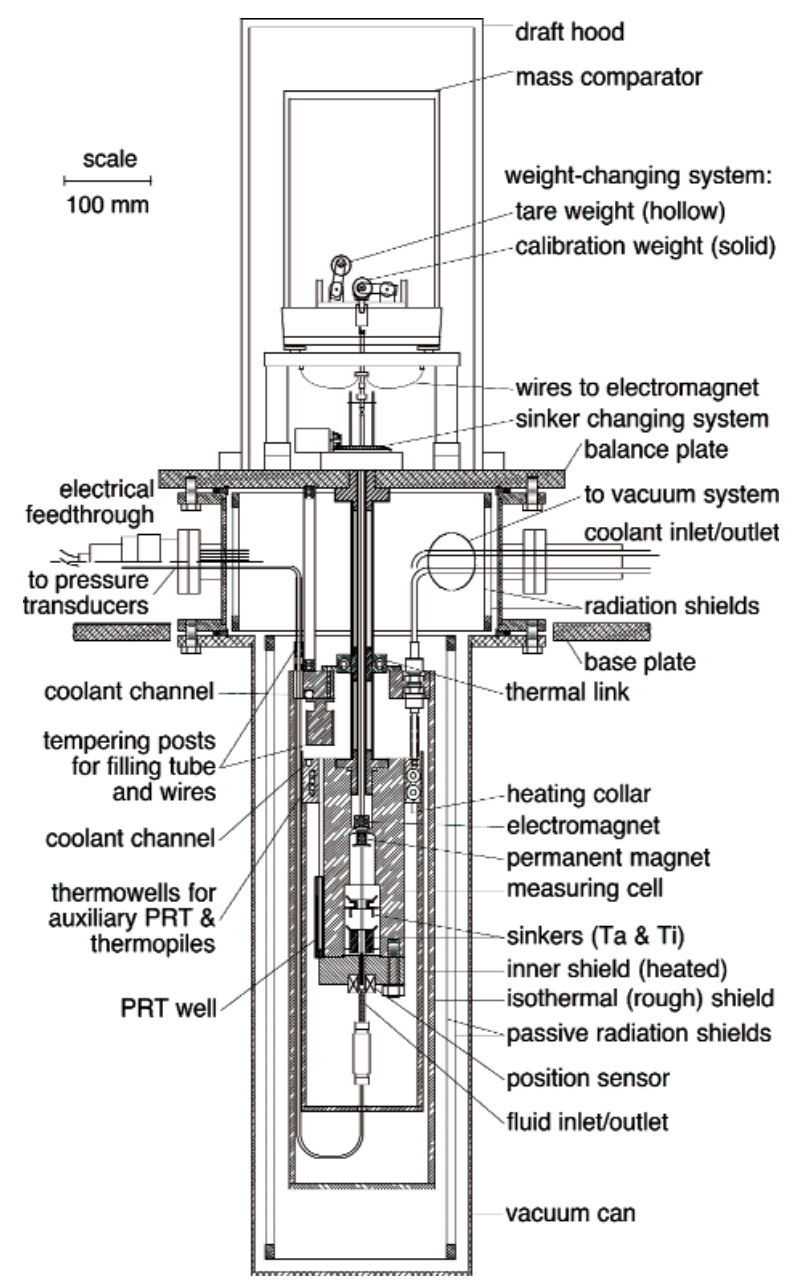

Fig. 2. Detailed schematic of the density system and thermostat.

\subsection{Experimental Material}

The material used is identical to the previous SRM, which is described as "a high purity liquid toluene ... obtained from a commercial source." [4] The SRM is provided in $5 \mathrm{~mL}$ flame-sealed glass ampoules. At the same time the $5 \mathrm{~mL}$ ampoules were prepared, several large $1.5 \mathrm{~L}$ flame-sealed ampoules were also prepared containing the same toluene. We worked with material from one of the $1.5 \mathrm{~L}$ ampoules, except for some of the chemical analysis, which used the $5 \mathrm{~mL}$ ampoules. We transferred the toluene from the $1.5 \mathrm{~L}$ ampoule to a $2.5 \mathrm{~L}$ stainless-steel sample cylinder for convenience in sample handling.

The sample was degassed by freezing the stainlesssteel cylinder in liquid nitrogen, evacuating the vapor space, and thawing. The freeze/pump/thaw process was repeated a total of three times. The residual pressure over the frozen sample on the final cycle was
$0.0002 \mathrm{~Pa}$. The SRM as supplied by NIST contains some amount of dissolved air. The sample was degassed to obtain a well characterized state for the measurements. Also, we were concerned that dissolved air could react with the toluene at the elevated temperatures measured in this work. We felt that the uncertainties introduced by "purifying" the SRM material in this way would be offset by a reduction in possible effects resulting from reaction of the toluene with air. This point is discussed further in Sec. 4.3.

A chemical analysis by gas chromatography-mass spectrometry revealed the presence of trace levels of dimethyl benzenes and ethyl benzene; these are heavier impurities that would be expected to be present in toluene. A quantitative analysis by gas chromatography with a flame ionization detector yielded an overall purity of $99.92 \%$ toluene with a standard uncertainty of $0.01 \%$. The sample was collected following the density measurements and reanalyzed; no significant differences were detected.

To quantify the effect of dissolved air on the density, additional measurements were made on a sample that was saturated with air at a temperature of $20^{\circ} \mathrm{C}$ and pressure of $0.10 \mathrm{MPa}$. A quantity of the degassed toluene was transferred to an evacuated $500 \mathrm{~mL}$ stainless steel sample cylinder. Dry air was admitted to the cylinder to a pressure of $0.10 \mathrm{MPa}$; additional air was admitted periodically over the course of 24 hours to maintain the pressure at $0.10 \mathrm{MPa}$. The cylinder was periodically mixed to promote equilibrium. The air used was commercial "breathing air" with a moisture specification of $3 \mathrm{ppm}$. (Breathing air is air of normal atmospheric composition that has been dried.)

\subsection{Experimental Procedures}

Each density determination involved weighings in the order: tantalum (Ta) sinker, titanium (Ti) sinker, balance calibration weight, balance tare weight, balance tare weight (again), balance calibration weight, Ti sinker, and Ta sinker, for a total of eight weighings - two for each object. For each weighing, the balance was read five times over the course of ten seconds. For each object, the ten balance readings were averaged for use in Eqs. (2 to 5). Between each of the object weighings, and also before the first weighing and following the final weighing, the temperature and pressure were recorded, for a total of nine readings of $t$ and $p$; these were also averaged. A complete density determination required $12 \mathrm{~min}$. The weighing design was symmetrical with respect to time, and this tended to cancel the effects of any drift in the temperature or pressure. 
The sample was loaded at a low temperature and pressure. Higher pressures were generated by heating the liquid-filled cell; this avoided the need for any type of compressor, which could have been a source of contamination, such as residual material from a previous test fluid. Starting at the lowest temperature and pressure for a given filling, measurements were made at increasing temperatures (and nearly constant density) until the maximum desired pressure was reached. The sample was then vented to a lower pressure along an isotherm.

The densimeter control program monitored the system temperatures and pressures once every 60 seconds. A running average and standard deviation of the temperatures and pressures were computed for the preceding eight readings. When these were within preset tolerances of the set-point conditions, a weighing sequence was triggered. Once the specified number of replicate density determinations were made at a given $(t, p)$ state point, the control program then moved to the next temperature or automatically vented the sample to the next pressure on an isotherm.

Between each filling, and also before the first filling and following the last filling, the system was evacuated and the density recorded multiple times. The indicated density was used to determine the apparatus zero $\rho_{0}$. The value of $\rho_{0}$ used in Eq. (5) is the time-weighted average of $\rho_{0}$ values measured before and after a given density determination.

\section{Calibrations}

\subsection{Temperature and Pressure}

The main platinum resistance thermometer (SPRT) used to measure the temperature of the fluid was calibrated on ITS-90 from $83 \mathrm{~K}$ to $505 \mathrm{~K}$ by use of fixed point cells (argon triple point, mercury triple point, water triple point, indium freezing point and tin freezing point). This was done as a system calibration, meaning that the SPRT was removed from its thermowell in the measuring cell and inserted into the fixed point cell using the same lead wires, standard resistor, and resistance bridge that were used in the density measurements. The manufacturers of the fixed points have certified traceability to NIST and provide a temperature uncertainty of $1 \mathrm{mK}$ or less. The fixed points and our calibration procedures were verified by checking each of the fixed point systems against a NISTcalibrated SPRT.

A full calibration of the main SPRT was carried out two months prior to the beginning of the toluene measurements. The resistance at the triple point of water was checked 16 months later; the resistance had changed by the equivalent of $0.5 \mathrm{mK}$. The standard $(k=1)$ uncertainty in the temperature, including uncertainty in the fixed point cells, drift in the SPRT, and temperature gradients between the SPRT and the actual fluid sample, is estimated to be $2 \mathrm{mK}$.

The pressure transducer was calibrated with a hybrid gas-oil piston gage system at pressures up to $40 \mathrm{MPa}$. Again, this calibration was done in-situ by connecting the piston gage to the sample port of the filling manifold. Based on the uncertainty for the piston gage, the repeatability observed for these transducers, and the uncertainties associated with the hydrostatic head correction, we estimate the standard uncertainty in pressure to be $\left[(0.000026 \cdot p)^{2}+(2.0 \mathrm{kPa})^{2}\right]^{0.5}$, where the first term arises from uncertainties in the calibration, and the second term is a conservative estimate of the uncertainties arising from the head correction and the drift in the pressure transducer between calibrations.

\subsection{Balance Calibration}

An automated calibration of the mass comparator (i.e., the $\alpha$ in Eq. (2)) is an integral part of each density determination; it was achieved by a mechanism that lowers tare and calibration weights onto a modified balance pan. (The tare weight is required because the balance has a limited weighing range; without the tare weight, the balance would be "under-range.") The weights were cylindrical in shape and fabricated of stainless steel (calibration weight) and hollow stainless steel (tare weight) with a mass difference of $15.2 \mathrm{~g}$. The masses of these weights were determined by an SXXStype comparison to standard masses [5]. The correction for air buoyancy on the standard mass was calculated by use of the BIPM air density equation [6] with ambient conditions measured with an electronic barometer and a temperature and humidity transmitter with the sensor located next to the balance.

The two weights were nearly identical in volume and surface area. The volumes of the calibration weights were determined by a simple hydrostatic determination using water as the density reference. Each volume was determined to be $7.4788 \mathrm{~cm}^{3}$. This provided a balance calibration that is very nearly independent of the density of the air or nitrogen purge gas surrounding the balance.

\subsection{Sinker Volumes at $20^{\circ} \mathrm{C}$}

Uncertainty in the sinker volumes was the major component of the overall fluid density uncertainty (as discussed in Sec. 5), and considerable effort was expended in determining these volumes accurately. The 
sinker volumes were determined using the hydrostatic comparator technique described by Bowman et al. $[7,8]$. This method differs from the traditional hydrostatic technique in that the known density is that of a solid object rather than that of a reference fluid, such as water. The standard and unknown objects are suspended in a fluid, but the fluid serves only to transfer the density knowledge of the standard to that of the unknown. The density of the fluid itself need not be known - it needs only to be constant during the period necessary to complete the measurement.

\subsubsection{Hydrostatic Apparatus}

A separate apparatus has been developed at NIST to carry out the sinker volume determinations. It is modeled closely after the apparatus of Bowman et al. [7]. A thermostatted fluid bath contains a "stage" that allows the submerged objects to be placed one at a time onto a weighing "pan" that is suspended from the weighing hook of an analytical balance. The apparatus is shown in Fig. 3.

The fluid bath is a custom-built triple-walled beaker of borosilicate glass. The inner volume (approximately $170 \mathrm{~mm}$ inside diameter by $295 \mathrm{~mm}$ high) contains the hydrostatic fluid. It is surrounded by a water jacket

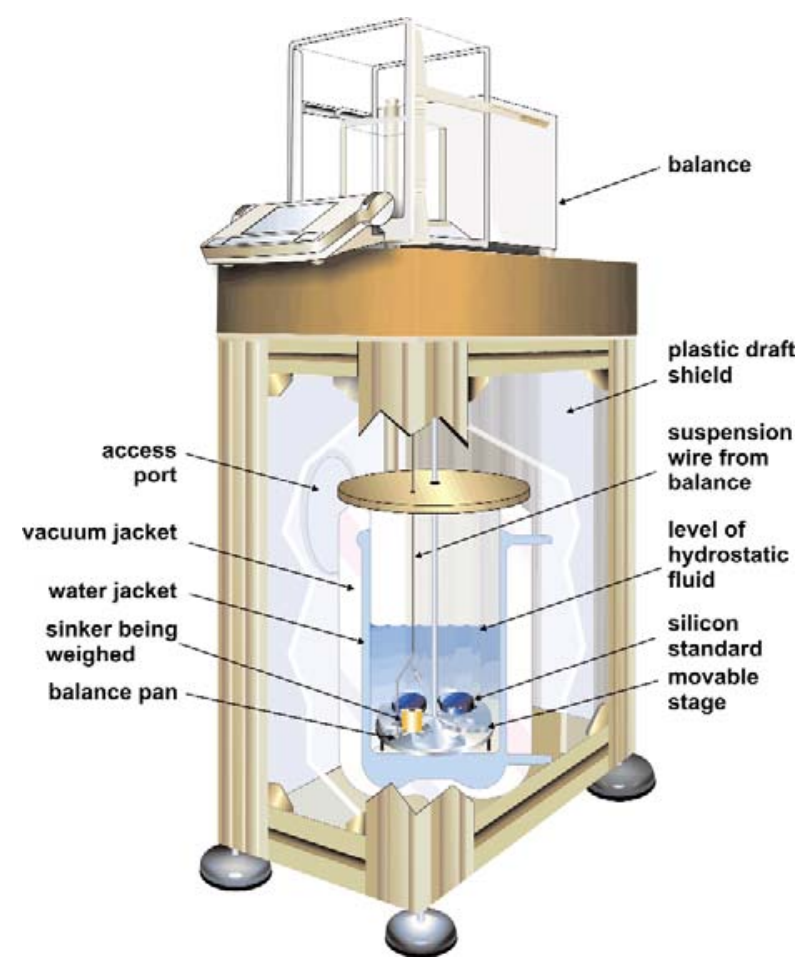

Fig. 3. Cut-away view of the hydrostatic apparatus used to determine sinker volumes. connected to a circulating bath. The outermost jacket is evacuated for thermal insulation. A brass cover plate serves to minimize evaporation and temperature gradients. The bath is contained within a sturdy aluminum frame with plastic side panels to control drafts. The frame is topped by a $40 \mathrm{~kg}$ limestone block on which the balance sits.

The bath fluid is a high-density fluoroether (2-trifluoromethyl-3-ethoxydodecafluorohexane). This fluid has several advantages over water. Its high density of approximately $1631 \mathrm{~kg} / \mathrm{m}^{3}$ increases the buoyancy force on the submerged objects and thus the sensitivity of the volume determination. Its lower surface tension (16 N/m compared to $73 \mathrm{~N} / \mathrm{m}$ for water) decreases the forces on the suspension wire. This and the much higher gas solubility compared to that of water greatly reduce the problems associated with small air bubbles clinging to the objects.

The temperature of the fluid bath was measured with a standard-reference-quality SPRT in a thermowell located in close proximity to the weighing pan. The SPRT was calibrated on ITS-90 at the triple point of water $\left(0.01^{\circ} \mathrm{C}\right)$ and the melting point of gallium $\left(29.7646^{\circ} \mathrm{C}\right)$. The circulating bath was started at least 16 hours prior to the weighings to allow temperature equilibrium to be achieved. During the weighings, the standard deviation of the bath temperature was $1.7 \mathrm{mK}$, with a maximum deviation of $6 \mathrm{mK}$ from the average value of $293.135 \mathrm{~K}$.

The stage is a simple "turntable" that holds the objects to be weighed. It was manually lifted and rotated (using a central axle extending above the bath cover plate) to place the objects on the weighing pan. The weighing pan was suspended from the balance with a stainless steel wire $0.08 \mathrm{~mm}$ in diameter. The balance had a capacity of $205 \mathrm{~g}$, resolution of $10 \mu \mathrm{g}$, and linearity of $30 \mu \mathrm{g}$. The balance was calibrated immediately before each determination with its built-in calibration weights and automatic calibration sequence. The balance was then checked with a $100 \mathrm{~g}$ standard mass (class E2; certified mass $99.99994 \pm 0.00005$ g). The balance reading was consistently low by an average of $0.14 \mathrm{mg}$, and an adjustment of $1.4 \mathrm{ppm}$ was applied to all subsequent balance readings to compensate for this difference.

The standards are made of hyperpure, float-zone, single-crystal silicon. They are in the shape of right circular cylinders $(49.8 \mathrm{~mm}$ diameter by $22.1 \mathrm{~mm}$ high) with a nominal mass of $100 \mathrm{~g}$. Their densities were determined and certified by the NIST Mass Group [9] with an expanded $(k=2)$ uncertainty of $0.000032 \mathrm{~g} / \mathrm{cm}^{3}$, which is equal to $0.0014 \%$ of their 
density of $2.329095 \mathrm{~g} / \mathrm{cm}^{3}$. This determination was carried out using techniques very similar to those described here. The density standards used by the NIST Mass Group were silicon crystals that are the U.S. national solid-density standards. In fact, they are the artifacts described by Bowman et al. [7], which are directly traceable to densities determined by dimensional measurements of near-perfect spheres by interferometry and mass measurements commencing with the U.S. national mass standards. Silicon is an ideal density standard because single-crystal material of very high purity is readily available at moderate cost. Its coefficient of thermal expansion and, thus, variation in density as a function of temperature, are known very well [10].

\subsubsection{Experimental Design}

The hydrostatic apparatus accommodates four objects-two standards and two unknowns. This allows the simultaneous determination of the volumes of the tantalum and titanium sinkers and also provides the redundancy that permits a statistical analysis of the measurements. The experiment involves a series of A-B-A type weighings to yield ratios of the volumes of A and B. Bowman et al. [7] described a set of 15 weighings needed to determine six volume ratios. Here, the design was modified slightly to 16 weighings:

\section{A-B-A-C-A-D-A-D-B-D-C-D-C-B-C-B,}

where " $\mathrm{A}$ " is standard \#1, " $\mathrm{B}$ " is the tantalum sinker, " $C$ " is standard \#2, and " $D$ " is the titanium sinker. This design yields the ratios $\mathrm{AB}, \mathrm{AC}, \mathrm{AD}, \mathrm{DA}, \mathrm{DB}, \mathrm{DC}, \mathrm{CD}$, $\mathrm{CB}$ and $\mathrm{BC}$, or three more ratios than in the Bowman sequence, for only one additional weighing.

Each "weighing" in the experimental design consisted of the following steps:

1. Raise and rotate the stage to place the desired object into position above the weighing pan (this is defined as time 0:00).

2. Record the bath temperature and the balance reading for the empty weighing pan at time 8:00. (Rotation of the stage causes turbulence in the bath, and so several minutes were needed for this to subside.)

3. Lower the stage to place the object onto the weighing pan shortly after step 2 (approximately 8:30 to 9:00).
4. Record the bath temperature and the balance reading for the loaded weighing pan at time 16:00.

This sequence was repeated 15 more times (plus an additional weighing of the empty pan at the end) for a total elapsed time of $264 \mathrm{~min}$. The thermometer and balance readings were recorded by computer within a few milliseconds of the specified times. This strict adherence to timing and the A-B-A design compensated for any linear drift in the balance zero and/or drift in the fluid density over the course of the experiment. The time between weighings was more than adequate to allow turbulence to subside (steady weighings were typically observed within three minutes of moving the stage). Also, the object was in the proximity of the SPRT for nearly 15 min before it was weighed, allowing time for temperature equilibration with the fluid in the vicinity of the SPRT. At the end of the complete weighing sequence the balance was tared (but not recalibrated) and again checked with the $100 \mathrm{~g}$ class E2 mass; the drift was less than $0.08 \mathrm{mg}$.

The masses of the sinkers and standards were determined at least twice on different days and the average value used in the analysis. A conventional mass determination in air was carried out using the balance. The correction for air buoyancy was calculated with the BIPM air density equation [6] with ambient conditions measured with an electronic barometer and a temperature and humidity transducer with the sensor located next to the balance.

Each balance weighing $W$ is a summation of mass and buoyancy terms. For the empty pan

$$
W_{\text {pan }}=\left[m_{\text {pan }}-\rho_{\text {fluid }} V_{\text {pan }}\right] /\left(1-\frac{\rho_{\text {air }}}{\rho_{\text {weights }}}\right),
$$

where $m$ is mass, $V$ is volume and $\rho$ is density. For the pan loaded with object "B"

$$
W_{\mathrm{pan}+\mathrm{B}}=\frac{\left[m_{\mathrm{pan}}+m_{\mathrm{B}}-\rho_{\text {fluid }}\left(V_{\mathrm{pan}}+V_{\mathrm{B}}\right)\right]}{\left(1-\frac{\rho_{\text {air }}}{\rho_{\text {weights }}}\right)} .
$$

The $\left(1-\rho_{\text {air }} / \rho_{\text {weights }}\right)$ terms correct for air buoyancythe balance was calibrated in air with stainless steel calibration masses with density $\rho_{\text {weights }}$, but the submerged objects are not subject to air buoyancy. The air density in Eqs. (6) and (7) is that at the time of the balance calibration. 
The average of the pan weighings immediately preceding and following each object weighing were subtracted from Eq. (7) to yield

$$
W_{\mathrm{B}}=\left[m_{\mathrm{B}}-\rho_{\text {fluid }} V_{\mathrm{B}}\right] /\left(1-\frac{\rho_{\text {air }}}{\rho_{\text {weights }}}\right) \text {. }
$$

(Equations (6) to (8) are properly written in terms of force, not mass, since the balance used is a force transducer. But the acceleration of gravity cancels, and, by convention, the $m \times g$ force measured by the balance is recorded in terms of mass.)

Combining Eq. (8) with the average of two similar equations for the weighings of a second object immediately preceding and following the weighing of object $\mathrm{B}$ (i.e., the weighings of a A-B-A sequence) cancels the fluid density to yield the volume ratio:

$$
\frac{V_{\mathrm{A}}}{V_{\mathrm{B}}}=\frac{m_{\mathrm{A}}-W_{\mathrm{A}}\left(1-\rho_{\text {air }} / \rho_{\text {weights }}\right)}{m_{\mathrm{B}}-W_{\mathrm{B}}\left(1-\rho_{\text {air }} / \rho_{\text {weights }}\right)} .
$$

The measured volume ratios were determined at a temperature that differed slightly from the desired reference temperature of $20^{\circ} \mathrm{C}$. A small (maximum $0.26 \mathrm{ppm}$ ) correction was applied using literature values of the thermal expansion coefficient (Swenson [10] for silicon and Touloukian et al. [11] for tantalum and titanium) to adjust the volume ratios to the reference temperature.

\subsubsection{Results for Sinker Volumes}

The volume ratios and resulting sinker volumes are given in Table 1 . The experimental design provides a number of consistency checks. The repeat determinations of the volumes were very consistent, with a standard deviation of $0.000003 \mathrm{~cm}^{3}$ for the tantalum sinker and $0.000023 \mathrm{~cm}^{3}$ for the titanium sinker. Knowledge of the fluid density is not required, but the fluid density can be calculated from the results. (In fact, the apparatus serves as a highly sensitive single-sinker densimeter.) The fluid density was observed to have a nearly constant linear drift of $0.55 \times 10^{-6} \rho / \mathrm{hr}$. This could be due to a drift in the balance calibration and/or absorption of air and water into the fluid, but in either case the effect was negligible over the $48 \mathrm{~min}$ required to complete an A-B-A weighing sequence.

The experimental design also yields the volume ratios of the two standards and of the two sinkers; these allow a further check of consistency. The measured volume ratio of the silicon standards (ratio AC) can be compared to the value calculated with the known values of mass and density. The directly measured ratio of the sinker volumes (ratio DB) can be compared to the value obtained from the volumes calculated from the other ratios. These are compared in Table 2 and are seen to be well within the expected uncertainties discussed below.

\begin{tabular}{|c|c|c|c|c|c|}
\hline Object & Ratio & $\begin{array}{c}\text { Measured } \\
\text { Volume Ratio }\end{array}$ & $\begin{array}{l}\text { Ratio Adjusted } \\
\text { to } 20^{\circ} \mathrm{C}\end{array}$ & $\begin{array}{l}\text { Mass } \\
(\mathrm{g})\end{array}$ & $\begin{array}{l}\text { Volume } \\
\left(\mathrm{cm}^{3}\right)\end{array}$ \\
\hline \multirow[t]{5}{*}{ tantalum sinker } & $\mathrm{AB}$ & 11.746127 & 11.746129 & & 3.610246 \\
\hline & $\mathrm{CB}$ & 11.774715 & 11.774718 & & 3.610248 \\
\hline & $\mathrm{BC}$ & 0.084928 & 0.084928 & & 3.610242 \\
\hline & average & & & 60.17796 & 3.610245 \\
\hline & & & & & $\sigma=0.000003$ \\
\hline \multirow[t]{6}{*}{ titanium sinker } & $\mathrm{AD}$ & 3.177097 & 3.177098 & & 13.347530 \\
\hline & DA & 0.314753 & 0.314753 & & 13.347530 \\
\hline & DC & 0.313989 & 0.313989 & & 13.347572 \\
\hline & CD & 3.184823 & 3.184824 & & 13.347566 \\
\hline & average & & & 60.16341 & 13.347549 \\
\hline & & & & & $\sigma=0.000023$ \\
\hline
\end{tabular}

Table 1. Volume ratios and volumes determined by hydrostatic weighing

Table 2. Volume ratios determined by hydrostatic weighing compared to calculated values

\begin{tabular}{cccc}
\hline \hline Ratio & Measured Value & Calculated Value & Difference \\
\hline AC & 0.997576 & 0.997571 & 0.000005 \\
DB & 3.697088 & 3.697131 & -0.000043 \\
\hline
\end{tabular}




\section{Results-Density of SRM 211d}

\subsection{Experimental Results}

The SRM toluene was measured at 195 separate temperature and pressure state points; at most state points, five repeat density determinations were carried out for a total of $975 p-\rho-T$ data points, as shown in Fig. 4. These measurements represent three separate fillings. The measurements proceeded from low temperature to high temperature for each filling, except that after high-temperature measurements had been completed for fillings 2 and 3, the sample was cooled and measured again at $40^{\circ} \mathrm{C}$. (This required adding a small quantity of fresh sample to the cell, and these are referred to as fillings 2a, 3a, and 3b.) This provided a check on consistency between the fillings and also on any possible degradation of the sample due to exposure to high temperatures. These measurements were carried out January thru March, 2006; the experimental points are given in Table A1 (see 7. Appendix A).

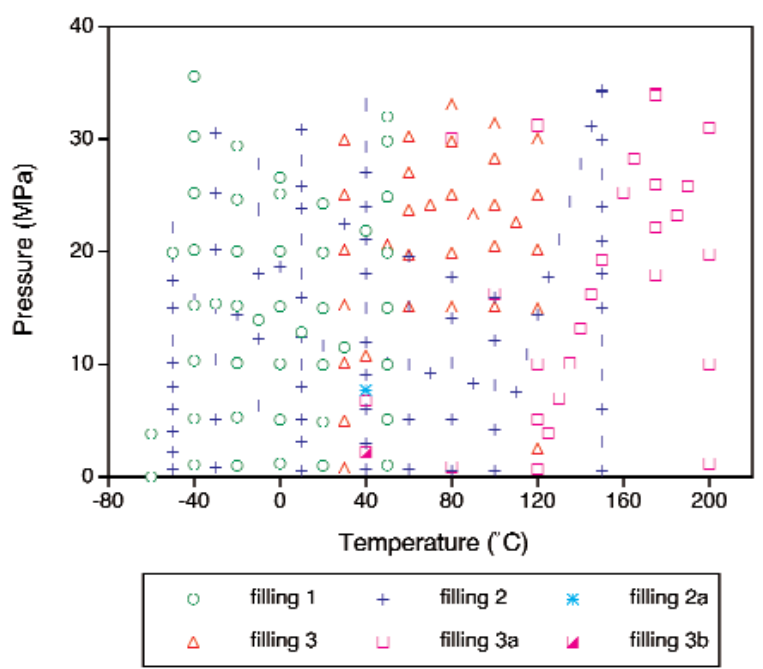

Fig. 4. Temperature-pressure state points measured for the SRM toluene; the different symbols represent the different fillings.

The effect of dissolved air was investigated with a separate set of measurements carried out in May 2007. An abbreviated set of measurements with the original (degassed) sample covered the temperature range $-40^{\circ} \mathrm{C}$ to $150^{\circ} \mathrm{C}$, with pressures to $32 \mathrm{MPa}$. Selected replicate measurements were made at $-40{ }^{\circ} \mathrm{C}$ to $50{ }^{\circ} \mathrm{C}$ in a separate filling. The density was measured at
51 temperature and pressure state points with an average of four repeat density determinations per state point, for a total of $216 p-\rho-T$ data points. The air-saturated sample was then measured at similar temperatures and pressures at 40 temperature and pressure state points for a total of $180 p-\rho-T$ data points. Following the measurements at $150{ }^{\circ} \mathrm{C}$, the sample was cooled to $50^{\circ} \mathrm{C}$ and measured again. The data for the degassed sample are given in Table A2 and the air-saturated data are given in Table A3 (see 7. Appendix A).

\subsection{Estimated Fluid Density}

The fluid density is represented using a 20-parameter empirical model

$$
\rho=\sum_{k=1}^{8} a_{k}\left(\frac{T}{100}\right)^{-b_{k}} p^{c_{k}},
$$

where $T$ is temperature and $p$ is pressure in $\mathrm{MPa}$. (We use $T$ to indicate temperatures in kelvins and $t$ for temperatures in ${ }^{\circ} \mathrm{C}$.) In fitting the model parameters, shown in Table 3, we excluded points with $t<-50^{\circ} \mathrm{C}$ or $t>150^{\circ} \mathrm{C}$. The empirical model can be used to estimate the density for any temperature in the range of $-50{ }^{\circ} \mathrm{C}$ to $150{ }^{\circ} \mathrm{C}(223.15 \mathrm{~K}$ to $423.15 \mathrm{~K})$ and any pressure in the range of $0.1 \mathrm{MPa}$ to $30 \mathrm{MPa}$. The lower pressure limit represents a modest extrapolation of the experimental data; the upper pressure limit is conservative, since we used the data at $p>30 \mathrm{MPa}$ in the fit. Table 4 gives values of $\rho$, calculated from Eq. (10) for even increments of temperature and pressure. Figure 5 displays the density measurements versus temperature and pressure that were used to fit the 20-parameter model.

Table 3. Parameters for empirical model (Eq. 10)

\begin{tabular}{cccc}
\hline \hline$k$ & $a_{k}$ & $b_{k}$ & $c_{k}$ \\
\hline 1 & $0.118648 \times 10^{4}$ & 0 & 0 \\
2 & $-0.133648 \times 10^{3}$ & -0.80 & 0 \\
3 & $-0.119260 \times 10^{-1}$ & -5.34 & 0 \\
4 & 0.229402 & -0.10 & 1.00 \\
5 & $0.187212 \times 10^{-4}$ & -7.60 & 1.00 \\
6 & $0.661127 \times 10^{-1}$ & -2.20 & 1.15 \\
7 & $-0.249953 \times 10^{-1}$ & -2.24 & 1.30 \\
8 & $-0.280091 \times 10^{-5}$ & -7.93 & 1.30 \\
\hline
\end{tabular}


Volume 113, Number 1, January-February 2008

Journal of Research of the National Institute of Standards and Technology

Table 4. Estimated fluid density $\rho$ in $\mathrm{kg} / \mathrm{m}^{3}$ for degassed samples ( $\mathrm{g}=0 \mathrm{~kg} / \mathrm{m}^{3}$ ) calculated from Eq. (10)

\begin{tabular}{|c|c|c|c|c|c|c|c|c|c|}
\hline \multirow[b]{2}{*}{$t\left({ }^{\circ} \mathrm{C}\right)$} & \multicolumn{9}{|c|}{ Pressure (MPa) } \\
\hline & 0.1 & 1 & 2 & 5 & 10 & 15 & 20 & 25 & 30 \\
\hline-50 & 931.655 & 932.100 & 932.605 & 934.118 & 936.595 & 939.011 & 941.370 & 943.678 & 945.937 \\
\hline-40 & 922.362 & 922.833 & 923.366 & 924.963 & 927.573 & 930.114 & 932.592 & 935.012 & 937.377 \\
\hline-30 & 913.101 & 913.598 & 914.162 & 915.848 & 918.600 & 921.274 & 923.877 & 926.415 & 928.893 \\
\hline-20 & 903.860 & 904.386 & 904.982 & 906.763 & 909.665 & 912.481 & 915.216 & 917.879 & 920.475 \\
\hline-10 & 894.627 & 895.184 & 895.815 & 897.699 & 900.762 & 903.726 & 906.602 & 909.397 & 912.118 \\
\hline 0 & 885.392 & 885.982 & 886.651 & 888.645 & 891.878 & 895.002 & 898.027 & 900.962 & 903.813 \\
\hline 10 & 876.142 & 876.769 & 877.478 & 879.589 & 883.006 & 886.300 & 889.482 & 892.564 & 895.554 \\
\hline 20 & 866.864 & 867.531 & 868.284 & 870.522 & 874.136 & 877.610 & 880.960 & 884.198 & 887.334 \\
\hline 30 & 857.545 & 858.255 & 859.056 & 861.432 & 865.257 & 868.924 & 872.453 & 875.856 & 879.145 \\
\hline 40 & 848.170 & 848.929 & 849.782 & 852.307 & 856.359 & 860.233 & 863.952 & 867.530 & 870.982 \\
\hline 50 & 838.726 & 839.537 & 840.448 & 843.134 & 847.432 & 851.529 & 855.450 & 859.215 & 862.838 \\
\hline 60 & 829.195 & 830.065 & 831.038 & 833.902 & 838.466 & 842.802 & 846.939 & 850.902 & 854.706 \\
\hline 70 & 819.562 & 820.496 & 821.539 & 824.597 & 829.450 & 834.043 & 838.413 & 842.586 & 846.581 \\
\hline 80 & 809.808 & 810.815 & 811.935 & 815.205 & 820.373 & 825.244 & 829.863 & 834.260 & 838.458 \\
\hline 90 & 799.916 & 801.003 & 802.208 & 805.713 & 811.225 & 816.397 & 821.283 & 825.919 & 830.330 \\
\hline 100 & 789.865 & 791.043 & 792.342 & 796.106 & 801.994 & 807.492 & 812.665 & 817.556 & 822.194 \\
\hline 110 & 779.634 & 780.914 & 782.318 & 786.369 & 792.669 & 798.521 & 804.005 & 809.167 & 814.044 \\
\hline 120 & $*$ & 770.596 & 772.118 & 776.486 & 783.239 & 789.478 & 795.295 & 800.748 & 805.878 \\
\hline 130 & $*$ & 760.069 & 761.722 & 766.443 & 773.694 & 780.353 & 786.531 & 792.294 & 797.691 \\
\hline 140 & $*$ & 749.309 & 751.110 & 756.222 & 764.022 & 771.140 & 777.707 & 783.803 & 789.481 \\
\hline 150 & $*$ & 738.293 & 740.259 & 745.808 & 754.214 & 761.832 & 768.820 & 775.270 & 781.246 \\
\hline
\end{tabular}

* above the normal boiling point temperature (liquid phase not stable at $p=0.1 \mathrm{MPa}$ )

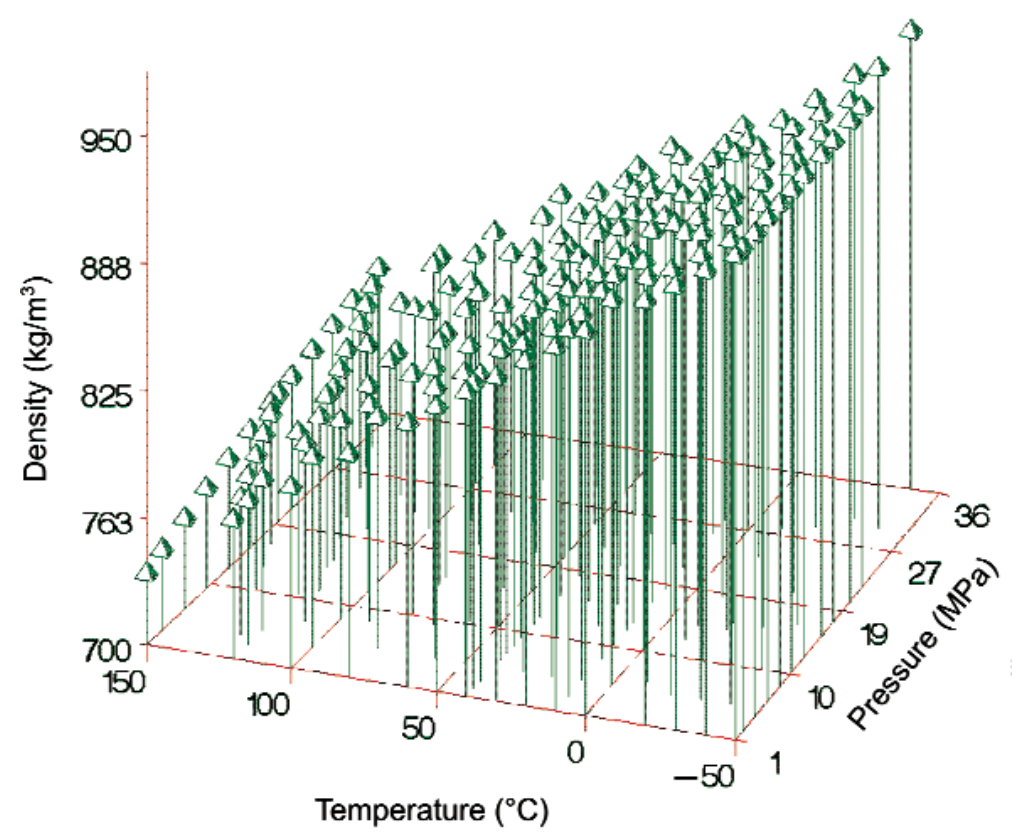

Fig. 5. 906 density measurements versus temperature and pressure used to develop the density model (Eq. 10). 


\subsection{Correction for Air-Saturated Samples}

While the data used to fit the empirical model Eq. (10) were collected for degassed samples, the data measured at near-ambient conditions for the previous issue of this SRM were based on samples having some degree of air saturation. Thus, a correction $\Delta$ was added to the computed fluid density to align the near-ambient SRM and degassed data so that the estimated fluid density is

$$
\rho_{\Delta}=\sum_{k=1}^{8} a_{k}\left(\frac{T}{100}\right)^{-b_{k}} p^{c_{k}}+\Delta=\rho+\Delta,
$$

where

$$
\Delta=F_{\text {air }} \cdot g,
$$

and $\Delta$ is a function of $t$ and $p$.

The value $F_{\text {air }}$ represents the fraction of air saturation and $g$ is the estimated density correction in $\mathrm{kg} / \mathrm{m}^{3}$. If measurements are based on degassed samples, then $F_{\text {air }}=0$, and the correction $\Delta$ and its associated uncertainty are zero.

The density correction for air-saturated samples was determined from the supplemental density measurements for both air-saturated and degassed samples (as listed in Tables A2 and A3). Because measurements for air-saturated and degassed samples could not be made at exactly the same temperatures and pressures, a rational function of the form

$\rho_{\text {saturated }}=\frac{a_{1}+a_{2} \ln (t)+a_{3} p+a_{4}[\ln (t)]^{2}+a_{5} p^{2}+a_{6} p \ln (t)}{1+a_{7} \ln (t)+a_{8} p+a_{9}[\ln (t)]^{2}+a_{10} p \ln (t)}$,

was fitted to the air-saturated density measurements, and a similar model was fitted separately to the degassed density measurements $\rho_{\text {degassed }}$. Next, the two rational functions were used to predict the density of each point in the combined air-saturated and degassed data sets. The predicted density correction is

$$
g=\hat{\rho}_{\text {saturated }}-\hat{\rho}_{\text {degassed }},
$$

where $\hat{\rho}_{\text {saturated }}-\hat{\rho}_{\text {degassed }}$ are the predicted densities based on each rational function.

We analyzed predicted corrections for pressures ranging from $0.1 \mathrm{MPa}$ to $20 \mathrm{MPa}$ and temperatures ranging from $-40{ }^{\circ} \mathrm{C}$ to $100^{\circ} \mathrm{C}$. The predicted correction surface for 228 different temperature and pressure combinations is shown in Fig. 6. We do not have a theoretical basis for selecting a functional form for the air-saturated density correction, and because this correction is only slightly larger than the uncertainties in the measured densities there is the danger of "overfitting" with a strictly empirical function. Thus, we fitted a very simple temperature/pressure model

$$
g=\hat{\rho}_{\text {saturated }}-\hat{\rho}_{\text {degassed }}=b_{1}+b_{2} t+b_{3} p+b_{4} t p
$$

to the predicted corrections. Thus, the estimated correction for air-saturation is determined from

$$
\begin{aligned}
g= & -0.0549-3.1589 \times 10^{-4} \cdot t+5.6019 \times 10^{-5} \cdot p \\
& -2.32 \times 10^{-6} \cdot(t \cdot p),
\end{aligned}
$$

where $t$ is in ${ }^{\circ} \mathrm{C}$ and $p$ is in MPa. For example, the estimated density correction at $25^{\circ} \mathrm{C}$ and $0.1 \mathrm{MPa}$ is $g=-0.0628 \mathrm{~kg} / \mathrm{m}^{3}$. This result is in excellent agreement with the value of $-0.062 \mathrm{~kg} / \mathrm{m}^{3} \pm 0.007 \mathrm{~kg} / \mathrm{m}^{3}$ reported by Ashcroft and Isa [12] for degassed versus air-saturated toluene at similar conditions. Figure 7 displays the estimated correction surface for air-saturation based on Eq. (16) for selected temperatures and pressures. The correction is not reliable for pressures smaller than $0.1 \mathrm{MPa}$ or larger than $20 \mathrm{MPa}$, and temperatures less than $-50^{\circ} \mathrm{C}$ or greater than $100{ }^{\circ} \mathrm{C}$.

We measured the air-saturated samples at temperatures up to $150^{\circ} \mathrm{C}$, but in fitting Eq. (16) we found that the trends in $g$ with temperature and pressure became inconsistent at temperatures above $100{ }^{\circ} \mathrm{C}$. We took this as evidence of decomposition and/or reaction of the toluene with oxygen at the higher temperatures. Thus, we fitted the correction only to the lower-temperature data. The lower temperature limit of $-50{ }^{\circ} \mathrm{C}$ for Eq. (16) represents a modest extrapolation of the experimental data.

The densities measured in May 2007 for the degassed toluene are, on average, $0.057 \mathrm{~kg} / \mathrm{m}^{3}$ higher than the densities measured during January to March 2006. The 2006 measurements (which form the basis for the "official" SRM densities) were also made on the same (degassed) sample. This difference is larger than the standard uncertainty in the measured densities, although it is within the expanded uncertainty. The sample had been stored in the 2.5 L stainless steel sample cylinder in the 13 months between the two series of measurements. Storage in a metal container may result in more degradation of the sample, compared to storage in the glass SRM vials. There is also the possibility that the densimeter drifted by this amount. We carry out periodic measurements on high-purity argon to check for any such drifts, and we found no significant differences between argon measurements made in January 2005 and those made in June 2007. 


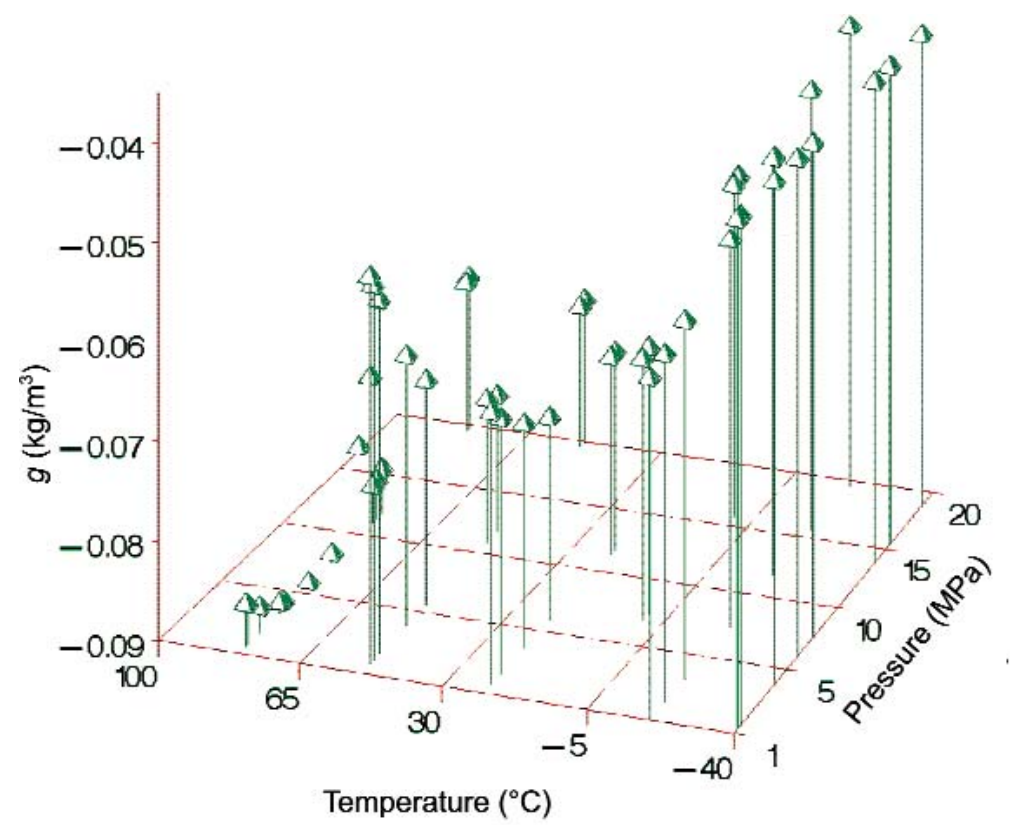

Fig. 6. Density correction for air-saturated versus degassed toluene based on experimentally measured points.

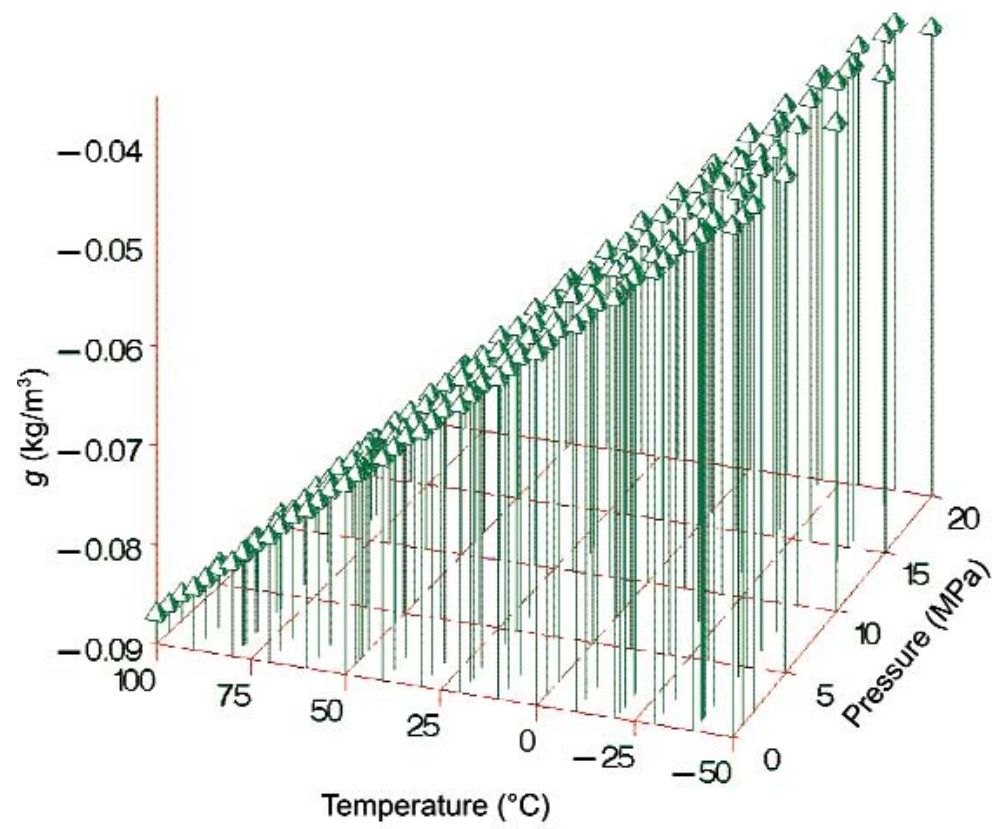

Fig. 7. Estimated correction surface for air-saturated versus degassed toluene (Eq. 16). 


\section{Uncertainty Analysis}

The overall uncertainty in the fluid density arises from several distinct sources. The first source is the empirical model used to represent the density and allow interpolation at a desired temperature and pressure. A second category relates to the material itself; these include uncertainties associated with the degree of air saturation of the toluene and possible degradation resulting from exposure to high temperatures. Since the SRM is provided in $5 \mathrm{~mL}$ ampoules (vials), the variation in density from vial to vial must also be considered. The third, and most complex, source arises from the experimental measurement of the density. Finally, when using the SRM for the calibration of a densimeter, the uncertainty in the user's temperature and pressure measurement must be included.

According to accepted methods for determining uncertainty [13], the measurement equation is the starting point for estimating uncertainty. For practical purposes, our measurement equation is given by Eq. (11), however vial-to-vial effects ( $V$ ), apparatus effects $(e)$, material degradation effects $(x)$, and errors in the user's temperature and pressure measurements $(t p)$ must also be included in the measurement equation even though their values are thought to be zero. The complete measurement equation is thus

$$
\rho_{\mathrm{C}}=\rho+\Delta+V+x+e+t p,
$$

where $\rho$ represents the density estimate from the empirical model and $\Delta$ is the correction for air saturation. Although the values of $V, x, e$, and tp are thought to be zero, they still have some uncertainty.

The combined standard uncertainty, assuming independent input quantities, for the estimated fluid density $\rho_{C}$ Eq. (17) is

$u_{C}=\left[u^{2}(\rho)+u^{2}(\Delta)+u^{2}(V)+u^{2}(x)+u^{2}(e)+u^{2}(t p)\right]^{0.5}$,

where $u(\rho)$ is the uncertainty associated with the empirical model, $u(V)$ is the uncertainty associated with vial-to-vial variations (based on measurements carried out at near-ambient conditions), and $u(x)$ is the uncertainty associated with any possible degradation (i.e., change in chemical composition) of the sample resulting from exposing it to high temperatures. The uncertainty associated with the "air-saturated" correction is $u(\Delta)$. If samples are degassed before taking measurements, then no correction is needed and $u(\Delta)=0$. The quantity $u(e)$ is the uncertainty associated with a single experimental density measurement, which we can think of as a method/apparatus uncertainty. The final uncertainty component $u(t p)$ represents the uncertainty associated with the user's temperature and pressure measurements.

Details regarding the estimation of each of these uncertainty components are provided below.

\subsection{Uncertainty $u(\rho)$ Due to Empirical Model}

Our best estimate of the uncertainty associated with the 20-parameter empirical model to fit density versus temperature and pressure is the root-mean-squared error of the fit, or

$$
u(\rho)=\left[\frac{\sum_{i=1}^{n}\left(\rho_{i}-\rho_{\mathrm{fit}}\right)^{2}}{n-p}\right]^{0.5},
$$

where $n$ is the number of observations used in the fit, $p$ is the number of parameters estimated, $\rho_{i}$ denotes the $i$ th observation of density, and $\rho_{\text {fit }}$ is the fitted value associated with the $i$ th observation. The value of $u(\rho)$ is $0.0086 \mathrm{~kg} / \mathrm{m}^{3}$ for our fit, and there are $906-20=886$ degrees of freedom associated with $u(\rho)\left(d f_{\rho}=886\right)$.

\subsection{Uncertainty $u(\Delta)$ Due to Air-Saturation of Samples}

Based on the air-saturation correction equation $\Delta=F_{\text {air }} \cdot \mathrm{g}$, the standard uncertainty associated with $\Delta$ (Eq. 12) is

$$
\begin{aligned}
u(\Delta) & =\left[\left(\frac{\partial \Delta}{\partial F_{\text {air }}}\right)^{2} u^{2}\left(F_{\text {air }}\right)+\left(\frac{\partial \Delta}{\partial g}\right)^{2} u^{2}(g)\right]^{0.5} \\
& =\left[g^{2} u^{2}\left(F_{\text {air }}\right)+F_{\text {air }}^{2} u^{2}(g)\right]^{0.5},
\end{aligned}
$$

obtained by use of propagation of errors techniques and by assuming that $F_{\text {air }}$ and $g$ are independent. The value of $u(\Delta)$ depends on both input quantities as well as their associated uncertainties. If the user is taking measurements on degassed samples, then $\Delta=0$ and $u(\Delta)=0$. The standard uncertainty associated with the correction $g$ is $u(g)=0.0075 \mathrm{~kg} / \mathrm{m}^{3}$, based on the worst-case prediction error associated with the model fit, i.e. Eq. (16). The degrees of freedom associated with $u(g)$ are $d f_{g}=224$, based on $228(t, p)$ data points and four model parameters.

The value of $F_{\text {air }}$ for the SRM samples is estimated to be 0.59 . We will assume the error in $F_{\text {air }}$ is uniformly distributed within the interval 0.49 to 0.69 so that the standard uncertainty of $F_{\text {air }}$ is

$$
u\left(F_{\text {air }}\right)=\frac{0.69-0.49}{2 \sqrt{3}}=0.058 .
$$


Assuming that the "uncertainty of the uncertainty" is $25 \%$, eight degrees of freedom are appropriate for the uncertainty due to $F_{\text {air }}\left(d f F_{\text {air }}=8\right.$ ). (See equation G.3 of [13] for details regarding the degrees of freedom approximation.)

The degrees of freedom associated with $u(\Delta)$ are

$$
d f_{\Delta}=\frac{u^{4}(\Delta)}{\frac{\left[g \cdot u\left(F_{\text {air }}\right)\right]^{4}}{d f_{F_{\text {air }}}}+\frac{\left[F_{\text {air }} \cdot u(g)\right]^{4}}{d f_{g}}},
$$

based on the Welch-Satterthwaite approximation [13]. The values of $\Delta$ and $u(\Delta)$ for the SRM at $\left(20^{\circ} \mathrm{C}\right.$, $0.10 \mathrm{MPa}$, and $\left.F_{\text {air }}=0.59\right)$ are $\Delta=-0.0361 \mathrm{~kg} / \mathrm{m}^{3}$ and $u(\Delta)=0.0054 \mathrm{~kg} / \mathrm{m}^{3}$ with $d f_{\Delta}=25$.

\subsection{Uncertainty $u(V)$ Due to Vial-to-Vial Variability at Near-Ambient Conditions}

The value of $u(V)$ represents the combined vial-tovial, day-to-day, and apparatus uncertainties at nearambient conditions provided in the previous SRM report of analysis [4]. This analysis involved using a vibrating-tube densimeter to compare the density of samples from randomly selected $5 \mathrm{~mL}$ ampoules with the toluene used in the hydrostatic apparatus described by Bean and Houser [4]. The three sources of uncertainty included in $u(V)$, and their degrees of freedom, are listed in Table 5 for convenience. The value of $u(V)=0.0114 \mathrm{~kg} / \mathrm{m}^{3}$ was determined by adding the three sources in quadrature and taking the square root of the sum. The degrees of freedom, $d f_{V}=32$, were

Table 5. Uncertainty and degrees of freedom associated with vial-to-vial variability at near-ambient conditions (from Bean and Houser [4])

\begin{tabular}{ccc}
\hline \hline Source & Uncertainty $\left(\mathrm{kg} / \mathrm{m}^{3}\right)$ & Degrees of Freedom \\
\hline Apparatus & $u(A)=0.0032$ & $d f_{A}=\infty$ \\
Day-to-day & $u(D)=0.0047$ & $d f_{D}=5$ \\
$\begin{array}{c}\text { Ampoule-to- } \\
\text { ampoule }\end{array}$ & $u(v)=0.0099$ & $d f_{v}=23$ \\
\hline Total & $u(V)=0.0114$ & $d f_{V}=32$ \\
\hline
\end{tabular}

calculated with the Welch-Satterthwaite approximation. We assume that $u(V)$ is the same for all temperatures and pressures.

\subsection{Uncertainty Due to Material Degradation and Time $u(x)$}

Replicate measurements collected at $40{ }^{\circ} \mathrm{C}$ at the completion of a filling were used to determine the uncertainty due to material degradation and time effects. Any degradation in the toluene would be expected to be a function of both time and temperature (a short time at a high temperature would yield degradation similar to that resulting from a prolonged exposure to a moderate temperature). This term is also confounded with any possible drift in the experimental apparatus with time. While repeat measurements for a target temperature are easily obtained, target pressures are more difficult to achieve, and thus the pressures vary among the replicates. Figure 8 displays measurements taken at $40^{\circ} \mathrm{C}$ over the course of this study.

A fourth-order polynomial was fitted to the "complete" $40^{\circ} \mathrm{C}$ isotherm for the filling \#2 data in Fig. 8; these measurements were made before the sample was exposed to higher temperatures. The residuals from the fit are shown in Fig. 9. The data from other fillings provide information about how the material may have changed over time and/or with exposure to high temperatures. The residuals indicate that the data from the other fillings are similar to the filling \#2 data, with the exception of the filling \#1 measurements at about $22 \mathrm{MPa}$. We will assume that the largest residual (conservatively estimated at $0.006 \mathrm{~kg} / \mathrm{m}^{3}$ ) represents the worst-case error that might be observed. If the worst-case error is also assumed to represent the bounds of a uniform distribution, $\left(-0.006 \mathrm{~kg} / \mathrm{m}^{3}\right.$, $0.006 \mathrm{~kg} / \mathrm{m}^{3}$ ) we can approximate the uncertainty due to material degradation and time effects as

$$
u(x)=\frac{0.006 \mathrm{~kg} / \mathrm{m}^{3}}{\sqrt{3}}=0.0035 \mathrm{~kg} / \mathrm{m}^{3} .
$$

This uncertainty is assumed to be valid for all temperatures included in this study. Assuming that the "uncertainty of the uncertainty" is $25 \%$, eight degrees of freedom are appropriate for the uncertainties due to material degradation and time errors $\left(d f_{\mathrm{x}}=8\right)$. 


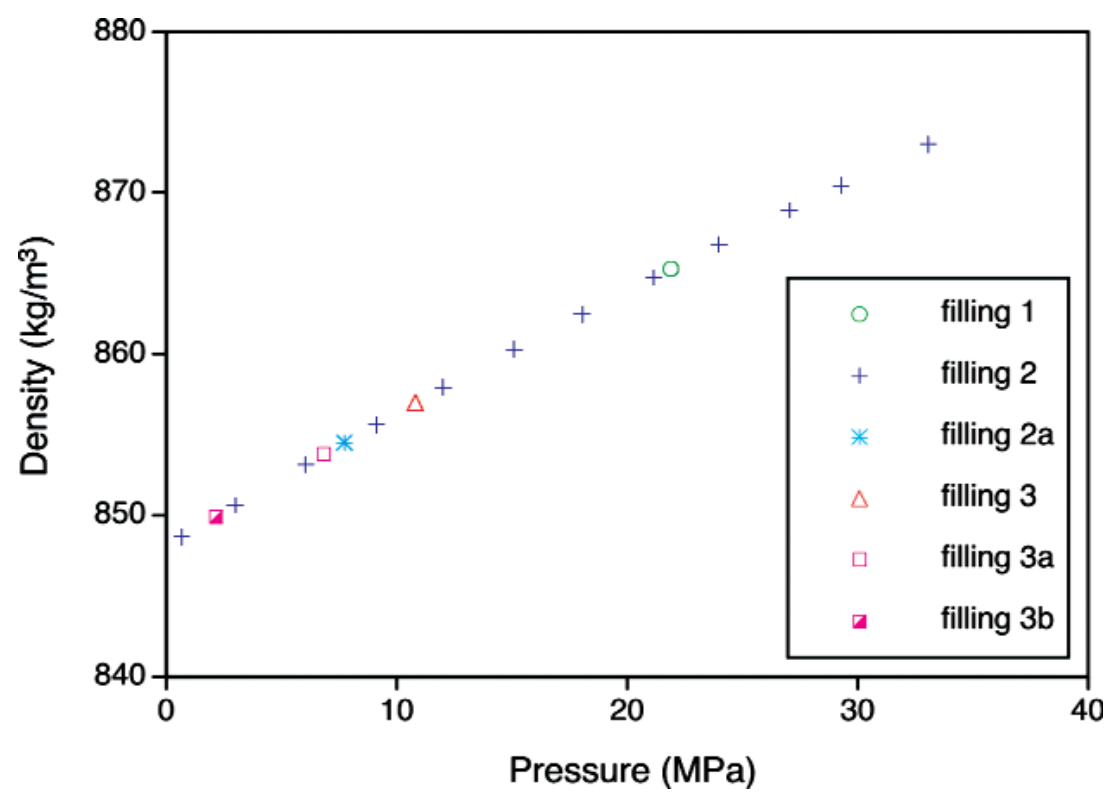

Fig. 8. Replicate measurements at $40^{\circ} \mathrm{C}$ for the various fillings of toluene.

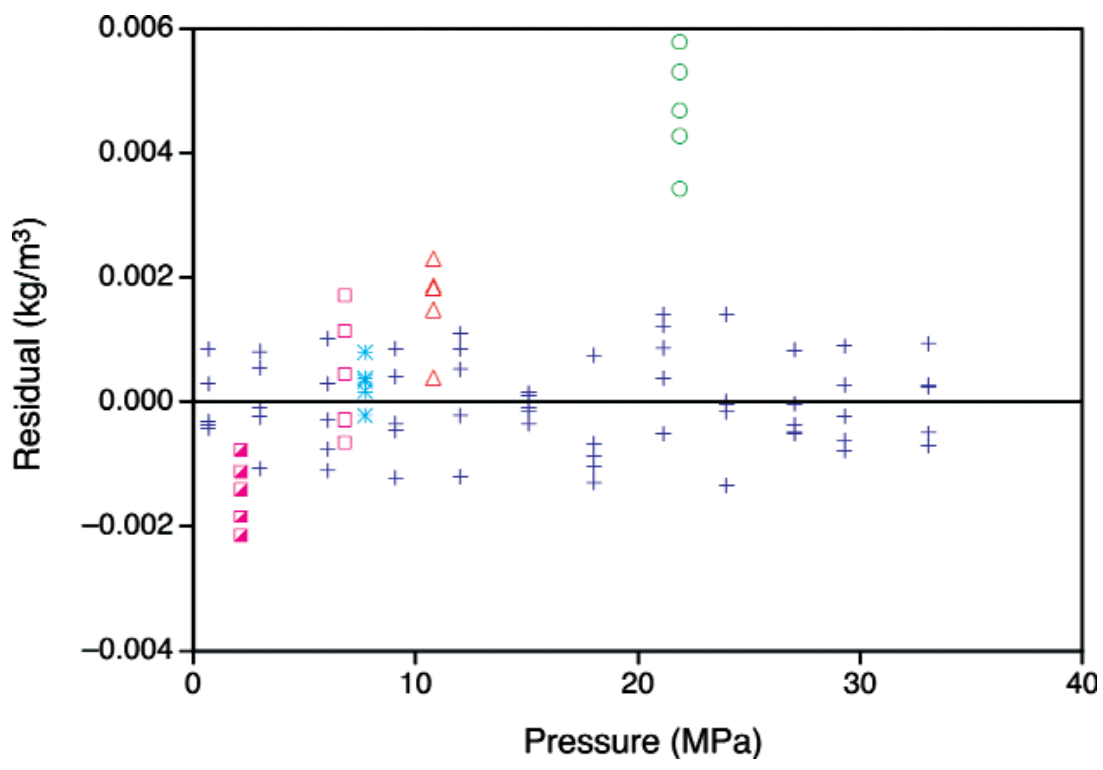

Fig. 9. Residuals from the polynomial fit to filling $\# 2$ data at $40{ }^{\circ} \mathrm{C}$; the plot symbols are the same as in Fig. 8. 


\subsection{Uncertainty u (e) Due to Method/Apparatus}

To estimate $u(e)$ for given values of temperature $\left({ }^{\circ} \mathrm{C}\right)$ and pressure (MPa), the polynomial equation

$$
u(e)=\left\{\begin{array}{c}
0.02670+2.064 \times 10^{-6} \cdot t+2.468 \times 10^{-6} \cdot t^{2} \\
-1.88661 \times 10^{-8} \cdot t^{3} \\
+4.56257 \times 10^{-11} \cdot t^{4}+4.662 \times 10^{-5} \cdot p \\
+3.41 \times 10^{-6} \cdot p^{2}
\end{array}\right\}
$$

was fitted to values of the uncertainty associated with each measurement of fluid density across the temperature-pressure surface. Details regarding the computation of the uncertainty of fluid density measurements $u\left(\rho_{\text {fluid }}\right)$ are discussed in the sections that follow. The quantity $u(e)$ denotes the uncertainty predicted by the polynomial based on the values of $u$ ( $\rho_{\text {fluid }}$ ) computed for each data point. The error introduced into $u(e)$ by using the polynomial equation is negligible compared to the magnitude of $u(e)$. The degrees of freedom associated with $u\left(\rho_{\text {fluid }}\right)$ vary depending on pressure and temperature, and range from 9 to 18 . Thus, a conservative estimate for the degrees of freedom associated with $u(e)$ is $9\left(d f_{e}=9\right)$.

\subsubsection{Uncertainty $u\left(\rho_{\text {fluid }}\right)$ in Fluid Density Measurements}

As discussed in Sec. 2, the experimental fluid density data were calculated with Eqs. (2 to 5). The uncertainty of a single fluid density measurement, $\rho_{\text {fluid }}$, thus, is a function of the 14 input quantities:

$$
\begin{gathered}
u\left(\rho_{\text {fluid }}\right)=f\left(m_{\text {cal }}, m_{\text {tare }}, m_{1}, m_{2}, V_{\text {cal }}, V_{\text {tare }}, V_{1}, V_{2},\right. \\
\left.\rho_{\mathrm{N}_{2}}, W_{\text {cal }}, W_{\text {tare }}, W_{1}, W_{2}, \rho_{0}\right) .
\end{gathered}
$$

Many of the 14 input quantities are, in turn, dependent upon other measured quantities.

The values of $u$ ( $\left.\rho_{\text {fluid }}\right)$ computed for each data point will be used to determine the parameters of a polynomial to predict uncertainty for a given temperature and pressure. The predicted uncertainty, $u(e)$, represents the method/apparatus error. Based on propagation of errors techniques, assuming that all the input quantities are independent, the variance of $\rho_{\text {fluid }}$ is

$$
\begin{aligned}
u^{2}\left(\rho_{\text {fluid }}\right) & =\left(\frac{\partial \rho_{\text {fluid }}}{\partial m_{\text {cal }}}\right)^{2} u^{2}\left(m_{\text {cal }}\right)+\left(\frac{\partial \rho_{\text {fluid }}}{\partial m_{\text {tare }}}\right)^{2} u^{2}\left(m_{\text {are }}\right) \\
& +\left(\frac{\partial \rho_{\text {fluid }}}{\partial m_{1}}\right)^{2} u^{2}\left(m_{1}\right)+\left(\frac{\partial \rho_{\text {fluid }}}{\partial m_{2}}\right)^{2} u^{2}\left(m_{2}\right) \\
& +\left(\frac{\partial \rho_{\text {fluid }}}{\partial V_{\text {cal }}}\right)^{2} u^{2}\left(V_{\text {cal }}\right)+\left(\frac{\partial \rho_{\text {fluid }}}{\partial V_{\text {tare }}}\right)^{2} u^{2}\left(V_{\text {tare }}\right) \\
& +\left(\frac{\partial \rho_{\text {fluid }}}{\partial V_{1}}\right)^{2} u^{2}\left(V_{1}\right)+\left(\frac{\partial \rho_{\text {fluid }}}{\partial V_{2}}\right)^{2} u^{2}\left(V_{2}\right) \\
& +\left(\frac{\partial \rho_{\text {fluid }}}{\partial \rho_{\mathrm{N} 2}}\right)^{2} u^{2}\left(\rho_{\mathrm{N} 2}\right)+\left(\frac{\partial \rho_{\text {fluid }}}{\partial W_{\text {cal }}}\right)^{2} u^{2}\left(W_{\text {cal }}\right) \\
& +\left(\frac{\partial \rho_{\text {fluid }}}{\partial W_{\text {tare }}}\right)^{2} u^{2}\left(W_{\text {tare }}\right)+\left(\frac{\partial \rho_{\text {fluid }}}{\partial W_{1}}\right)^{2} u^{2}\left(W_{1}\right) \\
& +\left(\frac{\partial \rho_{\text {fluid }}}{\partial W_{2}}\right)^{2} u^{2}\left(W_{2}\right)+\left(\frac{\partial \rho_{\text {fluid }}}{\partial \rho_{0}}\right)^{2} u^{2}\left(\rho_{0}\right)
\end{aligned}
$$

and the combined standard uncertainty is the square root of the variance.

The Welch-Satterthwaite approximation [13] was used to estimate the degrees of freedom associated with $u\left(\rho_{\text {fluid }}\right)$ :

$$
d f_{\text {fluid }}=\frac{u^{4}\left(\rho_{\text {fluid }}\right)}{D}
$$

where

$$
D=\sum_{i} \frac{\left(\frac{\partial \rho_{\text {fluid }}}{\partial \Psi_{i}}\right)^{4} u^{4}\left(\Psi_{i}\right)}{d f_{\Psi_{i}}},
$$

and $\Psi_{i}$ represents each of the 14 input variables in Eq. (25). The derivatives in $u$ ( $\left.\rho_{\text {fluid }}\right)$ and $d f_{\text {fluid }}$ are quite complicated, so we used a commercial symbolic algebra software package to generate the derivatives.

Next, we will provide details regarding the estimation of each individual component of uncertainty and its associated degrees of freedom. 


\subsubsection{Uncertainties $u\left(m_{\text {cal }}\right), u\left(m_{\text {tare }}\right), u\left(m_{1}\right)$, and $u\left(m_{2}\right)$ in Masses}

A single measurement of the mass of an unknown object, $m_{\mathrm{x}}$, is determined by comparison to standard masses using a "SXXS" method (with S referring to a standard and $\mathrm{X}$ the unknown). By this method the mass of the unknown is given by

$$
\begin{aligned}
m_{\mathrm{xi}}= & \left\{m_{\mathrm{s}}\left(1-\frac{\rho_{\mathrm{air}}}{\rho_{\mathrm{s}}}\right)+\left[\frac{\left(O_{2}-O_{1}\right)+\left(O_{3}-O_{4}\right)}{2\left(O_{3}-O_{2}\right)}\right]\right. \\
& \left.m_{\mathrm{sw}}\left(1-\frac{\rho_{\mathrm{air}}}{\rho_{\mathrm{sw}}}\right)\right\} /\left(1-\frac{\rho_{\mathrm{air}}}{\rho_{\mathrm{x}}}\right),
\end{aligned}
$$

where the $O_{i}$ are the balance readings, the $m_{\mathrm{s}}$ and $m_{\mathrm{sw}}$ are standard masses, and $\rho_{\mathrm{s}}$ and $\rho_{\mathrm{sw}}$ are the densities of the standard masses. This method is described as "Standard Operating Procedure 4" by Harris and Torres [5]. We need to estimate the mass and the uncertainty of the mass for two sinkers, $m_{1}$ and $m_{2}$. We will assume the uncertainties associated with the calibration masses $m_{\text {cal }}$ and $m_{\text {tare }}$ are the same as those for $m_{1}$ and $m_{2}$.

Propagation of errors was used to determine the uncertainty associated with a single mass measurement. Assuming all input quantities are independent, the variance of the unknown mass is

$$
\begin{aligned}
u^{2}\left(m_{\mathrm{x} i}\right) & =\left(\frac{\partial m_{\mathrm{xi}}}{\partial m_{\mathrm{s}}}\right)^{2} u^{2}\left(m_{\mathrm{s}}\right)+\left(\frac{\partial m_{\mathrm{xi}}}{\partial m_{\mathrm{sw}}}\right)^{2} u^{2}\left(m_{\mathrm{sw}}\right) \\
& +\left(\frac{\partial m_{\mathrm{x} i}}{\partial \rho_{\mathrm{air}}}\right)^{2} u^{2}\left(\rho_{\mathrm{air}}\right)+\left(\frac{\partial m_{\mathrm{xi}}}{\partial \rho_{\mathrm{s}}}\right)^{2} u^{2}\left(\rho_{\mathrm{s}}\right) \\
& +\left(\frac{\partial m_{\mathrm{x} i}}{\partial \rho_{\mathrm{sw}}}\right)^{2} u^{2}\left(\rho_{\mathrm{sw}}\right)+\left(\frac{\partial m_{\mathrm{x} i}}{\partial \rho_{\mathrm{x}}}\right)^{2} u^{2}\left(\rho_{\mathrm{x}}\right) \\
& +\left(\frac{\partial m_{\mathrm{x} i}}{\partial O_{1}}\right)^{2} u^{2}\left(O_{1}\right)+\left(\frac{\partial m_{\mathrm{xi}}}{\partial O_{2}}\right)^{2} u^{2}\left(O_{2}\right) \\
& +\left(\frac{\partial m_{\mathrm{xi}}}{\partial O_{3}}\right)^{2} u^{2}\left(O_{3}\right)+\left(\frac{\partial m_{\mathrm{x} i}}{\partial O_{4}}\right)^{2} u^{2}\left(O_{4}\right)
\end{aligned}
$$

and the combined standard uncertainty of the unknown mass is $u\left(m_{x i}\right)=\left[u^{2}\left(m_{x i}\right)\right]^{0.5}$.

Next, we describe the evaluation of each individual uncertainty component in the mass determination. Table 6 displays information for the standard masses provided by their manufacturer's calibration laboratory.
Table 6. Calibration data for the standard masses used in this work

\begin{tabular}{cccc}
\hline \hline $\begin{array}{c}\text { Nominal Mass } \\
(\mathrm{g})\end{array}$ & $\begin{array}{c}\text { True Mass } \\
(\mathrm{g})\end{array}$ & $\begin{array}{c}\text { Uncertainty } \\
(\mathrm{g})\end{array}$ & $\begin{array}{c}\text { Density } \\
\left(\mathrm{g} / \mathrm{cm}^{3}\right)\end{array}$ \\
\hline 50 & 50.0001507 & 0.00001145 & 7.85 \\
10 & 9.9999966 & 0.00000815 & 7.85 \\
2 & 2.0000193 & 0.0000032 & 7.85 \\
\hline
\end{tabular}

Since the nominal value of $m_{\mathrm{s}}=60 \mathrm{~g}$ is obtained by use of the $50 \mathrm{~g}$ and $10 \mathrm{~g}$ standards together, the uncertainty of $m_{\mathrm{s}}$ is

$$
\begin{aligned}
u\left(m_{\mathrm{s}}\right) & =\left[(0.00001145 \mathrm{~g})^{2}+(0.00000815 \mathrm{~g})^{2}\right]^{0.5} \\
& =0.000014 \mathrm{~g} .
\end{aligned}
$$

The nominal value of $m_{\mathrm{sw}}$ is $2 \mathrm{~g}$, so $u\left(m_{\mathrm{sw}}\right)=0.0000032 \mathrm{~g}$. We believe the errors associated with the density of the standard masses are best described by a uniform distribution bounded by $0.05 \mathrm{~g} / \mathrm{cm}^{3}$. Thus standard uncertainties of $\rho_{\mathrm{s}}$ and $\rho_{\mathrm{sw}}$ are

$$
u\left(\rho_{\mathrm{s}}\right)=u\left(\rho_{\mathrm{sw}}\right)=\frac{0.05 \mathrm{~g} / \mathrm{cm}^{3}}{\sqrt{3}}=0.029 \mathrm{~g} / \mathrm{cm}^{3} .
$$

We know from the analysis of the sinker volume determination (Secs. 3.3 and 5.5.4) that the standard uncertainties associated with the densities of $m_{1}$ and $m_{2}$ used in our experiment are $u\left(\rho_{\mathrm{x}}\right)=0.00011 \mathrm{~g} / \mathrm{cm}^{3}$ for the density of sinker 1 (titanium) and $u\left(\rho_{\mathrm{x}}\right)=$ $0.00042 \mathrm{~g} / \mathrm{cm}^{3}$ for the density of sinker 2 (tantalum). The repeatability standard deviation of the balance is $0.03 \mathrm{mg}$ or $0.00003 \mathrm{~g}$, so the standard uncertainties of the observed balance readings are $u\left(O_{1}\right)=u\left(O_{2}\right)=$ $u\left(O_{3}\right)=u\left(O_{4}\right)=0.00003 \mathrm{~g}$.

A single determination of the density of moist air, $\rho_{\text {air }}$, was computed using the function of Davis [6], which is ultimately a function of temperature $(t)$, pressure $(p)$, and relative humidity $(h)$. Using propagation of errors, and assuming independence of input quantities, the combined standard uncertainty of a single measurement of $\rho_{\text {air }}$ is

$$
\begin{aligned}
u\left(\rho_{\text {air }}\right) & =\left[\left(\frac{\partial \rho_{\text {air }}}{\partial t}\right)^{2} u^{2}(t)+\left(\frac{\partial \rho_{\text {air }}}{\partial p}\right)^{2} u^{2}(p)\right. \\
& \left.+\left(\frac{\partial \rho_{\text {air }}}{\partial h}\right)^{2} u^{2}(h)\right]^{0.5} .
\end{aligned}
$$


For a single determination of air density, the standard uncertainties for temperature, pressure, and humidity are $u(t)=0.2 \mathrm{~K}, u(p)=0.0001 \cdot p \mathrm{kPa}$, and $u(h)=0.02$.

The value $u\left(m_{\mathrm{x} i}\right)$ is the uncertainty associated with a single mass determination. The nominal mass values used in the density calculations are averages based on six repeat measurements (three measurements on each of two days), so we need to determine the uncertainty of the average mass.

Typically we would use the six repeat measurements to determine the uncertainty of the average mass value; however, a more extensive repeatability study was performed over four days with three repeated measurements per day. Thus, we will estimate the uncertainty of the average mass using the larger, more comprehensive data set and assume the uncertainty will be the same for the six measurements actually used. There appears to be no significant between-day effect for either sinker based on an analysis of variance, so we were able to combine all data and ignore the fact that the measurements were taken on different days.

We need to estimate two sources of variation-within measurements and between measurements-from the larger repeatability study in order to compute the uncertainty of the average mass. The within-measurement variance was computed as the average variance of the 12 repeated measurements,

$$
u^{2}\left(m_{\mathrm{w}}\right)=\frac{1}{12} \sum_{i=1}^{12} u^{2}\left(m_{\mathrm{x} i}\right)
$$

The values of $u^{2}\left(m_{\mathrm{x}}\right)$ were computed as described earlier in this section. The between-measurement variance is computed as the variance of the 12 mass measurements

$$
u^{2}\left(m_{\mathrm{b}}\right)=\frac{1}{12-1} \sum_{i=1}^{12}\left(m_{\mathrm{x} i}-\bar{m}_{\mathrm{x}}\right)^{2}
$$

Assuming the within-measurement and betweenmeasurement variation based on the larger repeatability study are the same for the six measurements actually used in the experiment, the uncertainty of the average mass based on six observations is

$$
u\left(m_{\mathrm{x}}\right)=\left[\frac{u^{2}\left(m_{\mathrm{w}}\right)}{6}+u^{2}\left(m_{\mathrm{b}}\right)\right]^{0.5} .
$$

The estimated uncertainties for sinker 1 and sinker 2 are $u\left(m_{1}\right)=0.000021 \mathrm{~g}$ and $u\left(m_{2}\right)=0.000023 \mathrm{~g}$, and each uncertainty estimate has $6-1=5$ degrees of free$\operatorname{dom}\left(d f_{m 1}=d f_{m 2}=5\right)$.

The values of $m_{\text {cal }}$ and $m_{\text {tare }}$ were estimated in a similar fashion; however, there is only one determination of each mass, and $u\left(m_{\text {cal }}\right)=u\left(m_{\text {tare }}\right)=0.000050 \mathrm{~g}$. Because there is only one observation for $m_{\text {cal }}$ and $m_{\text {tare }}$, we will use engineering judgment to determine the degrees of freedom associated with $u\left(m_{\text {cal }}\right)$ and $u\left(m_{\text {tare }}\right)$. Assuming that the "uncertainty of the uncertainty" is $50 \%$, there are two degrees of freedom associated with each uncertainty estimate $\left(d f_{\text {mcal }}=d f_{\text {mare }}=2\right)$.

\subsubsection{Uncertainties $u\left(V_{\text {cal }}\right)$ and $u\left(V_{\text {tare }}\right)$ in Volumes of the Calibration Masses}

The limits to error of $V_{\text {cal }}$ and $V_{\text {tare }}$ were estimated to be $0.05 \%$ of the nominal sinker volume based on engineering judgment. Assuming the limits represent a uniform distribution, the standard uncertainties associated with $V_{\text {cal }}$ and $V_{\text {tare }}$ are

$u\left(V_{\text {cal }}\right)=\frac{0.0005 \cdot V_{\text {cal }}}{\sqrt{3}}$ and $u\left(V_{\text {tare }}\right)=\frac{0.0005 \cdot V_{\text {tare }}}{\sqrt{3}}$.

We determined that eight degrees of freedom were appropriate based on the assumption that the "uncertainty of the uncertainty" is $25 \%\left(d f_{\text {Val }}=d f_{\text {Vtare }}=8\right)$.

\subsubsection{Uncertainty $u\left(V_{1}\right)$ and $u\left(V_{2}\right)$ in Sinker Volumes}

The determination of the sinker volumes involves the determination of their volumes at $20^{\circ} \mathrm{C}$ and atmospheric pressure by the hydrostatic experiment described in Sec. 3.3. These values must then be adjusted for the effects of temperature and pressure. Each of these components involves multiple sources of uncertainties.

\subsubsection{Uncertainty $u\left(V_{\text {ref }}\right)$ in Sinker Volumes at $20^{\circ} \mathrm{C}$}

A summary of the uncertainties contributing to the sinker volume uncertainty at the reference temperature of $20^{\circ} \mathrm{C}$ is presented in Table 7 . The uncertainty in the density of the silicon standards is that assigned by the NIST Mass Group [9]. The uncertainty in the mass determinations of the standards and sinkers includes the balance linearity, uncertainty in the calibration masses, uncertainty in air buoyancy, and possible surface adsorption of water. For the hydrostatic weighings, the effects of the balance calibration and linearity are reduced because of the relatively small weight differences measured. Air buoyancy and surface adsorption do not apply. (The sinkers were immersed in the 
Table 7. Summary of standard uncertainties in volumes determined by hydrostatic weighing

\begin{tabular}{|c|c|c|c|c|c|}
\hline \multirow[b]{2}{*}{ Source of Error } & \multirow[b]{2}{*}{ Magnitude of Error } & \multicolumn{4}{|c|}{ Uncertainty in Volume $\left(\mathrm{cm}^{3}\right)$} \\
\hline & & Sinker $1(\mathrm{Ti})$ & Sinker 2 (Ta) & Si ref to Si & Ta ref to $\mathrm{Ti}$ \\
\hline Density of standard & $1.6 \times 10^{-5} \mathrm{~g} / \mathrm{cm}^{3}$ & $9.15 \times 10^{-5}$ & $2.48 \times 10^{-5}$ & $29.2 \times 10^{-5}$ & $2.66 \times 10^{-5}$ \\
\hline Mass of standard & $5.0 \times 10^{-5} \mathrm{~g}$ & $0.29 \times 10^{-5}$ & $0.80 \times 10^{-5}$ & $0.92 \times 10^{-5}$ & $0.53 \times 10^{-5}$ \\
\hline Mass of object & $5.0 \times 10^{-5} \mathrm{~g}$ & $3.07 \times 10^{-5}$ & $3.07 \times 10^{-5}$ & $3.07 \times 10^{-5}$ & $3.07 \times 10^{-5}$ \\
\hline Weighing of standard & $5.0 \times 10^{-5} \mathrm{~g}$ & $0.96 \times 10^{-5}$ & $0.26 \times 10^{-5}$ & $3.07 \times 10^{-5}$ & $0.83 \times 10^{-5}$ \\
\hline Weighing of object & $5.0 \times 10^{-5} \mathrm{~g}$ & $3.07 \times 10^{-5}$ & $3.07 \times 10^{-5}$ & $3.07 \times 10^{-5}$ & $3.07 \times 10^{-5}$ \\
\hline Root-sum-of-squares & & $10.2 \times 10^{-5}$ & $5.07 \times 10^{-5}$ & $29.7 \times 10^{-5}$ & $5.19 \times 10^{-5}$ \\
\hline
\end{tabular}

fluid for more than 48 hours prior to the volume determination, giving them time to come to equilibrium with the fluid.) However, the hydrostatic weighings were affected by an observed linear drift of $0.0003 \mathrm{~g} / \mathrm{h}$, as determined by the drift in the pan weighings taken every 16 minutes over the course of the test. The largest deviation from the linear trend was $0.00012 \mathrm{~g}$, with an average of less than $0.00005 \mathrm{~g}$.

The effects of the error sources on the calculated volumes are given for four cases. The columns labeled "Sinker 1 (Ti)" and "Sinker 2 (Ta)" are for the two sinkers, where the silicon standards were taken as the knowns, i.e., the ratios $\mathrm{AB}, \mathrm{CB}$, and $\mathrm{BC}$ for the $\mathrm{Ta}$ sinker and the ratios $\mathrm{AD}, \mathrm{DA}, \mathrm{DC}$, and $\mathrm{CD}$ for the Ti sinker. The column "Si ref to Si" is for the check measurement comparing one silicon standard to the other (the ratio AC). "Ta ref to Ti" is for the calculation of the tantalum sinker volume taking the titanium sinker volume as the known (the ratio DB). The overall uncertainty varied from $0.0000052 \mathrm{~cm}^{3}$ to $0.000030 \mathrm{~cm}^{3}$, with objects having the highest density (i.e., the smallest volume and buoyancy force) having the highest relative uncertainties.

The measured volumes of the two sinkers at the reference temperature $V_{\text {1ref }}$ and $V_{\text {2ref }}$ have uncertainties due to both random and systematic effects. The standard uncertainties associated with random errors, from a least-squares analysis of the hydrostatic data, are $u\left(V_{1 \mathrm{R}}\right)=0.0000023 \mathrm{~cm}^{3}$ and $u\left(V_{2 \mathrm{R}}\right)=0.0000031 \mathrm{~cm}^{3}$. There are six degrees of freedom associated with each estimate $\left(d f_{V 1 R}=d f_{V 2 R}=6\right)$. The standard uncertainties associated with systematic calibration effects are $u\left(V_{1 \mathrm{~S}}\right)=0.000102 \mathrm{~cm}^{3}$ and $u\left(V_{2 \mathrm{~S}}\right)=0.000050 \mathrm{~cm}^{3}$. Assuming that the "uncertainty of the uncertainty" is $25 \%$, eight degrees of freedom are appropriate for the uncertainties due to systematic effects $\left(d f_{V 1 S}=d f_{V 2 S}=8\right)$.
Thus, the combined standard uncertainty of the volume of sinker 1 at reference conditions $\left(20^{\circ} \mathrm{C}\right.$ and $\left.0.08 \mathrm{MPa}\right)$ is

$$
u\left(V_{1 \mathrm{ref}}\right)=\left[u^{2}\left(V_{1 \mathrm{R}}\right)+u^{2}\left(V_{1 \mathrm{~S}}\right)\right]^{0.5},
$$

and the degrees of freedom are given by

$$
d f_{V 1 \text { ref }}=\frac{u^{4}\left(V_{1 \text { ref }}\right)}{\frac{u^{4}\left(V_{1 \mathrm{R}}\right)}{d f_{V 1 \mathrm{R}}}+\frac{u^{4}\left(V_{1 \mathrm{~S}}\right)}{d f_{V 1 \mathrm{~S}}}} .
$$

Similar equations were used to determine the combined standard uncertainty and degrees of freedom for the measured volume of sinker 2 .

\subsubsection{Uncertainty in Sinker Volumes $u\left(V_{1}\right)$ and $u\left(V_{2}\right)$ as a Function of $T$ and $p$}

The volumes of sinker 1 (Ti) and sinker 2 (Ta) determined by the hydrostatic comparator experiment at $20{ }^{\circ} \mathrm{C}\left(V_{\text {1ref }}\right.$ and $\left.V_{\text {2ree }}\right)$ must be modified by three additional corrections to account for temperature and pressure effects:

$$
V_{i}=V_{i, \text { ref }} \cdot V_{\kappa} \cdot V_{\alpha} \cdot V_{T},
$$

where $V_{\kappa}$ accounts for pressure effects and $V_{\alpha}$ and $V_{T}$ account for temperature effects (i.e., thermal expansion).

The combined standard uncertainties for the volumes of the sinkers, based on propagation of errors and independent input quantities, are given by

$$
\begin{aligned}
u\left(V_{i}\right)= & {\left[\left(\frac{\partial V_{i}}{\partial V_{i, \text { ref }}}\right)^{2} u^{2}\left(V_{i, \text { ref }}\right)+\left(\frac{\partial V_{i}}{\partial V_{\kappa}}\right)^{2} u^{2}\left(V_{\kappa}\right)\right.} \\
& \left.+\left(\frac{\partial V_{i}}{\partial V_{T}}\right)^{2} u^{2}\left(V_{T}\right)\right]^{0.5} .
\end{aligned}
$$


The uncertainty of the temperature correction $V_{T}$ also includes uncertainty of the $V_{\alpha}$ correction (as discussed below), so $u\left(V_{\alpha}\right)$ does not appear in the uncertainty calculation. The degrees of freedom associated with $u\left(V_{1}\right)$ are

$$
\frac{d f_{V 1}=}{\frac{\left(\frac{\partial V_{1}}{\partial V_{\text {1ref }}}\right)^{4} u^{4}\left(V_{\text {1ref }}\right)}{d f_{V 1 \text { ref }}}+\frac{\left(\frac{\partial V_{1}}{\partial V_{\kappa}}\right)^{4} u^{4}\left(V_{\kappa}\right)}{d f_{V \kappa}}+\frac{\left(\frac{\partial V_{1}}{\partial V_{T}}\right)^{4} u^{4}\left(V_{T}\right)}{d f_{V T}}} .
$$

A similar equation is used to compute $d f_{V 2}$.

The correction, $V_{\kappa}$, is defined as

$$
V_{\kappa}=1-\frac{p-p_{\text {ref }}}{\kappa_{0}},
$$

where $\kappa_{0}$ is the bulk modulus of the sinker material. The uncertainties of the two pressures are negligible compared to the uncertainty of $\kappa_{0}$. Thus, the standard uncertainty of $V_{\kappa}$ is

$$
\begin{aligned}
u\left(V_{\kappa}\right) & =\sqrt{\left(\frac{\partial V_{\kappa}}{\partial \kappa_{0}}\right)^{2} u^{2}\left(\kappa_{0}\right)}=\sqrt{\left(\frac{p-p_{\text {ref }}}{\kappa_{0}^{2}}\right)^{2} u^{2}\left(\kappa_{0}\right)} \\
& =\left(\frac{p-p_{\text {ref }}}{\kappa_{0}^{2}}\right) u\left(\kappa_{0}\right),
\end{aligned}
$$

where $u\left(\kappa_{0}\right)=0.05 \cdot \kappa_{0}$, based on engineering judgment. The value of $\kappa_{0}$ for titanium is $108.4 \times 10^{6} \mathrm{GPa}^{-1}$ and the value for tantalum is $196.3 \times 10^{6} \mathrm{GPa}^{-1}$ [14] Assuming that the "uncertainty of the uncertainty" is $25 \%, 8$ degrees of freedom were appropriate $\left(d f_{V K}=8\right)$.

Because volume measurements were taken at a nominal temperature of $20^{\circ} \mathrm{C}$, we need to correct the volume of the sinkers for density measurements taken at other temperatures. $V_{\alpha}$ is a correction based on measured values of the thermal expansion of the titanium and tantalum used to fabricate the sinkers (see [1]).

$V_{T}$ is an additional calibration based on measurements of low-pressure (i.e., nearly ideal) gases in the two-sinker densimeter. Gas densities were measured at several (nearly identical) pressures along several isotherms. The densities at corresponding pressures along pairs of isotherms were ratioed and extrapolated to zero pressure, where the ideal-gas law applies:

$$
\frac{\rho(T)}{\rho\left(T_{\text {ref }}\right)}=\frac{T_{\text {ref }}}{T},
$$

where $T_{\text {ref }}$ is the temperature ( $293.15 \mathrm{~K}$ ) of the hydrostatic sinker volume determination. The basic concept is that of a gas thermometer, except inverted (i.e., the temperatures are the known quantities and the densities are the unknown quantities, rather than vice versa). The difference (in percent) between the extrapolated density ratio and the measured temperature ratio for a given pair of isotherms is the percentage adjustment in the sinker volumes resulting from this calibration. The results are summarized in Fig. 10 for these calibrations on three different gases. (See McLinden [15] for a

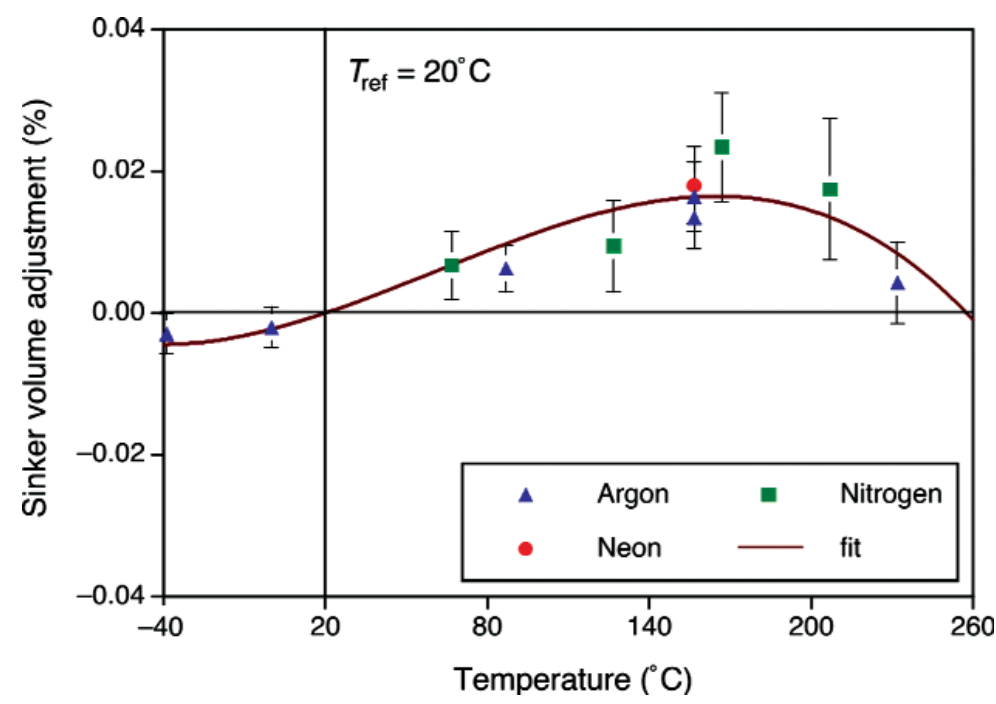

Fig. 10. Sinker volume adjustment as a function of temperature based on measurements of low-density gases (adapted from McLinden [15]). The reference temperature for the adjustment is $20.00{ }^{\circ} \mathrm{C}$, and the error bars represent standard uncertainties. 
complete discussion of this calibration, its uncertainties, and a listing of the data.)

We used weighted least-squares regression to fit a cubic polynomial, which was constrained to pass through zero at the reference temperature of $20^{\circ} \mathrm{C}$, to the sinker volume adjustment data. A quadratic equation based on the standard uncertainties given by McLinden [15] (and shown by the error bars in Fig. 10) was used as the weighting function for the regression analysis. The weighted regression equation was used to estimate $V_{T}$, and the standard uncertainty of $V_{T}$ is the standard error of a predicted $V_{T}$. Both $V_{T}$ and $u\left(V_{T}\right)$ depend on the temperature; values of $V_{T}$ range from $-0.0036 \%$ to $0.0163 \%$ of the sinker volume, and values of $u\left(V_{T}\right)$ range from $0.0021 \%$ to $0.0105 \%$. Since 11 observations and three model parameters were used in the fit, there are 8 degrees of freedom associated with $u\left(V_{T}\right)\left(d f_{V T}=8\right)$.

The $V_{T}$ calibration was applied to sinker volume data that include the $V_{\alpha}$ correction, and any error in $V_{\alpha}$ will result in a different value for the $V_{T}$ calibration. Indeed, the entire purpose of the $V_{T}$ calibration is to improve upon the $V_{\alpha}$ correction. This is why $u\left(V_{\alpha}\right)$ does not appear in Eqs. (41) and (42).

\subsubsection{Uncertainty in Purge Gas Density $u\left(\rho_{\mathrm{N} 2}\right)$}

The density of the nitrogen purge gas in the balance chamber was computed with a virial expansion

$$
\rho_{\mathrm{N} 2}=\frac{W_{m}}{2 B}\left[-1+\sqrt{1+\frac{4 B p}{R T}}\right],
$$

where $W_{m}$ is the molar mass, $R$ is the molar gas constant, and the second virial coefficient $B$ is a function of temperature given by Span et al. [16]. The estimated uncertainty in the nitrogen density calculated by Eq. (46) at the near-ambient conditions of interest here is less than $0.01 \%$. The combined standard uncertainty of the density of nitrogen, $u\left(\rho_{\mathrm{N} 2}\right)$, is a function of pressure and temperature, so that

$$
u\left(\rho_{\mathrm{N} 2}\right)=\sqrt{\left(\frac{\partial \rho_{\mathrm{N} 2}}{\partial T}\right)^{2} u^{2}(T)+\left(\frac{\partial \rho_{\mathrm{N} 2}}{\partial p}\right)^{2} u^{2}(p)},
$$

with degrees of freedom

$$
d f_{N 2}=\frac{u^{4}\left(\rho_{N 2}\right)}{\frac{\left(\frac{\partial \rho_{\mathrm{N} 2}}{\partial T}\right)^{4} u^{4}(T)}{d f_{T}}+\frac{\left(\frac{\partial \rho_{\mathrm{N} 2}}{\partial p}\right)^{4} u^{4}(p)}{d f_{p}}} .
$$

We need to determine $u(T), u(p), d f_{T}$, and $d f_{p}$ to calculate $u\left(\rho_{N 2}\right)$ and $d f_{N 2}$. Each of the uncertainties
$u(T)$ and $u(p)$ has a random component since we use the average of six repeat measurements in each density calculation. The uncertainties also have systematic components that are given by the standard uncertainties $0.2 \mathrm{~K}$ for temperature and $0.01 \%$ for pressure. The combined standard uncertainties for temperature and pressure are

$$
u(T)=\left[\left(\frac{1}{\sqrt{6}} S_{T}\right)^{2}+(0.2 \mathrm{~K})^{2}\right]^{0.5}
$$

and

$$
u(p)=\left[\left(\frac{1}{\sqrt{6}} S_{p}\right)^{2}+(0.0001 \cdot p)^{2}\right]^{0.5},
$$

where $S_{T}$ and $S_{p}$ are standard deviations in the six temperature and pressure readings, respectively. There are five degrees of freedom associated with each random component. Assuming the "uncertainty of the uncertainty" of each systematic component is $25 \%$, based on engineering judgment, there are eight degrees of freedom associated with each systematic component. The degrees of freedom for $u(T)$ and $u(p)$ can be computed from the Welch-Satterthwaite approximation, as follows:

$$
\begin{aligned}
& d f_{T}=\frac{u^{4}(T)}{\frac{1}{5}\left(\sqrt{\frac{1}{6}} S_{T}\right)^{4}+\frac{1}{8}(0.2 \mathrm{~K})^{4}}, \\
& d f_{p}=\frac{u^{4}(p)}{\frac{1}{5}\left(\sqrt{\frac{1}{6}} S_{p}\right)^{4}+\frac{1}{8}(0.0001 p)^{4}} .
\end{aligned}
$$

\subsubsection{Uncertainty $u\left(W_{\text {cal }}\right), u\left(W_{\text {tare }}\right), u\left(W_{1}\right)$, and $u\left(W_{2}\right)$ in Weighings}

The values of $W_{\text {cal }}, W_{\text {tare }}, W_{1}$, and $W_{2}$ are all averages of ten measurements, so the estimated standard uncertainties of the four weighings are

$$
\begin{aligned}
& u\left(W_{\text {cal }}\right)=\frac{S_{\mathrm{Wcal}}}{\sqrt{10}}, \quad u\left(W_{\text {tare }}\right)=\frac{S_{\mathrm{Wtare}}}{\sqrt{10}}, \\
& u\left(W_{1}\right)=\frac{S_{\mathrm{W} 1}}{\sqrt{10}} \text {, and } u\left(W_{2}\right)=\frac{S_{\mathrm{W} 2}}{\sqrt{10}} \text {. }
\end{aligned}
$$

Each uncertainty has 9 degrees of freedom $\left(d f_{w_{\text {cal }}}=\right.$ $d f_{W_{\text {tare }}}=d f_{W_{1}}=d f_{W_{2}}=9$ ). 


\subsubsection{Uncertainty $u\left(\rho_{0}\right)$ in Apparatus Zero}

Zero pressure (or vacuum) density readings were collected between toluene fillings to provide an indication of the amount of drift in the measurement system over time. The vacuum data were collected in the following sequence:

vacuum data "A": January 5, 2006

toluene filling \#1

vacuum data "B": January 20, 2006

vacuum data "C": February 1, 2006

toluene fillings \#2 and 2a

vacuum data "D": February 24, 2006

toluene fillings \#3, 3a, and $3 \mathrm{~b}$

vacuum data "E": March 11, 2006.

Four separate straight-line regression equations were fit to consecutive pairs of vacuum measurements. For example, a straight line fit to vacuum data $\mathrm{A}$ and vacuum data $B$ would be used to estimate the amount of drift for measurements taken during toluene filling \#1. Thus, the regression equations depend on the elapsed time from the start of the experiment to the measure- ment of interest. The estimated density $\rho_{0}$ for a measurement taken at elapsed time $\tau_{0}$ is

$$
\rho_{0}=c_{0}+c_{1} \tau_{0},
$$

where $c_{0}$ and $c_{1}$ are fitting parameters, and the standard uncertainty of $\rho_{0}$ is

$$
u\left(\rho_{0}\right)=s\left[\frac{1}{n}+\left(\tau_{0}-\bar{\tau}\right)^{2} / \sum_{i=1}^{n}\left(\tau_{i}-\bar{\tau}\right)^{2}\right]^{0.5},
$$

where $n$ is the number of observations used to estimate the regression line and $s$ is the standard deviation of the fit. There are $n-2$ degrees of freedom associated with $u\left(\rho_{0}\right)\left(d f_{\rho 0}=n-2\right)$.

\subsubsection{Summary of $u\left(\rho_{\text {fluid }}\right)$}

Table 8 displays two examples of calculations of $u\left(\rho_{\text {fluid }}\right)$ for density determinations near ambient conditions $\left(t=20^{\circ} \mathrm{C}\right.$ and $p=1.0 \mathrm{MPa}$, Table 8a) and for more extreme conditions $\left(t=150{ }^{\circ} \mathrm{C}\right.$ and $p=30 \mathrm{MPa}$, Table $8 b$ ). Since there are multiple observations at the

Table 8a. Uncertainty "budget” for $\rho_{\text {fluid }}$ (Eq. 26) for two sets (a, b) of operating conditions. The sensitivity coefficients have been multiplied by

\begin{tabular}{|c|c|c|c|c|}
\hline \multirow[b]{3}{*}{ Source } & \multicolumn{4}{|c|}{$t=20^{\circ} \mathrm{C}, p=1 \mathrm{MPa}$} \\
\hline & Standard Uncertainty & Sensitivity Coefficient & & \\
\hline & $u\left(x_{i}\right)$ & $c_{i}$ & $\begin{array}{c}c_{i} \cdot u\left(x_{i}\right) \\
\left(\mathrm{kg} / \mathrm{m}^{3}\right)\end{array}$ & $\begin{array}{r}\text { Degrees of } \\
\text { Freedom }\end{array}$ \\
\hline$W_{\text {cal }}$ & $2.557 \times 10^{-7} \mathrm{~g}$ & 42.039 & $1.075 \times 10^{-5}$ & 9 \\
\hline$W_{\text {tare }}$ & $2.131 \times 10^{-7} \mathrm{~g}$ & 56.478 & $1.203 \times 10^{-5}$ & 9 \\
\hline$m_{\text {cal }}$ & $5.000 \times 10^{-5} \mathrm{~g}$ & 42.041 & $2.102 \times 10^{-3}$ & 2 \\
\hline$m_{\text {tare }}$ & $5.000 \times 10^{-5} \mathrm{~g}$ & 56.481 & $2.824 \times 10^{-3}$ & 2 \\
\hline$V_{\text {cal }}$ & $2.159 \times 10^{-3} \mathrm{~cm}^{3}$ & 0.039 & $8.362 \times 10^{-5}$ & 8 \\
\hline$V_{\text {tare }}$ & $2.159 \times 10^{-3} \mathrm{~cm}^{3}$ & 0.053 & $1.142 \times 10^{-4}$ & 8 \\
\hline$\rho_{\text {air }}$ & $6.295 \times 10^{-7} \mathrm{~g} / \mathrm{cm}^{3}$ & 107.996 & $6.799 \times 10^{-5}$ & 8 \\
\hline$m_{1}$ & $2.100 \times 10^{-5} \mathrm{~g}$ & 97.345 & $2.044 \times 10^{-3}$ & 5 \\
\hline$m_{2}$ & $2.300 \times 10^{-5} \mathrm{~g}$ & 82.905 & $1.907 \times 10^{-3}$ & 5 \\
\hline$V_{1}$ & $3.161 \times 10^{-4} \mathrm{~g}$ & 84.451 & $2.670 \times 10^{-2}$ & 9 \\
\hline$V_{2}$ & $9.513 \times 10^{-5} \mathrm{~g}$ & 71.924 & $6.842 \times 10^{-3}$ & 13 \\
\hline$W_{1}$ & $1.832 \times 10^{-6} \mathrm{~g}$ & 97.342 & $1.784 \times 10^{-4}$ & 9 \\
\hline$W_{2}$ & $3.967 \times 10^{-7} \mathrm{~g}$ & 82.903 & $3.289 \times 10^{-5}$ & 9 \\
\hline$\rho_{0}$ & $4.402 \times 10^{-9} \mathrm{~g} / \mathrm{cm}^{3}$ & 1000.0 & $4.402 \times 10^{-6}$ & 48 \\
\hline & & & $\sum\left(c_{i} \cdot u\right.$ & $\mathrm{g} / \mathrm{m}^{3}$ \\
\hline
\end{tabular}
1000 to convert to $\mathrm{kg} / \mathrm{m}^{3}$ 


\begin{tabular}{|c|c|c|c|c|}
\hline \multirow[b]{2}{*}{ Source } & \multicolumn{4}{|c|}{$t=150^{\circ} \mathrm{C}, p=30 \mathrm{MPa}$} \\
\hline & $\begin{array}{c}\text { Standard Uncertainty } \\
\qquad u\left(x_{i}\right)\end{array}$ & $\begin{array}{l}\text { Sensitivity Coefficient } \\
\qquad c_{i} \\
\end{array}$ & $\begin{array}{c}c_{i} \cdot u\left(x_{i}\right) \\
\mathrm{kg} / \mathrm{m}^{3}\end{array}$ & $\begin{array}{c}\text { Degrees of } \\
\text { Freedom }\end{array}$ \\
\hline$W_{\text {cal }}$ & $1.281 \times 10^{-6} \mathrm{~g}$ & 37.860 & $4.851 \times 10^{-5}$ & 9 \\
\hline$W_{\text {tare }}$ & $4.202 \times 10^{-7} \mathrm{~g}$ & 50.865 & $2.138 \times 10^{-5}$ & 9 \\
\hline$m_{\text {cal }}$ & $5.000 \times 10^{-5} \mathrm{~g}$ & 37.862 & $1.893 \times 10^{-3}$ & 2 \\
\hline$m_{\text {tare }}$ & $5.000 \times 10^{-5} \mathrm{~g}$ & 50.867 & $2.543 \times 10^{-3}$ & 2 \\
\hline$V_{\text {cal }}$ & $2.159 \times 10^{-3} \mathrm{~cm}^{3}$ & 0.036 & $7.784 \times 10^{-5}$ & 8 \\
\hline$V_{\text {tare }}$ & $2.159 \times 10^{-3} \mathrm{~cm}^{3}$ & 0.048 & $1.035 \times 10^{-4}$ & 8 \\
\hline$\rho_{\text {air }}$ & $6.416 \times 10^{-7} \mathrm{~g} / \mathrm{cm}^{3}$ & 97.261 & $6.240 \times 10^{-5}$ & 8 \\
\hline$m_{1}$ & $2.100 \times 10^{-5} \mathrm{~g}$ & 97.532 & $2.048 \times 10^{-3}$ & 5 \\
\hline$m_{2}$ & $2.300 \times 10^{-5} \mathrm{~g}$ & 84.527 & $1.944 \times 10^{-3}$ & 5 \\
\hline$V_{1}$ & $5.904 \times 10^{-4} \mathrm{~cm}^{3}$ & 76.189 & $4.498 \times 10^{-2}$ & 10 \\
\hline$V_{2}$ & $1.596 \times 10^{-4} \mathrm{~cm}^{3}$ & 66.030 & $1.054 \times 10^{-2}$ & 10 \\
\hline$W_{1}$ & $1.019 \times 10^{-5} \mathrm{~cm}^{3}$ & 97.530 & $9.941 \times 10^{-4}$ & 9 \\
\hline$W_{2}$ & $5.222 \times 10^{-6} \mathrm{~cm}^{3}$ & 84.526 & $4.414 \times 10^{-4}$ & 9 \\
\hline$\rho_{0}$ & $3.226 \times 10^{-9} \mathrm{~g} / \mathrm{cm}^{3}$ & 1000.0 & $3.226 \times 10^{-6}$ & 38 \\
\hline & & & $\left.\cdot u\left(x_{i}\right)\right)^{2}$ & \\
\hline
\end{tabular}

selected temperature and pressure combinations, the values in the table represent average uncertainties and sensitivity coefficients. The information in the table provides some insight into the role of the magnitude of the uncertainty and sensitivity coefficient for each source of uncertainty. Table 8 considers only the apparatus/method uncertainties and their associated degrees of freedom; they are a subset of the overall combined uncertainty discussed in Sec. 5.7.

Although there are 14 individual sources of uncertainty in $u\left(\rho_{\text {fluid }}\right)$, not all sources contribute a significant amount to the total uncertainty. We selected a few temperature and pressure combinations and computed the percentage of the total variation for all 14 sources of uncertainty. Table 9 displays the percentage of total variation for the top six contributing sources as well as the combined percentage of the remaining eight sources and the value of $u$ ( $\left.\rho_{\text {fluid }}\right)$. Again, the values in the table represent average percentages and the average uncertainties. The largest contributor to $u$ ( $\left.\rho_{\text {fluid }}\right)$ for all temperature and pressure combinations is $u\left(V_{1}\right)$, the uncertainty in the volume of the titanium sinker, followed by $u\left(V_{2}\right)$, the volume of the tantalum sinker. These two sources of uncertainty account for $98 \%$ to $99 \%$ of the total variation in $\rho_{\text {fluid. }}$.

\subsection{Uncertainty in Temperature and Pressure $u(t p)$}

Since the fluid density is a function of temperature and pressure, uncertainties in the measured temperature and pressure will contribute to the uncertainty of the reported density. A sensitivity study was used to estimate $u(t p)$ in which temperature and pressure were varied in Eq. (10) according to their corresponding uncertainty levels. The uncertainty $u(t p)$ was determined from the resulting density values. For the present measurements $u(t)=0.002{ }^{\circ} \mathrm{C}$ and $u(p)=2 \mathrm{kPa}$, so that $u(t p)=$ $0.0025 \mathrm{~kg} / \mathrm{m}^{3}$. Assuming that the "uncertainty of the uncertainty" is $25 \%$, eight degrees of freedom are appropriate for this uncertainty $\left(d f_{t p}=8\right)$. The very small magnitude of this effect is a result of the nearlyincompressible nature of toluene over the temperatures and pressures studied. This effect would be much more significant if the present apparatus were used for measurements on a gas or a fluid near its critical point.

When this SRM is used in the calibration of a densimeter, $u(t p)$ depends on the user's temperature and pressure errors. Since each user's measurement apparatus is different, we performed a sensitivity study for this uncertainty by varying temperature and pressure according to nine different combinations of error levels and 
Table 9. Percentages of total variation in $u\left(\rho_{\text {fluid }}\right)$ for six sources of uncertainty at various temperatures and pressures. The column labeled "all others" contains the combined percentage of total variation for the remaining eight sources. The value of $u$ ( $\left.\rho_{\text {fluid }}\right)$ is also listed. The quantities in the table represent average values for the given temperatures and pressures

\begin{tabular}{|c|c|c|c|c|c|c|c|c|c|}
\hline \multirow[b]{2}{*}{$\begin{array}{c}t \\
\left({ }^{\circ} \mathrm{C}\right)\end{array}$} & \multirow[b]{2}{*}{$\begin{array}{c}p \\
(\mathrm{MPa})\end{array}$} & \multicolumn{7}{|c|}{ Percent of Total Variation } & \multirow[b]{2}{*}{$\begin{array}{c}u\left(\rho_{\text {fluid }}\right) \\
\left(\mathrm{kg} / \mathrm{m}^{3}\right)\end{array}$} \\
\hline & & $V_{1}$ & $V_{2}$ & $m_{\mathrm{cal}}$ & $m_{\text {tare }}$ & $m_{1}$ & $m_{2}$ & $\begin{array}{c}\text { all } \\
\text { others }\end{array}$ & \\
\hline-50 & 1 & 92.7 & 5.6 & 0.4 & 0.7 & 0.3 & 0.3 & 0.0 & 0.036 \\
\hline-50 & 15 & 93.0 & 5.4 & 0.4 & 0.7 & 0.3 & 0.3 & 0.0 & 0.037 \\
\hline 0 & 15 & 91.7 & 5.7 & 0.6 & 1.1 & 0.5 & 0.4 & 0.0 & 0.028 \\
\hline 50 & 1 & 92.1 & 5.8 & 0.4 & 0.8 & 0.4 & 0.4 & 0.0 & 0.031 \\
\hline 50 & 15 & 92.5 & 5.6 & 0.4 & 0.7 & 0.4 & 0.4 & 0.0 & 0.032 \\
\hline 50 & 30 & 93.4 & 5.0 & 0.4 & 0.6 & 0.3 & 0.3 & 0.0 & 0.035 \\
\hline 100 & 1 & 93.0 & 5.7 & 0.3 & 0.5 & 0.3 & 0.3 & 0.0 & 0.037 \\
\hline 100 & 15 & 93.3 & 5.5 & 0.3 & 0.5 & 0.3 & 0.2 & 0.0 & 0.039 \\
\hline 150 & 15 & 93.6 & 5.5 & 0.2 & 0.3 & 0.2 & 0.2 & 0.0 & 0.044 \\
\hline 150 & 30 & 93.9 & 5.2 & 0.2 & 0.3 & 0.2 & 0.2 & 0.1 & 0.046 \\
\hline
\end{tabular}

Table 10. Estimated uncertainty $u(t p)$ due to user's temperature and pressure uncertainties

\begin{tabular}{ccc}
\hline \hline $\begin{array}{c}\text { Limit to } \\
\text { Temperature Error }\left({ }^{\circ} \mathrm{C}\right)\end{array}$ & $\begin{array}{c}\text { Limit to } \\
\text { Pressure Error }(\mathrm{MPa})\end{array}$ & $u(t p)\left(\mathrm{kg} / \mathrm{m}^{3}\right)$ \\
\hline \pm 0.001 & \pm 0.001 & 0.001 \\
& \pm 0.01 & 0.005 \\
& \pm 0.1 & 0.051 \\
\pm 0.01 & \pm 0.001 & \\
& \pm 0.01 & 0.005 \\
& \pm 0.1 & 0.007 \\
& & 0.051 \\
& \pm 0.001 & 0.053 \\
& \pm 0.01 & 0.054 \\
& \pm 0.1 & 0.075 \\
\hline
\end{tabular}

quantifying the effect on density. The results of the sensitivity study are shown in Table 10 . The error values listed in the first two columns of Table 10 represent a user's limits to error (rather than a standard uncertainty), and the values of $u(t p)$ are typical uncertainties across all temperatures and pressures in the test region. Ultimately, the user is responsible for estimating an appropriate value of $u(t p)$ and its associated degrees of freedom.

\subsection{Combined Standard Uncertainty}

The combined standard uncertainty associated with an estimated fluid density is given by Eq. (17). The values of $u(\rho), u(V)$, and $u(x)$ are constant for all temperature and pressure combinations. The value of $u(e)$ depends on the operating temperature and pressure and is calculated from Eq. (24). The value of $u(\Delta)$ depends on the degree of air saturation in the measured sample (for degassed samples, $u(\Delta)=0$ ), and $u(t p)$ depends on the level of error associated with the operating temperature and pressure in the user's apparatus.

The values of the individual uncertainty components for the measurements described in this work are displayed along with their associated degrees of freedom in Table 11. Table 12 displays the combined standard uncertainty for four of the uncertainty components, $u(\rho), u(V), u(x)$ and $u(e)$ (from Table 11 and Eq. 24) for the same even increments of temperatures and pressures listed in Table 4. 
Table 11. Uncertainties and degrees of freedom for measurements described in this document *

\begin{tabular}{lcc}
\hline \hline Source & Uncertainty $\left(\mathrm{kg} / \mathrm{m}^{3}\right)$ & Degrees of Freedom \\
\hline$u(\rho)$ & 0.0086 & 886 \\
$u(V)$ & 0.0114 & 32 \\
$u(x)$ & 0.003 & 8 \\
$u(t p)$ & 0.00247 & 8 \\
\hline
\end{tabular}

* Degassed samples only $(u(\Delta)=0)$.

\subsection{Expanded Uncertainty and Degrees of Freedom}

The expanded uncertainty is $U=k u_{C}$, where the coverage factor $k$ is obtained from the Student's $t$ distribution based on the effective degrees of freedom for $u_{C}$. In general, the expanded uncertainty associated with a $100 \cdot(1-\alpha) \%$ coverage probability ( $\alpha$ is 0.05 for $95 \%$ coverage) is given by $U=t_{(1-\alpha / 2, d f e f f)} \cdot u_{C}$. Typically, $k=2$ is used to compute the expanded uncertainty associated with a $95 \%$ uncertainty interval. However, if the effective degrees of freedom are less than 30 , the interval coverage is less than $95 \%$. Thus, we recommend that the effective degrees of freedom be computed to determine the proper coverage factor.

The effective degrees of freedom obtained from the Welch-Satterthwaite approximation are

$$
\begin{aligned}
& d f_{\text {eff }}= \\
& \frac{u^{4}(\rho)}{d f_{\rho}}+\frac{u^{4}(V)}{d f_{V}}+\frac{u^{4}(x)}{d f_{x}}+\frac{u^{4}(e)}{d f_{e}}+\frac{u^{4}(\Delta)}{d f_{\Delta}}+\frac{u^{4}(t p)}{d f_{t p}}
\end{aligned}
$$

Since the effective degrees of freedom depend on the value of $u(e)$ for a given temperature and pressure, we will provide a conservative estimate of $d f_{\text {eff }}$ for all degassed measurements given in this document. The smallest (most conservative) value of $d f_{\text {eff }}$ is observed when $u(e)$ is large since all other uncertainty sources and degrees of freedom are fixed. We used the largest value of $u(e)$ observed for our data, $u(e)=0.053$ $\mathrm{kg} / \mathrm{m}^{3}\left(d f_{e}=9\right)$, and the remaining uncertainties and associated degrees of freedom from Table 11 to compute $d f_{\text {eff }}$. Thus, a conservative value for all degassed measurements reported in this document is $d f_{\text {eff }}=10$,

\begin{tabular}{|c|c|c|c|c|c|c|c|c|c|}
\hline \multirow[b]{2}{*}{$t\left({ }^{\circ} \mathrm{C}\right)$} & \multicolumn{9}{|c|}{ Pressure (MPa) } \\
\hline & 0.1 & 1 & 2 & 5 & 10 & 15 & 20 & 25 & 30 \\
\hline-40 & 0.035 & 0.035 & 0.035 & 0.035 & 0.036 & 0.036 & 0.037 & 0.038 & 0.039 \\
\hline-30 & 0.033 & 0.033 & 0.033 & 0.033 & 0.034 & 0.034 & 0.035 & 0.036 & 0.037 \\
\hline-20 & 0.031 & 0.031 & 0.031 & 0.032 & 0.032 & 0.033 & 0.033 & 0.034 & 0.035 \\
\hline-10 & 0.031 & 0.031 & 0.031 & 0.031 & 0.031 & 0.032 & 0.033 & 0.034 & 0.035 \\
\hline 0 & 0.030 & 0.030 & 0.031 & 0.031 & 0.031 & 0.032 & 0.032 & 0.033 & 0.034 \\
\hline 10 & 0.031 & 0.031 & 0.031 & 0.031 & 0.031 & 0.032 & 0.033 & 0.034 & 0.035 \\
\hline 20 & 0.031 & 0.031 & 0.031 & 0.031 & 0.032 & 0.033 & 0.033 & 0.034 & 0.035 \\
\hline 30 & 0.032 & 0.032 & 0.032 & 0.032 & 0.033 & 0.033 & 0.034 & 0.035 & 0.036 \\
\hline 40 & 0.033 & 0.033 & 0.033 & 0.033 & 0.034 & 0.034 & 0.035 & 0.036 & 0.037 \\
\hline 60 & 0.035 & 0.035 & 0.035 & 0.036 & 0.036 & 0.037 & 0.037 & 0.038 & 0.039 \\
\hline 70 & 0.037 & 0.037 & 0.037 & 0.037 & 0.037 & 0.038 & 0.039 & 0.040 & 0.041 \\
\hline 80 & 0.038 & 0.038 & 0.038 & 0.038 & 0.039 & 0.039 & 0.040 & 0.041 & 0.042 \\
\hline 90 & 0.039 & 0.039 & 0.039 & 0.039 & 0.040 & 0.040 & 0.041 & 0.042 & 0.043 \\
\hline 100 & 0.040 & 0.040 & 0.040 & 0.040 & 0.041 & 0.041 & 0.042 & 0.043 & 0.044 \\
\hline 110 & 0.041 & 0.041 & 0.041 & 0.041 & 0.042 & 0.042 & 0.043 & 0.044 & 0.045 \\
\hline 120 & $*$ & 0.042 & 0.042 & 0.042 & 0.043 & 0.043 & 0.044 & 0.045 & 0.046 \\
\hline 130 & $*$ & 0.043 & 0.043 & 0.043 & 0.044 & 0.044 & 0.045 & 0.046 & 0.047 \\
\hline 140 & $*$ & 0.044 & 0.044 & 0.044 & 0.044 & 0.045 & 0.046 & 0.047 & 0.048 \\
\hline 150 & $*$ & 0.044 & 0.045 & 0.045 & 0.045 & 0.046 & 0.047 & 0.048 & 0.049 \\
\hline
\end{tabular}

Table 12. Combined standard uncertainty $u$ in $\mathrm{kg} / \mathrm{m}^{3}$, including the effects of $u(\rho), u(V)$, and $u(x)$ and $u(e)$

*above the normal boiling point temperature (liquid phase not stable at $p=0.1 \mathrm{MPa}$ ) 
and the appropriate coverage factor for a $95 \%$ uncertainty interval is 2.228 .

When the SRM is used to calibrate a user's densimeter, two of the uncertainty components of $u_{C}$, ie. $u(\Delta)$ and $u(t p)$, depend on the user's conditions, so the final value of the user's $d f_{\text {eff }}$ cannot be calculated in this document.

\subsection{Uncertainty Example}

We shall estimate the density and its uncertainty at $t=-23{ }^{\circ} \mathrm{C}$ and $p=12 \mathrm{MPa}$ for a degassed sample $\left(\Delta=0 \mathrm{~kg} / \mathrm{m}^{3}\right.$ and $\left.u(\Delta)=0 \mathrm{~kg} / \mathrm{m}^{3}\right)$. The values of temperature and pressure are input into Eq. (10), resulting in a density estimate of $913.461 \mathrm{~kg} / \mathrm{m}^{3}$. Similarly, $u(e)=0.0292 \mathrm{~kg} / \mathrm{m}^{3}$ is calculated from Eq. (24). If the limit to temperature error is thought to be $\pm 0.1^{\circ} \mathrm{C}$, and the limit to pressure error is $\pm 0.1 \mathrm{MPa}$, then from Table $10, u(t p)=0.075 \mathrm{~kg} / \mathrm{m}^{3}$. The combined standard uncertainty of the estimated density is then

$$
\begin{aligned}
& u_{C}=\left[u^{2}(\rho)+u^{2}(V)+u^{2}(x)+u^{2}(e)+u^{2}(t p)\right]^{0.5} \\
& u_{C}=\left[\begin{array}{l}
\left(0.0086 \mathrm{~kg} / \mathrm{m}^{3}\right)^{2}+\left(0.0114 \mathrm{~kg} / \mathrm{m}^{3}\right)^{2} \\
+\left(0.003 \mathrm{~kg} / \mathrm{m}^{3}\right)^{2}+\left(0.0292 \mathrm{~kg} / \mathrm{m}^{3}\right)^{2} \\
+\left(0.075 \mathrm{~kg} / \mathrm{m}^{3}\right)^{2}
\end{array}\right]^{0.5} \\
& u_{C}=0.082 \mathrm{~kg} / \mathrm{m}^{3} .
\end{aligned}
$$

If the levels of error defining $u(t p)$ are well known, then we will assume $d f_{t p}=30$. Using $d f_{e}=9$ from Sec. 5.5, the effective degrees of freedom associated with $u_{C}$ are

$$
\begin{aligned}
d f_{\text {eff }}= & \frac{u_{C}^{4}}{\frac{u^{4}(\rho)}{d f_{\rho}}+\frac{u^{4}(V)}{d f_{V}}+\frac{u^{4}(x)}{d f_{x}}+\frac{u^{4}(e)}{d f_{e}}+\frac{u^{4}(t p)}{d f_{t p}}} \\
d f_{\text {eff }}= & \left(0.082 \mathrm{~kg} / \mathrm{m}^{3}\right)^{4} / \\
& {\left[\frac{\left(0.0086 \mathrm{~kg} / \mathrm{m}^{3}\right)^{4}}{886}+\frac{\left(0.0114 \mathrm{~kg} / \mathrm{m}^{3}\right)^{4}}{32}\right.} \\
& +\frac{\left(0.003 \mathrm{~kg} / \mathrm{m}^{3}\right)^{4}}{8}+\frac{\left(0.0292 \mathrm{~kg} / \mathrm{m}^{3}\right)^{4}}{9} \\
& \left.+\frac{\left(0.075 \mathrm{~kg} / \mathrm{m}^{3}\right)^{4}}{30}\right] \\
d f_{\text {eff }}= & 39,
\end{aligned}
$$

and the appropriate coverage factor for a $95 \%$ uncertainty interval is 2.0227 .

\section{Discussion and Conclusions}

We report values for the density of liquid toluene that form the basis of NIST Standard Reference Material ${ }^{\circledR}$ 211d "Toluene Liquid Density-Extended Range." This work extends the range of this SRM, which was previously limited to $15^{\circ} \mathrm{C}$ to $25^{\circ} \mathrm{C}$ and normal atmospheric pressure, to the temperature range $-50{ }^{\circ} \mathrm{C}$ to $150{ }^{\circ} \mathrm{C}$ and pressure range $0.1 \mathrm{MPa}$ to $30 \mathrm{MPa}$. This SRM will be invaluable in calibration of industrial densimeters.

The uncertainties for the density values were obtained by a thorough statistical analysis of multiple sources of uncertainty. In many cases, a measured quantity depends on other underlying measurands, and the uncertainties at each level were considered. We have presented the uncertainty analysis in considerable detail with the hope that it will serve as an example for others carrying out fluid property measurements.

The measurements reported here are directly traceable to SI quantities. The density was determined by weighing sinkers immersed in the fluid. The volume (or, equivalently, density) of the sinkers was determined by comparison to solid density standards that are directly traceable to the meter and kilogram. The balance that carried out the weighings was calibrated for each density determination using calibration weights, which were, in turn, calibrated against standard masses. The temperature of the fluid was measured with a standard platinum resistance thermometer calibrated with ITS-90 fixed points. The pressure transducer was calibrated against a piston gage pressure standard.

\section{Appendix A-Experimental Values of Density}

Table A1. Experimentally measured temperatures $t$, pressures $p$, and densities $\rho_{\text {exp }}$ for degassed SRM toluene with the standard uncertainty $u\left(\rho_{\text {fluid }}\right)$

\begin{tabular}{ccccc}
\hline \hline & $\begin{array}{c}t \\
\left({ }^{\circ} \mathrm{C}\right)\end{array}$ & $\begin{array}{c}p \\
(\mathrm{MPa})\end{array}$ & $\begin{array}{c}\rho_{\text {exp }} \\
\left(\mathrm{kg} \mathrm{m}^{-3}\right)\end{array}$ & $\begin{array}{c}u\left(\rho_{\text {fluid }}\right) \\
\left(\mathrm{kg} \mathrm{m}^{-3}\right)\end{array}$ \\
\hline Filling 1 & & & & \\
& -59.999 & 0.0089 & 940.943 & 0.042 \\
& -59.998 & 0.0090 & 940.942 & 0.042 \\
& -59.999 & 0.0090 & 940.943 & 0.042 \\
& -59.998 & 0.0089 & 940.943 & 0.042 \\
& -59.998 & 0.0088 & 940.941 & 0.042 \\
& -59.999 & 3.8239 & 942.780 & 0.042 \\
& -59.999 & 3.8232 & 942.781 & 0.042 \\
& -59.998 & 3.8266 & 942.782 & 0.042 \\
& -59.999 & 3.8248 & 942.782 & 0.042 \\
& -59.999 & 3.8249 & 942.781 & 0.042
\end{tabular}


Volume 113, Number 1, January-February 2008

Journal of Research of the National Institute of Standards and Technology

Table A1 (continued)

Table A1 (continued)

\begin{tabular}{|c|c|c|c|}
\hline-49.997 & 19.9442 & 941.344 & 0.038 \\
\hline-49.997 & 19.9435 & 941.343 & 0.038 \\
\hline-49.998 & 19.9420 & 941.342 & 0.038 \\
\hline-49.997 & 19.9431 & 941.343 & 0.038 \\
\hline-49.996 & 19.9449 & 941.344 & 0.038 \\
\hline - 39.997 & 35.6032 & 939.966 & 0.038 \\
\hline-39.998 & 35.5999 & 939.964 & 0.038 \\
\hline - 39.998 & 35.6019 & 939.966 & 0.038 \\
\hline - 39.997 & 35.6009 & 939.965 & 0.038 \\
\hline-39.997 & 35.6034 & 939.967 & 0.038 \\
\hline - 39.997 & 30.2614 & 937.496 & 0.036 \\
\hline-39.996 & 30.2627 & 937.496 & 0.036 \\
\hline - 39.996 & 30.2633 & 937.496 & 0.036 \\
\hline - 39.997 & 30.2634 & 937.497 & 0.036 \\
\hline-39.996 & 30.2643 & 937.497 & 0.036 \\
\hline-39.998 & 25.2278 & 935.115 & 0.035 \\
\hline - 39.997 & 25.2297 & 935.116 & 0.035 \\
\hline - 39.998 & 25.2305 & 935.117 & 0.035 \\
\hline - 39.997 & 25.2323 & 935.116 & 0.035 \\
\hline - 39.997 & 25.2318 & 935.117 & 0.035 \\
\hline - 39.998 & 20.1557 & 932.661 & 0.034 \\
\hline - 39.997 & 20.1571 & 932.660 & 0.034 \\
\hline-39.998 & 20.1612 & 932.662 & 0.034 \\
\hline-39.996 & 20.1635 & 932.663 & 0.034 \\
\hline - 39.996 & 20.1602 & 932.661 & 0.034 \\
\hline - 39.997 & 15.2720 & 930.241 & 0.033 \\
\hline-39.997 & 15.2718 & 930.241 & 0.033 \\
\hline - 39.997 & 15.2726 & 930.240 & 0.033 \\
\hline - 39.996 & 15.2724 & 930.240 & 0.033 \\
\hline - 39.997 & 15.2716 & 930.240 & 0.033 \\
\hline-39.998 & 10.3463 & 927.742 & 0.032 \\
\hline - 39.997 & 10.3466 & 927.741 & 0.032 \\
\hline-39.996 & 10.3486 & 927.742 & 0.032 \\
\hline-39.996 & 10.3489 & 927.742 & 0.032 \\
\hline - 39.997 & 10.3464 & 927.742 & 0.032 \\
\hline - 39.997 & 5.2108 & 925.070 & 0.032 \\
\hline - 39.996 & 5.2123 & 925.071 & 0.032 \\
\hline - 39.997 & 5.2134 & 925.070 & 0.032 \\
\hline-39.997 & 5.2121 & 925.071 & 0.032 \\
\hline-39.996 & 5.2137 & 925.070 & 0.032 \\
\hline - 39.997 & 1.0800 & 922.867 & 0.032 \\
\hline - 39.997 & 1.0753 & 922.865 & 0.032 \\
\hline-39.996 & 1.0756 & 922.864 & 0.032 \\
\hline-39.996 & 1.0761 & 922.863 & 0.032 \\
\hline-39.997 & 1.0727 & 922.862 & 0.032 \\
\hline-30.002 & 15.4119 & 921.486 & 0.030 \\
\hline-30.001 & 15.4118 & 921.482 & 0.030 \\
\hline-30.001 & 15.4149 & 921.484 & 0.030 \\
\hline-30.002 & 15.4134 & 921.483 & 0.030 \\
\hline-30.001 & 15.4134 & 921.484 & 0.030 \\
\hline-20.002 & 29.4361 & 920.184 & 0.032 \\
\hline-20.002 & 29.4313 & 920.182 & 0.032 \\
\hline-20.001 & 29.4308 & 920.181 & 0.032 \\
\hline-20.000 & 29.4330 & 920.182 & 0.032 \\
\hline-20.001 & 29.4324 & 920.180 & 0.032 \\
\hline-20.002 & 24.6818 & 917.708 & 0.031 \\
\hline-20.001 & 24.6767 & 917.706 & 0.031 \\
\hline-20.001 & 24.6755 & 917.705 & 0.031 \\
\hline
\end{tabular}

\begin{tabular}{|c|c|c|c|}
\hline-20.000 & 24.6765 & 917.704 & 0.031 \\
\hline-20.000 & 24.6692 & 917.700 & 0.031 \\
\hline-20.000 & 20.0503 & 915.236 & 0.030 \\
\hline-20.000 & 20.0500 & 915.237 & 0.030 \\
\hline-20.000 & 20.0496 & 915.236 & 0.030 \\
\hline-20.000 & 20.0494 & 915.236 & 0.030 \\
\hline-19.999 & 20.0503 & 915.236 & 0.030 \\
\hline-20.000 & 15.2040 & 912.587 & 0.029 \\
\hline-20.000 & 15.2049 & 912.588 & 0.029 \\
\hline-19.999 & 15.2051 & 912.586 & 0.029 \\
\hline-19.999 & 15.2058 & 912.587 & 0.029 \\
\hline-20.000 & 15.2062 & 912.587 & 0.029 \\
\hline-20.001 & 10.1332 & 909.738 & 0.028 \\
\hline-20.001 & 10.1346 & 909.737 & 0.028 \\
\hline-20.001 & 10.1322 & 909.737 & 0.028 \\
\hline-20.001 & 10.1318 & 909.737 & 0.028 \\
\hline-20.001 & 10.1308 & 909.735 & 0.028 \\
\hline-20.002 & 5.3089 & 906.948 & 0.028 \\
\hline-20.001 & 5.3142 & 906.951 & 0.028 \\
\hline-20.001 & 5.3162 & 906.950 & 0.028 \\
\hline-20.000 & 5.3166 & 906.950 & 0.028 \\
\hline-20.001 & 5.3176 & 906.951 & 0.028 \\
\hline-19.999 & 1.0111 & 904.389 & 0.027 \\
\hline-20.000 & 1.0099 & 904.389 & 0.027 \\
\hline-20.000 & 1.0110 & 904.389 & 0.027 \\
\hline-19.998 & 1.0108 & 904.388 & 0.027 \\
\hline-19.999 & 1.0101 & 904.388 & 0.027 \\
\hline-10.001 & 13.9588 & 903.114 & 0.028 \\
\hline-9.999 & 13.9669 & 903.117 & 0.028 \\
\hline-9.999 & 13.9669 & 903.118 & 0.028 \\
\hline-9.999 & 13.9678 & 903.117 & 0.028 \\
\hline-9.998 & 13.9684 & 903.117 & 0.028 \\
\hline-0.002 & 26.6266 & 901.902 & 0.031 \\
\hline-0.001 & 26.6226 & 901.898 & 0.031 \\
\hline 0.000 & 26.6236 & 901.897 & 0.031 \\
\hline 0.001 & 26.6235 & 901.897 & 0.031 \\
\hline 0.000 & 26.6221 & 901.896 & 0.031 \\
\hline 0.001 & 25.1503 & 901.048 & 0.030 \\
\hline 0.001 & 25.1507 & 901.049 & 0.030 \\
\hline 0.001 & 25.1516 & 901.049 & 0.030 \\
\hline 0.002 & 25.1522 & 901.049 & 0.030 \\
\hline 0.002 & 25.1526 & 901.049 & 0.030 \\
\hline 0.000 & 20.0628 & 898.064 & 0.029 \\
\hline 0.002 & 20.0638 & 898.064 & 0.029 \\
\hline 0.002 & 20.0633 & 898.063 & 0.029 \\
\hline 0.001 & 20.0633 & 898.064 & 0.029 \\
\hline 0.001 & 20.0646 & 898.064 & 0.029 \\
\hline 0.001 & 15.1485 & 895.092 & 0.028 \\
\hline 0.002 & 15.1487 & 895.091 & 0.028 \\
\hline 0.002 & 15.1499 & 895.093 & 0.028 \\
\hline 0.002 & 15.1490 & 895.091 & 0.028 \\
\hline 0.002 & 15.1486 & 895.091 & 0.028 \\
\hline 0.001 & 10.0567 & 891.915 & 0.028 \\
\hline 0.002 & 10.0575 & 891.914 & 0.028 \\
\hline 0.002 & 10.0570 & 891.914 & 0.028 \\
\hline 0.001 & 10.0523 & 891.912 & 0.028 \\
\hline 0.002 & 10.0518 & 891.911 & 0.028 \\
\hline 0.002 & 5.0765 & 888.701 & 0.027 \\
\hline 0.001 & 5.0753 & 888.701 & 0.027 \\
\hline
\end{tabular}


Volume 113, Number 1, January-February 2008

Journal of Research of the National Institute of Standards and Technology

Table A1 (continued)

Table A1 (continued)

$\begin{array}{llll}0.002 & 5.0757 & 888.700 & 0.027 \\ 0.002 & 5.0770 & 888.700 & 0.027 \\ 0.001 & 5.0764 & 888.700 & 0.027 \\ 0.001 & 1.1818 & 886.109 & 0.027 \\ 0.002 & 1.1821 & 886.108 & 0.027 \\ 0.002 & 1.1821 & 886.107 & 0.027 \\ 0.001 & 1.1809 & 886.107 & 0.027 \\ 0.001 & 1.1816 & 886.108 & 0.027 \\ & & & \\ 10.001 & 12.8459 & 884.896 & 0.028 \\ 10.002 & 12.8471 & 884.896 & 0.028 \\ 10.001 & 12.8456 & 884.896 & 0.028 \\ 10.001 & 12.8448 & 884.895 & 0.028 \\ 10.001 & 12.8447 & 884.895 & 0.028 \\ & & & \\ 20.000 & 24.2835 & 883.746 & 0.031 \\ 20.000 & 24.2826 & 883.746 & 0.031 \\ 20.000 & 24.2828 & 883.744 & 0.031 \\ 20.002 & 24.2842 & 883.744 & 0.031 \\ 20.001 & 24.2837 & 883.745 & 0.031 \\ 20.001 & 19.9622 & 880.938 & 0.030 \\ 20.001 & 19.9604 & 880.937 & 0.030 \\ 20.002 & 19.9599 & 880.937 & 0.030 \\ 20.002 & 19.9589 & 880.935 & 0.030 \\ 20.001 & 19.9584 & 880.935 & 0.030 \\ 20.000 & 14.9999 & 877.613 & 0.029 \\ 20.000 & 14.9992 & 877.613 & 0.029 \\ 20.002 & 15.0003 & 877.612 & 0.029 \\ 20.002 & 14.9987 & 877.611 & 0.029 \\ 20.001 & 14.9977 & 877.612 & 0.029 \\ 20.001 & 9.9660 & 874.116 & 0.029 \\ 20.001 & 9.9670 & 874.115 & 0.029 \\ 20.002 & 9.9683 & 874.115 & 0.029 \\ 20.002 & 9.9685 & 874.116 & 0.029 \\ 20.001 & 9.9684 & 874.117 & 0.029 \\ 20.002 & 4.9073 & 870.461 & 0.028 \\ 20.001 & 4.9095 & 870.464 & 0.028 \\ 20.002 & 4.9117 & 870.464 & 0.028 \\ 20.003 & 4.9122 & 870.464 & 0.028 \\ 20.002 & 4.9109 & 870.463 & 0.028 \\ 20.002 & 1.0214 & 867.551 & 0.028 \\ 20.002 & 1.0206 & 867.550 & 0.028 \\ 20.003 & 1.0222 & 867.551 & 0.028 \\ 20.004 & 1.0221 & 867.551 & 0.028 \\ 20.003 & 1.0216 & 867.551 & 0.028 \\ 30.001 & 11.5320 & 866.399 & 0.030 \\ 30.001 & 11.5308 & 866.399 & 0.030 \\ 30.001 & 11.5314 & 866.399 & 0.030 \\ 30.002 & 11.5311 & 866.399 & 0.030 \\ 30.001 & 11.5295 & 866.396 & 0.030 \\ 40.002 & 21.8779 & 865.315 & 0.032 \\ 40.001 & 21.8766 & 865.317 & 0.032 \\ 40.001 & 21.8769 & 865.315 & 0.032 \\ 40.001 & 21.8769 & 865.316 & 0.032 \\ 40.001 & 21.8764 & 865.316 & 0.032\end{array}$

\begin{tabular}{|c|c|c|c|c|}
\hline & 50.001 & 32.0188 & 864.264 & 0.036 \\
\hline & 50.000 & 32.0181 & 864.264 & 0.036 \\
\hline & 50.000 & 32.0184 & 864.265 & 0.036 \\
\hline & 50.001 & 32.0204 & 864.265 & 0.036 \\
\hline & 50.001 & 32.0199 & 864.264 & 0.036 \\
\hline & 50.001 & 29.8506 & 862.733 & 0.035 \\
\hline & 50.002 & 29.8515 & 862.734 & 0.035 \\
\hline & 50.001 & 29.8513 & 862.735 & 0.035 \\
\hline & 50.000 & 29.8499 & 862.733 & 0.035 \\
\hline & 50.001 & 29.8505 & 862.733 & 0.035 \\
\hline & 50.000 & 24.8786 & 859.129 & 0.034 \\
\hline & 50.001 & 24.8789 & 859.129 & 0.034 \\
\hline & 50.001 & 24.8781 & 859.127 & 0.034 \\
\hline & 50.000 & 24.8753 & 859.127 & 0.034 \\
\hline & 50.000 & 24.8779 & 859.128 & 0.034 \\
\hline & 50.000 & 19.9578 & 855.422 & 0.033 \\
\hline & 50.000 & 19.9592 & 855.424 & 0.03 \\
\hline & 50.000 & 19.9596 & 855.424 & 0.033 \\
\hline & 50.001 & 19.9606 & 855.424 & 0.033 \\
\hline & 50.001 & 19.9599 & 855.423 & 0.033 \\
\hline & 50.000 & 15.0142 & 851.543 & 0.032 \\
\hline & 50.000 & 15.0153 & 851.544 & 0.032 \\
\hline & 50.001 & 15.0157 & 851.543 & 0.032 \\
\hline & 50.001 & 15.0159 & 851.544 & 0.032 \\
\hline & 50.000 & 15.0151 & 851.544 & 0.03 \\
\hline & 50.000 & 9.9887 & 847.424 & 0.032 \\
\hline & 50.000 & 9.9850 & 847.420 & 0.032 \\
\hline & 50.000 & 9.9867 & 847.421 & 0.032 \\
\hline & 50.001 & 9.9864 & 847.420 & 0.032 \\
\hline & 50.000 & 9.9856 & 847.420 & 0.032 \\
\hline & 50.001 & 5.1148 & 843.235 & 0.031 \\
\hline & 50.000 & 5.1143 & 843.236 & 0.03 \\
\hline & 50.000 & 5.1141 & 843.235 & 0.03 \\
\hline & 50.002 & 5.1142 & 843.234 & 0.03 \\
\hline & 50.002 & 5.1149 & 843.235 & 0.031 \\
\hline & 50.000 & 1.0621 & 839.595 & 0.031 \\
\hline & 50.001 & 1.0604 & 839.592 & 0.031 \\
\hline & 50.001 & 1.0619 & 839.594 & 0.031 \\
\hline & 50.001 & 1.0612 & 839.594 & 0.031 \\
\hline & 50.000 & 1.0610 & 839.594 & 0.031 \\
\hline \multicolumn{5}{|l|}{ Filling 2} \\
\hline & -49.994 & 22.1054 & 942.346 & 0.0 \\
\hline & -49.995 & 22.1045 & 942.346 & 0.0 \\
\hline & -49.996 & 22.0986 & 942.344 & 0.038 \\
\hline & -49.995 & 22.0998 & 942.343 & 0.038 \\
\hline & -49.994 & 22.0994 & 942.344 & 0.03 \\
\hline & -49.995 & 19.6460 & 941.208 & 0.038 \\
\hline & -49.995 & 19.6488 & 941.210 & 0.03 \\
\hline & -49.995 & 19.6478 & 941.202 & 0.03 \\
\hline & -49.995 & 19.6467 & 941.201 & 0.0 \\
\hline & -49.995 & 19.6465 & 941.202 & 0.03 \\
\hline & -49.996 & 17.4593 & 940.175 & 0.03 \\
\hline & -49.996 & 17.4620 & 940.177 & 0.03 \\
\hline & -49.996 & 17.4623 & 940.178 & 0.03 \\
\hline & -49.996 & 17.4626 & 940.176 & 0.037 \\
\hline & -49.995 & 17.4652 & 940.177 & 0.03 \\
\hline & -49.996 & 15.0378 & 939.024 & 0.037 \\
\hline & -49.995 & 15.0403 & 939.026 & 0.037 \\
\hline & -49.996 & 15.0392 & 939.025 & 0.037 \\
\hline & -49.996 & 15.0385 & 939.025 & 0.037 \\
\hline
\end{tabular}


Volume 113, Number 1, January-February 2008

Journal of Research of the National Institute of Standards and Technology

Table A1 (continued)

Table A1 (continued)

\begin{tabular}{|c|c|c|c|}
\hline-49.997 & 12.1742 & 937.649 & 0.037 \\
\hline-49.996 & 12.1742 & 937.649 & 0.037 \\
\hline-49.995 & 12.1770 & 937.649 & 0.037 \\
\hline-49.996 & 12.1760 & 937.649 & 0.037 \\
\hline-49.996 & 12.1774 & 937.651 & 0.037 \\
\hline-49.997 & 10.0824 & 936.632 & 0.036 \\
\hline-49.996 & 10.0842 & 936.632 & 0.036 \\
\hline-49.996 & 10.0839 & 936.631 & 0.036 \\
\hline-49.997 & 10.0826 & 936.632 & 0.036 \\
\hline-49.996 & 10.0848 & 936.632 & 0.036 \\
\hline-49.996 & 7.9616 & 935.590 & 0.036 \\
\hline-49.995 & 7.9614 & 935.590 & 0.036 \\
\hline-49.995 & 7.9623 & 935.590 & 0.036 \\
\hline-49.996 & 7.9603 & 935.589 & 0.036 \\
\hline-49.996 & 7.9593 & 935.588 & 0.036 \\
\hline-49.996 & 6.0743 & 934.654 & 0.036 \\
\hline-49.996 & 6.0761 & 934.654 & 0.036 \\
\hline-49.996 & 6.0749 & 934.654 & 0.036 \\
\hline-49.997 & 6.0732 & 934.655 & 0.036 \\
\hline-49.995 & 6.0759 & 934.655 & 0.036 \\
\hline-49.999 & 4.0086 & 933.623 & 0.036 \\
\hline-49.996 & 4.0198 & 933.626 & 0.036 \\
\hline-49.996 & 4.0193 & 933.624 & 0.036 \\
\hline-49.996 & 4.0191 & 933.625 & 0.036 \\
\hline-49.996 & 4.0209 & 933.626 & 0.036 \\
\hline-49.997 & 2.1715 & 932.692 & 0.036 \\
\hline-49.995 & 2.1737 & 932.691 & 0.036 \\
\hline-49.996 & 2.1744 & 932.693 & 0.036 \\
\hline-49.996 & 2.1733 & 932.692 & 0.036 \\
\hline-49.996 & 2.1740 & 932.693 & 0.036 \\
\hline-49.996 & 0.7106 & 931.948 & 0.036 \\
\hline-49.996 & 0.7105 & 931.946 & 0.036 \\
\hline-49.996 & 0.7136 & 931.948 & 0.036 \\
\hline-49.996 & 0.7132 & 931.948 & 0.036 \\
\hline-49.995 & 0.7160 & 931.949 & 0.036 \\
\hline-39.996 & 15.8462 & 930.527 & 0.033 \\
\hline-39.996 & 15.8446 & 930.526 & 0.033 \\
\hline-39.995 & 15.8452 & 930.525 & 0.033 \\
\hline-39.995 & 15.8431 & 930.523 & 0.033 \\
\hline-39.995 & 15.8436 & 930.524 & 0.033 \\
\hline-30.000 & 30.5993 & 929.182 & 0.034 \\
\hline-29.999 & 30.5969 & 929.179 & 0.034 \\
\hline-30.000 & 30.5980 & 929.180 & 0.034 \\
\hline-30.000 & 30.5980 & 929.181 & 0.034 \\
\hline-29.999 & 30.6017 & 929.182 & 0.034 \\
\hline-30.000 & 25.2379 & 926.527 & 0.032 \\
\hline-30.000 & 25.2381 & 926.528 & 0.032 \\
\hline - 29.999 & 25.2391 & 926.527 & 0.032 \\
\hline-29.999 & 25.2392 & 926.527 & 0.032 \\
\hline-30.000 & 25.2392 & 926.527 & 0.032 \\
\hline-30.000 & 20.1482 & 923.945 & 0.031 \\
\hline - 29.999 & 20.1496 & 923.945 & 0.031 \\
\hline - 29.999 & 20.1493 & 923.943 & 0.031 \\
\hline-30.000 & 20.1500 & 923.944 & 0.031 \\
\hline-29.999 & 20.1501 & 923.944 & 0.031 \\
\hline-29.998 & 14.9375 & 921.229 & 0.030 \\
\hline-30.000 & 14.9361 & 921.230 & 0.030 \\
\hline-29.999 & 14.9371 & 921.229 & 0.030 \\
\hline
\end{tabular}

\begin{tabular}{|c|c|c|c|}
\hline-29.998 & 14.9385 & 921.229 & 0.030 \\
\hline-29.999 & 14.9376 & 921.230 & 0.030 \\
\hline-29.998 & 10.3699 & 918.790 & 0.030 \\
\hline-30.000 & 10.3680 & 918.789 & 0.030 \\
\hline-29.999 & 10.3703 & 918.791 & 0.030 \\
\hline-29.999 & 10.3715 & 918.792 & 0.030 \\
\hline-29.999 & 10.3702 & 918.791 & 0.030 \\
\hline-30.000 & 5.0564 & 915.876 & 0.029 \\
\hline-29.999 & 5.0586 & 915.877 & 0.029 \\
\hline-30.000 & 5.0596 & 915.877 & 0.029 \\
\hline-29.999 & 5.0593 & 915.877 & 0.029 \\
\hline-29.999 & 5.0596 & 915.877 & 0.029 \\
\hline-29.999 & 0.8122 & 913.483 & 0.029 \\
\hline-29.999 & 0.8149 & 913.485 & 0.029 \\
\hline-29.999 & 0.8131 & 913.485 & 0.029 \\
\hline-29.999 & 0.8098 & 913.483 & 0.029 \\
\hline-29.999 & 0.8119 & 913.483 & 0.029 \\
\hline-20.001 & 14.4426 & 912.164 & 0.029 \\
\hline-19.999 & 14.4442 & 912.164 & 0.029 \\
\hline-19.999 & 14.4423 & 912.162 & 0.029 \\
\hline-20.000 & 14.4418 & 912.162 & 0.029 \\
\hline-19.999 & 14.4424 & 912.161 & 0.029 \\
\hline-9.999 & 27.7494 & 910.898 & 0.031 \\
\hline-9.998 & 27.7489 & 910.898 & 0.031 \\
\hline-9.998 & 27.7510 & 910.898 & 0.031 \\
\hline-9.998 & 27.7492 & 910.898 & 0.031 \\
\hline-9.998 & 27.7478 & 910.897 & 0.031 \\
\hline-10.000 & 23.7707 & 908.713 & 0.030 \\
\hline-9.997 & 23.7733 & 908.713 & 0.030 \\
\hline-9.999 & 23.7708 & 908.712 & 0.030 \\
\hline-9.999 & 23.7732 & 908.714 & 0.030 \\
\hline-9.997 & 23.7739 & 908.713 & 0.030 \\
\hline-9.999 & 18.0750 & 905.499 & 0.029 \\
\hline-9.998 & 18.0765 & 905.499 & 0.029 \\
\hline-9.997 & 18.0780 & 905.499 & 0.029 \\
\hline-9.998 & 18.0770 & 905.499 & 0.029 \\
\hline-9.999 & 18.0772 & 905.499 & 0.029 \\
\hline-9.998 & 12.3044 & 902.132 & 0.028 \\
\hline-9.999 & 12.3005 & 902.131 & 0.028 \\
\hline-9.998 & 12.2999 & 902.130 & 0.028 \\
\hline-9.998 & 12.2995 & 902.130 & 0.028 \\
\hline-9.998 & 12.2991 & 902.130 & 0.028 \\
\hline - 9.999 & 6.2478 & 898.473 & 0.027 \\
\hline-9.999 & 6.2477 & 898.472 & 0.027 \\
\hline-9.998 & 6.2502 & 898.474 & 0.027 \\
\hline-9.998 & 6.2509 & 898.473 & 0.027 \\
\hline-9.999 & 6.2483 & 898.472 & 0.027 \\
\hline 0.012 & 18.7097 & 897.243 & 0.029 \\
\hline 0.012 & 18.7117 & 897.245 & 0.029 \\
\hline 0.013 & 18.7119 & 897.243 & 0.029 \\
\hline 0.012 & 18.7105 & 897.243 & 0.029 \\
\hline 0.012 & 18.7106 & 897.244 & 0.029 \\
\hline 10.000 & 30.8637 & 896.062 & 0.032 \\
\hline 10.002 & 30.8639 & 896.060 & 0.032 \\
\hline 10.002 & 30.8625 & 896.060 & 0.032 \\
\hline 10.002 & 30.8636 & 896.061 & 0.032 \\
\hline
\end{tabular}


Volume 113, Number 1, January-February 2008

Journal of Research of the National Institute of Standards and Technology

Table A1 (continued)

Table A1 (continued)

\begin{tabular}{|c|c|c|c|}
\hline 10.002 & 28.1806 & 894.476 & 0.032 \\
\hline 10.003 & 28.1828 & 894.476 & 0.032 \\
\hline 10.003 & 28.1815 & 894.474 & 0.032 \\
\hline 10.002 & 28.1810 & 894.475 & 0.032 \\
\hline 10.003 & 28.1819 & 894.475 & 0.032 \\
\hline 10.002 & 25.8708 & 893.090 & 0.031 \\
\hline 10.003 & 25.8709 & 893.090 & 0.031 \\
\hline 10.003 & 25.8691 & 893.088 & 0.031 \\
\hline 10.002 & 25.8695 & 893.089 & 0.031 \\
\hline 10.002 & 25.8705 & 893.090 & 0.031 \\
\hline 10.002 & 23.8631 & 891.870 & 0.030 \\
\hline 10.002 & 23.8594 & 891.869 & 0.030 \\
\hline 10.002 & 23.8583 & 891.869 & 0.030 \\
\hline 10.003 & 23.8609 & 891.869 & 0.030 \\
\hline 10.002 & 23.8598 & 891.869 & 0.030 \\
\hline 10.001 & 21.0399 & 890.130 & 0.030 \\
\hline 10.001 & 21.0401 & 890.130 & 0.030 \\
\hline 10.002 & 21.0411 & 890.131 & 0.030 \\
\hline 10.002 & 21.0419 & 890.131 & 0.030 \\
\hline 10.002 & 21.0417 & 890.129 & 0.030 \\
\hline 10.001 & 17.9894 & 888.213 & 0.029 \\
\hline 10.002 & 17.9863 & 888.210 & 0.029 \\
\hline 10.001 & 17.9866 & 888.212 & 0.029 \\
\hline 10.002 & 17.9878 & 888.212 & 0.029 \\
\hline 10.003 & 17.9908 & 888.213 & 0.029 \\
\hline 10.002 & 15.9128 & 886.886 & 0.029 \\
\hline 10.003 & 15.9118 & 886.885 & 0.029 \\
\hline 10.003 & 15.9159 & 886.886 & 0.029 \\
\hline 10.002 & 15.9183 & 886.889 & 0.029 \\
\hline 10.003 & 15.9191 & 886.889 & 0.029 \\
\hline 10.002 & 12.4496 & 884.632 & 0.028 \\
\hline 10.002 & 12.4507 & 884.632 & 0.028 \\
\hline 10.002 & 12.4512 & 884.632 & 0.028 \\
\hline 10.003 & 12.4535 & 884.633 & 0.028 \\
\hline 10.003 & 12.4526 & 884.633 & 0.028 \\
\hline 10.002 & 9.9215 & 882.952 & 0.028 \\
\hline 10.003 & 9.9227 & 882.952 & 0.028 \\
\hline 10.003 & 9.9226 & 882.952 & 0.028 \\
\hline 10.003 & 9.9227 & 882.953 & 0.028 \\
\hline 10.003 & 9.9228 & 882.953 & 0.028 \\
\hline 10.001 & 8.0081 & 881.661 & 0.028 \\
\hline 10.002 & 8.0097 & 881.661 & 0.028 \\
\hline 10.003 & 8.0096 & 881.661 & 0.028 \\
\hline 10.003 & 8.0111 & 881.662 & 0.028 \\
\hline 10.002 & 8.0108 & 881.662 & 0.028 \\
\hline 10.002 & 5.0658 & 879.638 & 0.027 \\
\hline 10.003 & 5.0663 & 879.638 & 0.027 \\
\hline 10.003 & 5.0670 & 879.638 & 0.027 \\
\hline 10.002 & 5.0640 & 879.637 & 0.027 \\
\hline 10.002 & 5.0615 & 879.636 & 0.027 \\
\hline 10.002 & 3.0677 & 878.240 & 0.027 \\
\hline 10.003 & 3.0716 & 878.242 & 0.027 \\
\hline 10.002 & 3.0696 & 878.241 & 0.027 \\
\hline 10.002 & 3.0697 & 878.241 & 0.027 \\
\hline 10.003 & 3.0720 & 878.242 & 0.027 \\
\hline 10.002 & 0.5198 & 876.425 & 0.027 \\
\hline 10.003 & 0.5205 & 876.425 & 0.027 \\
\hline 10.002 & 0.5194 & 876.425 & 0.027 \\
\hline 10.002 & 0.5201 & 876.425 & 0.027 \\
\hline 10.003 & 0.5194 & 876.424 & 0.027 \\
\hline
\end{tabular}

\begin{tabular}{lrrl}
20.002 & 11.5906 & 875.254 & 0.029 \\
20.002 & 11.5908 & 875.254 & 0.029 \\
20.002 & 11.5921 & 875.255 & 0.029 \\
20.001 & 11.5908 & 875.254 & 0.029 \\
20.002 & 11.5922 & 875.254 & 0.029 \\
& & & \\
30.001 & 22.4315 & 874.124 & 0.032 \\
30.002 & 22.4302 & 874.122 & 0.032 \\
30.002 & 22.4314 & 874.122 & 0.032 \\
30.001 & 22.4291 & 874.122 & 0.032 \\
30.001 & 22.4286 & 874.121 & 0.032 \\
40.001 & 33.0667 & 873.039 & 0.035 \\
40.001 & 33.0669 & 873.039 & 0.035 \\
40.001 & 33.0680 & 873.039 & 0.035 \\
40.001 & 33.0661 & 873.039 & 0.035 \\
40.001 & 33.0639 & 873.037 & 0.035 \\
40.002 & 29.2719 & 870.486 & 0.034 \\
40.001 & 29.2706 & 870.486 & 0.034 \\
40.002 & 29.2715 & 870.485 & 0.034 \\
40.002 & 29.2721 & 870.485 & 0.034 \\
40.002 & 29.2728 & 870.486 & 0.034 \\
40.002 & 27.0272 & 868.945 & 0.034 \\
40.002 & 27.0282 & 868.944 & 0.034 \\
40.001 & 27.0277 & 868.944 & 0.034 \\
40.003 & 27.0292 & 868.945 & 0.034 \\
40.003 & 27.0287 & 868.945 & 0.034 \\
40.001 & 23.9812 & 866.813 & 0.033 \\
40.002 & 23.9828 & 866.813 & 0.033 \\
40.003 & 23.9830 & 866.812 & 0.033 \\
40.002 & 23.9813 & 866.812 & 0.033 \\
40.001 & 23.9818 & 866.812 & 0.033 \\
40.001 & 21.1388 & 864.779 & 0.032 \\
40.000 & 21.1380 & 864.780 & 0.032 \\
40.000 & 21.1378 & 864.779 & 0.032 \\
40.002 & 21.1394 & 864.779 & 0.032 \\
40.000 & 21.1376 & 864.779 & 0.032 \\
40.001 & 18.0243 & 862.499 & 0.032 \\
40.001 & 18.0243 & 862.500 & 0.032 \\
40.002 & 18.0239 & 862.499 & 0.032 \\
40.002 & 18.0247 & 862.499 & 0.032 \\
40.001 & 18.0243 & 862.498 & 0.032 \\
40.001 & 15.0817 & 860.294 & 0.031 \\
40.001 & 15.0818 & 860.294 & 0.031 \\
40.001 & 15.0829 & 860.295 & 0.031 \\
40.002 & 15.0837 & 860.296 & 0.031 \\
40.001 & 15.0827 & 860.295 & 0.031 \\
40.002 & 12.0138 & 857.938 & 0.031 \\
40.001 & 12.0134 & 857.938 & 0.031 \\
40.001 & 12.0125 & 857.936 & 0.031 \\
40.002 & 12.0133 & 857.935 & 0.031 \\
40.002 & 12.0127 & 857.936 & 0.031 \\
40.001 & 9.0991 & 855.639 & 0.030 \\
40.000 & 9.0980 & 855.639 & 0.030 \\
40.001 & 6.03973 & 855.639 & 0.030 \\
& & 855.637 & 0.030 \\
40.0939 & 853.163 & 0.030 \\
40.163 & 0.030 \\
\hline
\end{tabular}


Volume 113, Number 1, January-February 2008

Journal of Research of the National Institute of Standards and Technology

Table A1 (continued)

Table A1 (continued)

\begin{tabular}{|c|c|c|c|c|c|c|c|}
\hline 40.002 & 6.0397 & 853.162 & 0.030 & 80.004 & 14.0743 & 824.356 & 0.036 \\
\hline 40.002 & 6.0396 & 853.162 & 0.030 & 80.004 & 10.0714 & 820.434 & 0.035 \\
\hline 40.001 & 6.0388 & 853.161 & 0.030 & 80.003 & 10.0715 & 820.434 & 0.035 \\
\hline 40.000 & 2.9800 & 850.616 & 0.030 & 80.004 & 10.0723 & 820.434 & 0.035 \\
\hline 40.001 & 2.9801 & 850.615 & 0.030 & 80.004 & 10.0729 & 820.435 & 0.035 \\
\hline 40.002 & 2.9809 & 850.615 & 0.030 & 80.003 & 10.0723 & 820.435 & 0.035 \\
\hline 40.002 & 2.9812 & 850.616 & 0.030 & 80.003 & 5.0880 & 815.286 & 0.035 \\
\hline 40.001 & 2.9801 & 850.616 & 0.030 & 80.003 & 5.0890 & 815.287 & 0.035 \\
\hline 40.001 & 0.6598 & 848.634 & 0.030 & 80.004 & 5.0891 & 815.285 & 0.035 \\
\hline 40.001 & 0.6592 & 848.634 & 0.030 & 80.004 & 5.0881 & 815.285 & 0.035 \\
\hline 40.002 & 0.6596 & 848.633 & 0.030 & 80.003 & 5.0885 & 815.285 & 0.035 \\
\hline 40.001 & 0.6598 & 848.634 & 0.030 & 80.003 & 0.5582 & 810.313 & 0.035 \\
\hline \multirow[t]{2}{*}{40.000} & 0.6615 & 848.635 & 0.030 & 80.004 & 0.5582 & 810.312 & 0.035 \\
\hline & & & & 80.004 & 0.5583 & 810.310 & 0.035 \\
\hline 49.998 & 10.1894 & 847.590 & 0.032 & 80.003 & 0.5576 & 810.311 & 0.035 \\
\hline 50.001 & 10.1912 & 847.589 & 0.032 & 80.003 & 0.5567 & 810.311 & 0.035 \\
\hline 50.001 & 10.1922 & 847.589 & 0.032 & & & & \\
\hline 50.001 & 10.1922 & 847.588 & 0.032 & 90.002 & 8.3064 & 809.389 & 0.037 \\
\hline \multirow[t]{2}{*}{50.001} & 10.1925 & 847.590 & 0.032 & 90.003 & 8.3062 & 809.387 & 0.037 \\
\hline & & & & 90.003 & 8.3063 & 809.387 & 0.037 \\
\hline 60.001 & 19.5563 & 846.580 & 0.034 & 90.004 & 8.3080 & 809.388 & 0.037 \\
\hline 60.001 & 19.5563 & 846.579 & 0.034 & 90.005 & 8.3073 & 809.387 & 0.037 \\
\hline 60.002 & 19.5572 & 846.579 & 0.034 & & & & \\
\hline 60.002 & 19.5568 & 846.579 & 0.034 & 100.003 & 15.9451 & 808.490 & 0.039 \\
\hline 60.001 & 19.5572 & 846.579 & 0.034 & 100.005 & 15.9460 & 808.491 & 0.039 \\
\hline 60.001 & 15.2272 & 842.992 & 0.034 & 100.006 & 15.9464 & 808.491 & 0.039 \\
\hline 60.002 & 15.2319 & 842.993 & 0.034 & 100.005 & 15.9461 & 808.491 & 0.039 \\
\hline 60.002 & 15.2319 & 842.994 & 0.034 & 100.004 & 15.9455 & 808.491 & 0.039 \\
\hline 60.002 & 15.2320 & 842.994 & 0.034 & 100.005 & 12.1105 & 804.352 & 0.038 \\
\hline 60.003 & 15.2330 & 842.994 & 0.034 & 100.004 & 12.1095 & 804.351 & 0.038 \\
\hline 60.002 & 10.0412 & 838.495 & 0.033 & 100.005 & 12.1099 & 804.351 & 0.038 \\
\hline 60.002 & 10.0410 & 838.495 & 0.033 & 100.006 & 12.1113 & 804.352 & 0.038 \\
\hline 60.002 & 10.0411 & 838.494 & 0.033 & 100.005 & 12.1119 & 804.353 & 0.038 \\
\hline 60.003 & 10.0424 & 838.496 & 0.033 & 100.005 & 8.2213 & 799.937 & 0.038 \\
\hline 60.003 & 10.0418 & 838.495 & 0.033 & 100.005 & 8.2214 & 799.937 & 0.038 \\
\hline 60.002 & 5.1271 & 834.013 & 0.032 & 100.006 & 8.2218 & 799.935 & 0.038 \\
\hline 60.002 & 5.1264 & 834.011 & 0.032 & 100.005 & 8.2212 & 799.937 & 0.038 \\
\hline 60.003 & 5.1284 & 834.013 & 0.032 & 100.005 & 8.2207 & 799.937 & 0.038 \\
\hline 60.003 & 5.1289 & 834.015 & 0.032 & 100.005 & 4.1477 & 795.045 & 0.037 \\
\hline 60.003 & 5.1282 & 834.013 & 0.032 & 100.005 & 4.1469 & 795.046 & 0.037 \\
\hline 60.002 & 0.6483 & 829.712 & 0.032 & 100.004 & 4.1463 & 795.044 & 0.037 \\
\hline 60.001 & 0.6480 & 829.714 & 0.032 & 100.005 & 4.1467 & 795.044 & 0.037 \\
\hline 60.002 & 0.6480 & 829.713 & 0.032 & 100.006 & 4.1470 & 795.044 & 0.037 \\
\hline 60.003 & 0.6491 & 829.713 & 0.032 & 100.004 & 0.5183 & 790.422 & 0.037 \\
\hline \multirow[t]{2}{*}{60.002} & 0.6481 & 829.714 & 0.032 & 100.004 & 0.5173 & 790.421 & 0.037 \\
\hline & & & & 100.005 & 0.5180 & 790.422 & 0.037 \\
\hline 70.002 & 9.2470 & 828.727 & 0.034 & 100.006 & 0.5180 & 790.421 & 0.037 \\
\hline 70.001 & 9.2479 & 828.728 & 0.034 & 100.004 & 0.5171 & 790.419 & 0.037 \\
\hline 70.003 & 9.2488 & 828.728 & 0.034 & & & & \\
\hline 70.003 & 9.2480 & 828.727 & 0.034 & 110.005 & 7.4964 & 789.570 & 0.039 \\
\hline \multirow[t]{2}{*}{70.002} & 9.2477 & 828.727 & 0.034 & 110.005 & 7.4973 & 789.569 & 0.039 \\
\hline & & & & 110.007 & 7.4982 & 789.571 & 0.039 \\
\hline 80.002 & 17.7099 & 827.773 & 0.036 & 110.006 & 7.4977 & 789.569 & 0.039 \\
\hline 80.003 & 17.7103 & 827.773 & 0.036 & 110.005 & 7.4977 & 789.570 & 0.039 \\
\hline 80.004 & 17.7111 & 827.773 & 0.036 & & & & \\
\hline 80.004 & 17.7110 & 827.773 & 0.036 & 115.006 & 10.9518 & 789.150 & 0.040 \\
\hline 80.003 & 17.7098 & 827.773 & 0.036 & 115.007 & 10.9532 & 789.151 & 0.040 \\
\hline 80.002 & 14.0712 & 824.354 & 0.036 & 115.007 & 10.9528 & 789.150 & 0.040 \\
\hline 80.004 & 14.0738 & 824.356 & 0.036 & 115.007 & 10.9529 & 789.151 & 0.040 \\
\hline 80.003 & 14.0734 & 824.355 & 0.036 & 115.007 & 10.9529 & 789.150 & 0.040 \\
\hline 80.003 & 14.0736 & 824.356 & 0.036 & & & & \\
\hline
\end{tabular}


Volume 113, Number 1, January-February 2008

Journal of Research of the National Institute of Standards and Technology

Table A1 (continued)

Table A1 (continued)

\begin{tabular}{|c|c|c|c|c|c|c|c|c|}
\hline 120.006 & 14.3813 & 788.734 & 0.041 & & 150.009 & 20.9252 & 770.031 & 0.045 \\
\hline 120.007 & 14.3829 & 788.733 & 0.041 & & 150.009 & 20.9242 & 770.029 & 0.045 \\
\hline 120.004 & 14.3791 & 788.733 & 0.041 & & 150.008 & 18.0045 & 766.091 & 0.044 \\
\hline 120.003 & 14.3780 & 788.732 & 0.041 & & 150.008 & 18.0022 & 766.086 & 0.044 \\
\hline 120.003 & 14.3788 & 788.731 & 0.041 & & 150.008 & 18.0014 & 766.086 & 0.044 \\
\hline 120.004 & 14.3805 & 788.733 & 0.041 & & 150.009 & 18.0015 & 766.085 & 0.044 \\
\hline \multirow[t]{2}{*}{120.004} & 14.3842 & 788.739 & 0.041 & & 150.010 & 18.0011 & 766.084 & 0.044 \\
\hline & & & & & 150.009 & 14.9905 & 761.818 & 0.044 \\
\hline 125.003 & 17.7973 & 788.335 & 0.042 & & 150.008 & 14.9888 & 761.817 & 0.044 \\
\hline 125.005 & 17.7999 & 788.335 & 0.042 & & 150.009 & 14.9884 & 761.815 & 0.044 \\
\hline 125.006 & 17.8008 & 788.335 & 0.042 & & 150.009 & 14.9884 & 761.813 & 0.044 \\
\hline 125.005 & 17.8007 & 788.336 & 0.042 & & 150.009 & 14.9880 & 761.814 & 0.044 \\
\hline \multirow[t]{2}{*}{125.004} & 17.7998 & 788.334 & 0.042 & & 150.008 & 12.0432 & 757.415 & 0.043 \\
\hline & & & & & 150.008 & 12.0430 & 757.414 & 0.043 \\
\hline 130.004 & 21.1756 & 787.916 & 0.043 & & 150.008 & 12.0433 & 757.413 & 0.043 \\
\hline 130.004 & 21.1749 & 787.916 & 0.043 & & 150.008 & 12.0423 & 757.412 & 0.043 \\
\hline 130.005 & 21.1758 & 787.916 & 0.043 & & 150.008 & 12.0423 & 757.413 & 0.043 \\
\hline 130.005 & 21.1754 & 787.916 & 0.043 & & 150.008 & 8.9974 & 752.595 & 0.043 \\
\hline \multirow[t]{2}{*}{130.004} & 21.1741 & 787.914 & 0.043 & & 150.008 & 8.9974 & 752.595 & 0.043 \\
\hline & & & & & 150.009 & 8.9971 & 752.594 & 0.043 \\
\hline 135.005 & 24.5319 & 787.505 & 0.044 & & 150.009 & 8.9969 & 752.593 & 0.043 \\
\hline 135.005 & 24.5318 & 787.506 & 0.044 & & 150.008 & 8.9957 & 752.593 & 0.043 \\
\hline 135.006 & 24.5321 & 787.504 & 0.044 & & 150.007 & 6.0425 & 747.616 & 0.042 \\
\hline 135.005 & 24.5320 & 787.505 & 0.044 & & 150.008 & 6.0433 & 747.618 & 0.042 \\
\hline \multirow[t]{2}{*}{135.005} & 24.5318 & 787.504 & 0.044 & & 150.009 & 6.0438 & 747.618 & 0.042 \\
\hline & & & & & 150.008 & 6.0429 & 747.616 & 0.042 \\
\hline 140.005 & 27.8683 & 787.101 & 0.045 & & 150.008 & 6.0427 & 747.617 & 0.042 \\
\hline 140.007 & 27.8689 & 787.099 & 0.045 & & 150.007 & 3.0537 & 742.226 & 0.042 \\
\hline 140.006 & 27.8690 & 787.100 & 0.045 & & 150.007 & 3.0535 & 742.226 & 0.042 \\
\hline 140.005 & 27.8697 & 787.103 & 0.045 & & 150.008 & 3.0542 & 742.225 & 0.042 \\
\hline \multirow[t]{2}{*}{140.006} & 27.8704 & 787.102 & 0.045 & & 150.008 & 3.0538 & 742.225 & 0.042 \\
\hline & & & & & 150.007 & 3.0540 & 742.225 & 0.042 \\
\hline 145.005 & 31.1942 & 786.714 & 0.046 & & 150.009 & 0.5414 & 737.362 & 0.042 \\
\hline 145.006 & 31.1930 & 786.712 & 0.046 & & 150.008 & 0.5407 & 737.362 & 0.042 \\
\hline 145.007 & 31.1935 & 786.711 & 0.046 & & 150.008 & 0.5411 & 737.362 & 0.042 \\
\hline 145.008 & 31.1929 & 786.709 & 0.046 & & 150.009 & 0.5413 & 737.362 & 0.042 \\
\hline \multirow[t]{2}{*}{145.007} & 31.1918 & 786.709 & 0.046 & & 150.008 & 0.5406 & 737.362 & 0.042 \\
\hline & & & & Filling 2a & & & & \\
\hline 150.007 & 34.3186 & 786.130 & 0.047 & & 40.000 & 7.7237 & 854.535 & 0.030 \\
\hline 150.008 & 34.2917 & 786.100 & 0.047 & & 40.002 & 7.7249 & 854.535 & 0.030 \\
\hline 150.007 & 34.2797 & 786.087 & 0.047 & & 40.001 & 7.7245 & 854.535 & 0.030 \\
\hline 150.007 & 34.2691 & 786.075 & 0.047 & & 40.001 & 7.7242 & 854.535 & 0.030 \\
\hline 150.008 & 34.2584 & 786.061 & 0.047 & & 40.002 & 7.7251 & 854.535 & 0.030 \\
\hline 150.008 & 29.9475 & 781.187 & 0.046 & Filling 3 & & & & \\
\hline 150.007 & 29.9386 & 781.178 & 0.046 & & 29.997 & 29.9617 & 879.126 & 0.033 \\
\hline 150.006 & 29.9322 & 781.171 & 0.046 & & 29.999 & 29.9633 & 879.125 & 0.033 \\
\hline 150.008 & 29.9264 & 781.162 & 0.046 & & 29.999 & 29.9607 & 879.125 & 0.033 \\
\hline 150.008 & 29.9205 & 781.156 & 0.046 & & 30.000 & 29.9601 & 879.123 & 0.033 \\
\hline 150.009 & 26.9681 & 777.657 & 0.046 & & 30.001 & 29.9588 & 879.122 & 0.033 \\
\hline 150.008 & 26.9621 & 777.650 & 0.046 & & 29.999 & 25.0914 & 875.922 & 0.032 \\
\hline 150.007 & 26.9584 & 777.646 & 0.046 & & 30.000 & 25.0912 & 875.921 & 0.032 \\
\hline 150.008 & 26.9558 & 777.642 & 0.046 & & 30.001 & 25.0919 & 875.921 & 0.032 \\
\hline 150.009 & 26.9529 & 777.639 & 0.046 & & 30.000 & 25.0903 & 875.920 & 0.032 \\
\hline 150.008 & 24.0254 & 774.027 & 0.045 & & 30.000 & 25.0906 & 875.919 & 0.032 \\
\hline 150.008 & 24.0142 & 774.012 & 0.045 & & 30.000 & 20.1581 & 872.566 & 0.031 \\
\hline 150.008 & 24.0127 & 774.010 & 0.045 & & 30.001 & 20.1592 & 872.565 & 0.031 \\
\hline 150.009 & 24.0108 & 774.008 & 0.045 & & 30.001 & 20.1595 & 872.566 & 0.031 \\
\hline 150.009 & 24.0078 & 774.004 & 0.045 & & 30.001 & 20.1591 & 872.565 & 0.031 \\
\hline 150.009 & 20.9296 & 770.037 & 0.045 & & 30.001 & 20.1574 & 872.565 & 0.031 \\
\hline 150.008 & 20.9281 & 770.035 & 0.045 & & 30.000 & 15.2638 & 869.116 & 0.030 \\
\hline 150.008 & 20.9264 & 770.034 & 0.045 & & 30.001 & 15.2657 & 869.117 & 0.030 \\
\hline
\end{tabular}


Volume 113, Number 1, January-February 2008

Journal of Research of the National Institute of Standards and Technology

Table A1 (continued)

Table A1 (continued)

\begin{tabular}{|c|c|c|c|c|c|c|c|}
\hline 30.002 & 15.2650 & 869.116 & 0.030 & 80.001 & 33.0852 & 840.951 & 0.040 \\
\hline 30.002 & 15.2648 & 869.116 & 0.030 & 80.001 & 33.0854 & 840.951 & 0.040 \\
\hline 30.001 & 15.2643 & 869.115 & 0.030 & 80.003 & 33.0863 & 840.951 & 0.040 \\
\hline 30.000 & 10.1390 & 865.363 & 0.029 & 80.003 & 33.0852 & 840.949 & 0.040 \\
\hline 30.000 & 10.1390 & 865.363 & 0.029 & 80.002 & 33.0840 & 840.948 & 0.040 \\
\hline 30.001 & 10.1406 & 865.364 & 0.029 & 80.002 & 29.8274 & 838.309 & 0.039 \\
\hline 30.001 & 10.1399 & 865.363 & 0.029 & 80.003 & 29.8279 & 838.309 & 0.039 \\
\hline 30.001 & 10.1394 & 865.361 & 0.029 & 80.004 & 29.8292 & 838.310 & 0.039 \\
\hline 30.000 & 5.0194 & 861.451 & 0.029 & 80.003 & 29.8288 & 838.310 & 0.039 \\
\hline 30.000 & 5.0200 & 861.451 & 0.029 & 80.003 & 29.8294 & 838.310 & 0.039 \\
\hline 30.001 & 5.0214 & 861.452 & 0.029 & 80.003 & 25.1394 & 834.373 & 0.038 \\
\hline 30.001 & 5.0218 & 861.452 & 0.029 & 80.003 & 25.1364 & 834.371 & 0.038 \\
\hline 30.001 & 5.0209 & 861.452 & 0.029 & 80.004 & 25.1369 & 834.371 & 0.038 \\
\hline 30.001 & 0.7644 & 858.066 & 0.029 & 80.004 & 25.1369 & 834.372 & 0.038 \\
\hline 30.001 & 0.7648 & 858.066 & 0.029 & 80.004 & 25.1368 & 834.371 & 0.038 \\
\hline 30.000 & 0.7635 & 858.066 & 0.029 & 80.004 & 19.9546 & 829.818 & 0.037 \\
\hline 30.001 & 0.7644 & 858.066 & 0.029 & 80.004 & 19.9530 & 829.816 & 0.037 \\
\hline \multirow[t]{2}{*}{30.002} & 0.7643 & 858.066 & 0.029 & 80.005 & 19.9495 & 829.812 & 0.037 \\
\hline & & & & 80.004 & 19.9472 & 829.810 & 0.037 \\
\hline 40.000 & 10.7884 & 856.979 & 0.031 & 80.004 & 19.9452 & 829.809 & 0.037 \\
\hline 40.000 & 10.7922 & 856.983 & 0.031 & 80.003 & 15.0964 & 825.330 & 0.036 \\
\hline 40.000 & 10.7919 & 856.982 & 0.031 & 80.002 & 15.0934 & 825.327 & 0.036 \\
\hline 40.000 & 10.7946 & 856.985 & 0.031 & 80.003 & 15.0935 & 825.327 & 0.036 \\
\hline \multirow[t]{2}{*}{40.000} & 10.7974 & 856.985 & 0.031 & 80.004 & 15.0938 & 825.326 & 0.036 \\
\hline & & & & 80.003 & 15.0918 & 825.326 & 0.036 \\
\hline 50.000 & 20.6246 & 855.930 & 0.033 & & & & \\
\hline 50.000 & 20.6247 & 855.930 & 0.033 & 90.002 & 23.3250 & 824.387 & 0.039 \\
\hline 50.000 & 20.6227 & 855.928 & 0.033 & 90.002 & 23.3252 & 824.388 & 0.039 \\
\hline 50.001 & 20.6240 & 855.929 & 0.033 & 90.004 & 23.3257 & 824.387 & 0.039 \\
\hline \multirow[t]{2}{*}{50.001} & 20.6227 & 855.927 & 0.033 & 90.004 & 23.3237 & 824.385 & 0.039 \\
\hline & & & & 90.003 & 23.3223 & 824.384 & 0.039 \\
\hline 59.999 & 30.2738 & 854.908 & 0.037 & & & & \\
\hline 59.999 & 30.2788 & 854.912 & 0.037 & 100.003 & 31.4102 & 823.456 & 0.042 \\
\hline 60.000 & 30.2822 & 854.913 & 0.037 & 100.003 & 31.4092 & 823.454 & 0.042 \\
\hline 60.001 & 30.2817 & 854.913 & 0.037 & 100.004 & 31.4095 & 823.454 & 0.042 \\
\hline 60.000 & 30.2843 & 854.915 & 0.037 & 100.005 & 31.4079 & 823.453 & 0.042 \\
\hline 59.999 & 27.0542 & 852.483 & 0.036 & 100.004 & 31.4066 & 823.453 & 0.042 \\
\hline 60.000 & 27.0563 & 852.483 & 0.036 & 100.004 & 28.3371 & 820.671 & 0.041 \\
\hline 60.001 & 27.0538 & 852.481 & 0.036 & 100.003 & 28.3347 & 820.670 & 0.041 \\
\hline 59.999 & 27.0523 & 852.481 & 0.036 & 100.004 & 28.3351 & 820.669 & 0.041 \\
\hline 60.001 & 27.0550 & 852.482 & 0.036 & 100.005 & 28.3342 & 820.669 & 0.041 \\
\hline 59.999 & 23.7636 & 849.938 & 0.035 & 100.003 & 28.3321 & 820.667 & 0.041 \\
\hline 60.001 & 23.7635 & 849.936 & 0.035 & 100.003 & 24.1976 & 816.784 & 0.040 \\
\hline 60.002 & 23.7573 & 849.931 & 0.035 & 100.003 & 24.1969 & 816.783 & 0.040 \\
\hline 60.001 & 23.7550 & 849.929 & 0.035 & 100.004 & 24.1981 & 816.784 & 0.040 \\
\hline 60.001 & 23.7544 & 849.929 & 0.035 & 100.004 & 24.1977 & 816.784 & 0.040 \\
\hline 60.000 & 19.7665 & 846.751 & 0.034 & 100.003 & 24.1966 & 816.783 & 0.040 \\
\hline 60.000 & 19.7624 & 846.746 & 0.034 & 100.003 & 20.5655 & 813.229 & 0.040 \\
\hline 60.000 & 19.7619 & 846.745 & 0.034 & 100.003 & 20.5650 & 813.229 & 0.040 \\
\hline 60.001 & 19.7620 & 846.745 & 0.034 & 100.004 & 20.5655 & 813.228 & 0.040 \\
\hline 60.002 & 19.7623 & 846.745 & 0.034 & 100.004 & 20.5659 & 813.230 & 0.040 \\
\hline 60.001 & 15.1296 & 842.908 & 0.033 & 100.003 & 20.5639 & 813.228 & 0.040 \\
\hline 60.001 & 15.1271 & 842.907 & 0.033 & 100.003 & 15.1512 & 807.651 & 0.039 \\
\hline 60.001 & 15.1268 & 842.905 & 0.033 & 100.003 & 15.1515 & 807.651 & 0.039 \\
\hline 60.001 & 15.1268 & 842.906 & 0.033 & 100.004 & 15.1532 & 807.653 & 0.039 \\
\hline \multirow[t]{2}{*}{60.001} & 15.1272 & 842.906 & 0.033 & 100.003 & 15.1536 & 807.652 & 0.039 \\
\hline & & & & 100.003 & 15.1533 & 807.654 & 0.039 \\
\hline 69.999 & 24.1977 & 841.929 & 0.036 & & & & \\
\hline 70.001 & 24.1982 & 841.927 & 0.036 & 110.000 & 22.6514 & 806.778 & 0.041 \\
\hline 70.001 & 24.1988 & 841.927 & 0.036 & 110.001 & 22.6517 & 806.779 & 0.041 \\
\hline 70.002 & 24.1988 & 841.925 & 0.036 & 110.002 & 22.6521 & 806.779 & 0.041 \\
\hline 70.002 & 24.2000 & 841.928 & 0.036 & & & & \\
\hline
\end{tabular}


Volume 113, Number 1, January-February 2008

Journal of Research of the National Institute of Standards and Technology

Table A1 (continued)

\begin{tabular}{|c|c|c|c|c|}
\hline & 110.001 & 22.6514 & 806.779 & 0.041 \\
\hline & 110.001 & 22.6502 & 806.777 & 0.041 \\
\hline & 120.000 & 30.0265 & 805.908 & 0.044 \\
\hline & 120.001 & 30.0241 & 805.905 & 0.044 \\
\hline & 120.002 & 30.0239 & 805.903 & 0.044 \\
\hline & 120.003 & 30.0227 & 805.901 & 0.044 \\
\hline & 120.003 & 30.0218 & 805.900 & 0.044 \\
\hline & 120.002 & 25.0898 & 800.840 & 0.043 \\
\hline & 120.002 & 25.0879 & 800.837 & 0.043 \\
\hline & 120.002 & 25.0870 & 800.836 & 0.043 \\
\hline & 120.003 & 25.0880 & 800.837 & 0.043 \\
\hline & 120.003 & 25.0868 & 800.836 & 0.043 \\
\hline & 120.001 & 20.2062 & 795.528 & 0.042 \\
\hline & 120.003 & 20.2079 & 795.528 & 0.042 \\
\hline & 120.002 & 20.2052 & 795.527 & 0.042 \\
\hline & 120.001 & 20.2028 & 795.525 & 0.042 \\
\hline & 120.001 & 20.2025 & 795.525 & 0.042 \\
\hline & 120.002 & 14.9413 & 789.414 & 0.041 \\
\hline & 120.001 & 14.9389 & 789.413 & 0.041 \\
\hline & 120.002 & 14.9386 & 789.411 & 0.041 \\
\hline & 120.002 & 14.9397 & 789.413 & 0.041 \\
\hline & 120.002 & 14.9377 & 789.411 & 0.041 \\
\hline & 120.001 & 2.5228 & 772.912 & 0.040 \\
\hline & 120.001 & 2.5230 & 772.914 & 0.040 \\
\hline & 120.002 & 2.5244 & 772.914 & 0.040 \\
\hline & 120.003 & 2.5243 & 772.913 & 0.040 \\
\hline & 120.002 & 2.5246 & 772.911 & 0.040 \\
\hline \multicolumn{5}{|l|}{ Filling 3a } \\
\hline & 39.999 & 6.8149 & 853.798 & 0.030 \\
\hline & 39.999 & 6.8149 & 853.798 & 0.030 \\
\hline & 39.999 & 6.8134 & 853.796 & 0.030 \\
\hline & 40.000 & 6.8154 & 853.797 & 0.030 \\
\hline & 40.000 & 6.8135 & 853.795 & 0.030 \\
\hline & 79.999 & 30.0548 & 838.496 & 0.039 \\
\hline & 80.000 & 30.0556 & 838.496 & 0.039 \\
\hline & 80.000 & 30.0545 & 838.495 & 0.039 \\
\hline & 80.001 & 30.0545 & 838.495 & 0.039 \\
\hline & 80.001 & 30.0531 & 838.494 & 0.039 \\
\hline & 79.997 & 0.8710 & 810.672 & 0.035 \\
\hline & 80.001 & 0.8754 & 810.673 & 0.035 \\
\hline & 80.002 & 0.8770 & 810.673 & 0.035 \\
\hline & 80.000 & 0.8760 & 810.673 & 0.035 \\
\hline & 80.000 & 0.8753 & 810.673 & 0.035 \\
\hline & 100.002 & 16.2965 & 808.862 & 0.039 \\
\hline & 100.002 & 16.2960 & 808.861 & 0.039 \\
\hline & 100.003 & 16.2962 & 808.859 & 0.039 \\
\hline & 100.003 & 16.2964 & 808.860 & 0.039 \\
\hline & 100.002 & 16.2962 & 808.860 & 0.039 \\
\hline & 120.002 & 31.2424 & 807.111 & 0.044 \\
\hline & 120.001 & 31.2414 & 807.111 & 0.044 \\
\hline & 120.001 & 31.2406 & 807.110 & 0.044 \\
\hline & 120.002 & 31.2399 & 807.108 & 0.044 \\
\hline & 120.002 & 31.2348 & 807.103 & 0.044 \\
\hline & 120.002 & 10.0450 & 783.303 & 0.040 \\
\hline & 120.002 & 10.0437 & 783.302 & 0.040 \\
\hline & 120.001 & 10.0426 & 783.299 & 0.040 \\
\hline & 120.002 & 10.0437 & 783.300 & 0.040 \\
\hline
\end{tabular}

Table A1 (continued)

\begin{tabular}{|c|c|c|c|}
\hline 120.003 & 10.0443 & 783.300 & 0.040 \\
\hline 120.001 & 5.0864 & 776.608 & 0.040 \\
\hline 120.002 & 5.0858 & 776.607 & 0.040 \\
\hline 120.001 & 5.0851 & 776.608 & 0.040 \\
\hline 120.002 & 5.0858 & 776.605 & 0.040 \\
\hline 120.002 & 5.0858 & 776.606 & 0.040 \\
\hline 119.999 & 0.7068 & 770.181 & 0.039 \\
\hline 120.000 & 0.7057 & 770.179 & 0.039 \\
\hline 120.001 & 0.7057 & 770.177 & 0.039 \\
\hline 120.001 & 0.7051 & 770.178 & 0.039 \\
\hline 120.001 & 0.7053 & 770.177 & 0.039 \\
\hline 125.001 & 3.8524 & 769.788 & 0.040 \\
\hline 125.002 & 3.8547 & 769.791 & 0.040 \\
\hline 125.002 & 3.8559 & 769.792 & 0.040 \\
\hline 125.002 & 3.8564 & 769.794 & 0.040 \\
\hline 125.003 & 3.8550 & 769.790 & 0.040 \\
\hline 130.003 & 6.9721 & 769.386 & 0.041 \\
\hline 130.003 & 6.9721 & 769.387 & 0.041 \\
\hline 130.003 & 6.9722 & 769.385 & 0.041 \\
\hline 130.004 & 6.9726 & 769.387 & 0.041 \\
\hline 130.004 & 6.9720 & 769.385 & 0.041 \\
\hline 135.004 & 10.0740 & 768.990 & 0.042 \\
\hline 135.003 & 10.0734 & 768.990 & 0.042 \\
\hline 135.003 & 10.0739 & 768.990 & 0.042 \\
\hline 135.005 & 10.0745 & 768.990 & 0.042 \\
\hline 135.004 & 10.0739 & 768.989 & 0.042 \\
\hline 140.004 & 13.1552 & 768.594 & 0.043 \\
\hline 140.004 & 13.1554 & 768.595 & 0.043 \\
\hline 140.003 & 13.1535 & 768.593 & 0.043 \\
\hline 140.004 & 13.1543 & 768.592 & 0.043 \\
\hline 140.004 & 13.1537 & 768.591 & 0.043 \\
\hline 140.003 & 13.1538 & 768.593 & 0.043 \\
\hline 145.004 & 16.2160 & 768.199 & 0.043 \\
\hline 145.004 & 16.2146 & 768.197 & 0.043 \\
\hline 145.005 & 16.2145 & 768.197 & 0.043 \\
\hline 145.004 & 16.2137 & 768.196 & 0.043 \\
\hline 145.004 & 16.2138 & 768.197 & 0.043 \\
\hline 150.002 & 19.2622 & 767.814 & 0.044 \\
\hline 150.002 & 19.2637 & 767.816 & 0.044 \\
\hline 150.002 & 19.2650 & 767.818 & 0.044 \\
\hline 150.003 & 19.2653 & 767.817 & 0.044 \\
\hline 150.003 & 19.2638 & 767.815 & 0.044 \\
\hline 160.003 & 25.2903 & 767.037 & 0.046 \\
\hline 160.005 & 25.2901 & 767.036 & 0.046 \\
\hline 160.004 & 25.2890 & 767.034 & 0.046 \\
\hline 160.004 & 25.2877 & 767.033 & 0.046 \\
\hline 160.004 & 25.2872 & 767.031 & 0.046 \\
\hline 165.004 & 28.2650 & 766.638 & 0.047 \\
\hline 165.004 & 28.2652 & 766.638 & 0.047 \\
\hline 165.004 & 28.2622 & 766.634 & 0.047 \\
\hline 165.004 & 28.2620 & 766.634 & 0.047 \\
\hline 165.005 & 28.2622 & 766.634 & 0.047 \\
\hline
\end{tabular}


Volume 113, Number 1, January-February 2008

Journal of Research of the National Institute of Standards and Technology

Table A1 (concluded)

\begin{tabular}{|c|c|c|c|}
\hline 175.007 & 33.9837 & 765.629 & 0.050 \\
\hline 175.007 & 33.9536 & 765.593 & 0.050 \\
\hline 175.008 & 33.9411 & 765.576 & 0.050 \\
\hline 175.009 & 33.9269 & 765.557 & 0.050 \\
\hline 175.008 & 33.9108 & 765.539 & 0.050 \\
\hline 175.006 & 25.9731 & 755.042 & 0.048 \\
\hline 175.007 & 25.9588 & 755.021 & 0.048 \\
\hline 175.006 & 25.9541 & 755.015 & 0.048 \\
\hline 175.007 & 25.9512 & 755.010 & 0.048 \\
\hline 175.008 & 25.9468 & 755.003 & 0.048 \\
\hline 175.006 & 22.1998 & 749.576 & 0.047 \\
\hline 175.006 & 22.1933 & 749.566 & 0.047 \\
\hline 175.006 & 22.1906 & 749.560 & 0.047 \\
\hline 175.007 & 22.1891 & 749.559 & 0.047 \\
\hline 175.008 & 22.1874 & 749.555 & 0.047 \\
\hline 175.007 & 22.1851 & 749.554 & 0.047 \\
\hline 175.006 & 17.9461 & 742.960 & 0.046 \\
\hline 175.007 & 17.9458 & 742.960 & 0.046 \\
\hline 175.006 & 17.9426 & 742.955 & 0.046 \\
\hline 175.007 & 17.9423 & 742.954 & 0.046 \\
\hline 175.007 & 17.9407 & 742.953 & 0.046 \\
\hline 185.006 & 23.2286 & 742.215 & 0.048 \\
\hline 185.007 & 23.2268 & 742.211 & 0.048 \\
\hline 185.008 & 23.2264 & 742.209 & 0.048 \\
\hline 185.007 & 23.2241 & 742.206 & 0.048 \\
\hline 185.007 & 23.2224 & 742.204 & 0.048 \\
\hline 190.009 & 25.8354 & 741.821 & 0.050 \\
\hline 190.008 & 25.8323 & 741.818 & 0.050 \\
\hline 190.009 & 25.8311 & 741.815 & 0.050 \\
\hline 190.009 & 25.8300 & 741.814 & 0.050 \\
\hline 190.009 & 25.8284 & 741.811 & 0.050 \\
\hline 200.010 & 31.0194 & 741.069 & 0.053 \\
\hline 200.010 & 31.0174 & 741.067 & 0.053 \\
\hline 200.011 & 31.0162 & 741.064 & 0.053 \\
\hline 200.012 & 31.0136 & 741.059 & 0.053 \\
\hline 200.010 & 19.7931 & 722.679 & 0.051 \\
\hline 200.013 & 19.7929 & 722.676 & 0.051 \\
\hline 200.012 & 19.7919 & 722.674 & 0.051 \\
\hline 200.011 & 19.7917 & 722.675 & 0.051 \\
\hline 200.013 & 19.7916 & 722.673 & 0.051 \\
\hline 200.011 & 10.0529 & 702.521 & 0.049 \\
\hline 200.012 & 10.0522 & 702.520 & 0.049 \\
\hline 200.011 & 10.0515 & 702.520 & 0.049 \\
\hline 200.012 & 10.0519 & 702.518 & 0.049 \\
\hline 200.012 & 1.2074 & 677.755 & 0.047 \\
\hline 200.012 & 1.2072 & 677.755 & 0.047 \\
\hline 200.012 & 1.2077 & 677.756 & 0.047 \\
\hline 200.013 & 1.2076 & 677.754 & 0.047 \\
\hline 200.013 & 1.2074 & 677.754 & 0.047 \\
\hline 40.000 & 2.1452 & 849.906 & 0.030 \\
\hline 40.000 & 2.1447 & 849.906 & 0.030 \\
\hline 39.999 & 2.1442 & 849.906 & 0.030 \\
\hline 40.000 & 2.1459 & 849.906 & 0.030 \\
\hline 40.000 & 2.1452 & 849.905 & 0.030 \\
\hline
\end{tabular}

Table A2. Experimentally measured temperatures $t$, pressures $p$, and densities $\rho_{\exp }$ for degassed toluene with the standard uncertainty $u\left(\rho_{\text {fluid }}\right)$; measurements carried out in 2007

\begin{tabular}{cccc}
\hline \hline$t$ & $p$ & $\rho_{\text {exp }}$ & $u\left(\rho_{\text {fluid }}\right)$ \\
$\left({ }^{\circ} \mathrm{C}\right)$ & $(\mathrm{MPa})$ & $\left(\mathrm{kg} \mathrm{m}^{-3}\right)$ & $\left(\mathrm{kg} \mathrm{m}^{-3}\right)$ \\
\hline
\end{tabular}

Filling 1

\begin{tabular}{|c|c|c|c|}
\hline-39.997 & 15.5527 & 930.436 & 0.033 \\
\hline-39.998 & 15.5480 & 930.434 & 0.033 \\
\hline-39.998 & 15.5451 & 930.432 & 0.033 \\
\hline-39.998 & 15.5409 & 930.430 & 0.033 \\
\hline-40.000 & 7.8831 & 926.526 & 0.032 \\
\hline-39.999 & 7.8898 & 926.529 & 0.032 \\
\hline-39.998 & 7.8887 & 926.528 & 0.032 \\
\hline-39.998 & 7.8846 & 926.525 & 0.032 \\
\hline-39.998 & 4.2666 & 924.626 & 0.032 \\
\hline-39.999 & 4.2674 & 924.628 & 0.032 \\
\hline-39.998 & 4.2682 & 924.627 & 0.032 \\
\hline-39.999 & 4.2670 & 924.627 & 0.032 \\
\hline-40.000 & 0.8126 & 922.781 & 0.031 \\
\hline-39.998 & 0.8148 & 922.783 & 0.031 \\
\hline-39.998 & 0.8171 & 922.785 & 0.031 \\
\hline-39.999 & 0.8159 & 922.784 & 0.031 \\
\hline-20.009 & 29.0323 & 920.043 & 0.031 \\
\hline-20.008 & 29.0385 & 920.044 & 0.031 \\
\hline-20.007 & 29.0396 & 920.045 & 0.031 \\
\hline-20.007 & 29.0390 & 920.042 & 0.031 \\
\hline-20.007 & 26.4114 & 918.680 & 0.031 \\
\hline-20.006 & 26.4135 & 918.680 & 0.031 \\
\hline-20.005 & 26.4125 & 918.681 & 0.031 \\
\hline-20.007 & 26.4091 & 918.679 & 0.031 \\
\hline-20.007 & 19.5375 & 915.026 & 0.029 \\
\hline-20.006 & 19.5397 & 915.026 & 0.029 \\
\hline-20.006 & 19.5404 & 915.028 & 0.029 \\
\hline-20.005 & 19.5418 & 915.026 & 0.029 \\
\hline-20.004 & 11.9133 & 910.812 & 0.028 \\
\hline-20.006 & 11.9124 & 910.811 & 0.028 \\
\hline-20.005 & 11.9102 & 910.809 & 0.028 \\
\hline-20.004 & 11.9097 & 910.807 & 0.028 \\
\hline-20.006 & 3.6629 & 906.040 & 0.027 \\
\hline-20.005 & 3.6685 & 906.042 & 0.027 \\
\hline-20.005 & 3.6685 & 906.042 & 0.027 \\
\hline-20.006 & 3.6651 & 906.041 & 0.027 \\
\hline-20.006 & 0.5244 & 904.163 & 0.027 \\
\hline-20.006 & 0.5208 & 904.158 & 0.027 \\
\hline-20.005 & 0.5281 & 904.164 & 0.027 \\
\hline-20.005 & 0.5259 & 904.161 & 0.027 \\
\hline-0.005 & 25.9724 & 901.585 & 0.030 \\
\hline-0.003 & 25.9741 & 901.585 & 0.030 \\
\hline-0.003 & 25.9724 & 901.583 & 0.030 \\
\hline-0.003 & 25.9730 & 901.584 & 0.030 \\
\hline-0.003 & 20.5865 & 898.437 & 0.028 \\
\hline-0.003 & 20.5868 & 898.437 & 0.028 \\
\hline-0.001 & 20.5882 & 898.436 & 0.028 \\
\hline-0.002 & 20.5839 & 898.434 & 0.028 \\
\hline-0.002 & 15.7960 & 895.548 & 0.028 \\
\hline-0.003 & 15.7957 & 895.549 & 0.028 \\
\hline-0.002 & 15.7962 & 895.551 & 0.028 \\
\hline
\end{tabular}


Volume 113, Number 1, January-February 2008

Journal of Research of the National Institute of Standards and Technology

Table A2 (continued)

Table A2 (continued)

\begin{tabular}{|c|c|c|c|c|c|c|c|}
\hline-0.002 & 15.7938 & 895.547 & 0.028 & 79.999 & 27.9757 & 836.823 & 0.038 \\
\hline-0.003 & 7.8170 & 890.543 & 0.027 & 79.999 & 27.9750 & 836.821 & 0.038 \\
\hline-0.002 & 7.8203 & 890.544 & 0.027 & 80.000 & 27.9765 & 836.822 & 0.038 \\
\hline-0.002 & 7.8215 & 890.546 & 0.027 & 80.000 & 27.9761 & 836.822 & 0.038 \\
\hline \multirow[t]{2}{*}{-0.001} & 7.8232 & 890.547 & 0.027 & 80.000 & 19.6924 & 829.628 & 0.036 \\
\hline & & & & 79.999 & 19.6907 & 829.627 & 0.036 \\
\hline 19.999 & 31.2309 & 888.146 & 0.032 & 79.999 & 19.6916 & 829.628 & 0.036 \\
\hline 20.000 & 31.2284 & 888.145 & 0.032 & 80.000 & 19.6937 & 829.629 & 0.036 \\
\hline 20.000 & 31.2275 & 888.144 & 0.032 & 79.998 & 11.5709 & 821.971 & 0.035 \\
\hline 20.000 & 31.2257 & 888.142 & 0.032 & 80.000 & 11.5716 & 821.970 & 0.035 \\
\hline 19.999 & 27.5973 & 885.895 & 0.031 & 79.999 & 11.5711 & 821.971 & 0.035 \\
\hline 19.999 & 27.5933 & 885.892 & 0.031 & 79.999 & 11.5711 & 821.970 & 0.035 \\
\hline 20.000 & 27.5929 & 885.892 & 0.031 & 79.997 & 3.7114 & 813.854 & 0.034 \\
\hline 20.001 & 27.5917 & 885.890 & 0.031 & 79.999 & 3.7131 & 813.853 & 0.034 \\
\hline 20.000 & 20.3644 & 881.254 & 0.029 & 79.999 & 3.7100 & 813.851 & 0.034 \\
\hline 20.001 & 20.3635 & 881.254 & 0.029 & 79.999 & 3.7099 & 813.850 & 0.034 \\
\hline 20.000 & 20.3615 & 881.253 & 0.029 & 79.999 & 1.2011 & 811.081 & 0.034 \\
\hline 20.000 & 20.3629 & 881.253 & 0.029 & 79.998 & 1.1996 & 811.082 & 0.034 \\
\hline 20.000 & 11.6260 & 875.333 & 0.028 & 79.999 & 1.2002 & 811.081 & 0.034 \\
\hline 20.000 & 11.6257 & 875.333 & 0.028 & 80.000 & 1.1997 & 811.081 & 0.034 \\
\hline 20.001 & 11.6313 & 875.336 & 0.028 & & & & \\
\hline 20.000 & 11.6279 & 875.334 & 0.028 & 99.993 & 16.6017 & 809.228 & 0.038 \\
\hline 19.999 & 4.0074 & 869.849 & 0.027 & 99.995 & 16.6061 & 809.230 & 0.038 \\
\hline 19.999 & 4.0093 & 869.850 & 0.027 & 99.997 & 16.6061 & 809.229 & 0.038 \\
\hline 20.001 & 4.0098 & 869.850 & 0.027 & 99.996 & 16.6058 & 809.230 & 0.038 \\
\hline 20.001 & 4.0100 & 869.849 & 0.027 & & & & \\
\hline 20.000 & 1.2611 & 867.787 & 0.027 & 119.997 & 31.5447 & 807.449 & 0.043 \\
\hline 20.000 & 1.2582 & 867.784 & 0.027 & 119.997 & 31.5429 & 807.448 & 0.043 \\
\hline 20.000 & 1.2570 & 867.782 & 0.027 & 119.998 & 31.5447 & 807.449 & 0.043 \\
\hline \multirow[t]{2}{*}{20.000} & 1.2572 & 867.780 & 0.027 & 119.998 & 31.5448 & 807.448 & 0.043 \\
\hline & & & & 119.996 & 27.7615 & 803.659 & 0.042 \\
\hline 49.996 & 32.1864 & 864.433 & 0.035 & 119.998 & 27.7598 & 803.653 & 0.042 \\
\hline 49.996 & 32.1857 & 864.432 & 0.035 & 119.997 & 27.7580 & 803.652 & 0.042 \\
\hline 49.997 & 32.1889 & 864.434 & 0.035 & 119.998 & 27.7580 & 803.651 & 0.042 \\
\hline 49.998 & 32.1914 & 864.434 & 0.035 & 119.997 & 20.2707 & 795.639 & 0.041 \\
\hline 50.001 & 27.9027 & 861.384 & 0.034 & 119.998 & 20.2717 & 795.639 & 0.041 \\
\hline 50.000 & 27.9014 & 861.384 & 0.034 & 119.998 & 20.2706 & 795.639 & 0.041 \\
\hline 49.999 & 27.9005 & 861.383 & 0.034 & 119.998 & 20.2705 & 795.638 & 0.041 \\
\hline 50.000 & 27.9014 & 861.384 & 0.034 & & & & \\
\hline 49.999 & 19.5104 & 855.126 & 0.032 & 119.997 & 11.7558 & 785.529 & 0.039 \\
\hline 50.001 & 19.5104 & 855.121 & 0.032 & 119.997 & 11.7565 & 785.531 & 0.039 \\
\hline 50.001 & 19.5122 & 855.125 & 0.032 & 119.997 & 11.7582 & 785.530 & 0.039 \\
\hline 50.000 & 19.5118 & 855.125 & 0.032 & 119.998 & 11.7595 & 785.533 & 0.039 \\
\hline 50.001 & 11.9712 & 849.117 & 0.031 & 119.998 & 4.0985 & 775.241 & 0.039 \\
\hline 50.000 & 11.9695 & 849.116 & 0.031 & 119.998 & 4.0985 & 775.243 & 0.039 \\
\hline 50.000 & 11.9692 & 849.115 & 0.031 & 119.997 & 4.0981 & 775.242 & 0.039 \\
\hline 50.001 & 11.9696 & 849.115 & 0.031 & 119.998 & 4.0944 & 775.236 & 0.039 \\
\hline 49.999 & 4.2940 & 842.557 & 0.030 & 119.997 & 0.7124 & 770.226 & 0.038 \\
\hline 50.001 & 4.2950 & 842.557 & 0.030 & 119.997 & 0.7132 & 770.229 & 0.038 \\
\hline 50.001 & 4.2943 & 842.557 & 0.030 & 119.997 & 0.7131 & 770.226 & 0.038 \\
\hline 50.001 & 4.2940 & 842.557 & 0.030 & 119.997 & 0.7142 & 770.228 & 0.038 \\
\hline 49.999 & 1.3048 & 839.865 & 0.030 & & & & \\
\hline 50.001 & 1.3056 & 839.865 & 0.030 & 149.997 & 19.2419 & 767.823 & 0.043 \\
\hline 50.000 & 1.3044 & 839.863 & 0.030 & 149.997 & 19.2422 & 767.823 & 0.043 \\
\hline \multirow[t]{2}{*}{50.000} & 1.3044 & 839.862 & 0.030 & 149.997 & 19.2423 & 767.824 & 0.043 \\
\hline & & & & 149.997 & 19.2421 & 767.823 & 0.043 \\
\hline 79.996 & 27.9725 & 836.822 & 0.038 & 149.997 & 19.2423 & 767.823 & 0.043 \\
\hline 79.997 & 27.9729 & 836.823 & 0.038 & 149.998 & 19.2436 & 767.824 & 0.043 \\
\hline 79.998 & 27.9729 & 836.821 & 0.038 & 149.997 & 19.2435 & 767.826 & 0.043 \\
\hline 79.998 & 27.9757 & 836.824 & 0.038 & 149.998 & 19.2438 & 767.825 & 0.043 \\
\hline
\end{tabular}


Volume 113, Number 1, January-February 2008

Journal of Research of the National Institute of Standards and Technology

Table A2 (concluded)

\begin{tabular}{|c|c|c|c|c|}
\hline & 149.999 & 11.6928 & 756.915 & 0.042 \\
\hline & 149.998 & 11.6928 & 756.915 & 0.042 \\
\hline & 149.998 & 11.6916 & 756.913 & 0.042 \\
\hline & 149.998 & 11.6925 & 756.915 & 0.042 \\
\hline & 149.998 & 4.0855 & 744.172 & 0.041 \\
\hline & 149.998 & 4.0847 & 744.171 & 0.041 \\
\hline & 149.998 & 4.0836 & 744.166 & 0.041 \\
\hline & 149.998 & 4.0833 & 744.168 & 0.041 \\
\hline & 149.999 & 1.0294 & 738.375 & 0.041 \\
\hline & 149.998 & 1.0290 & 738.376 & 0.041 \\
\hline & 149.998 & 1.0274 & 738.370 & 0.041 \\
\hline & 149.998 & 1.0265 & 738.368 & 0.041 \\
\hline \multicolumn{5}{|l|}{ Filling 2} \\
\hline & - 39.997 & 13.9488 & 929.635 & 0.033 \\
\hline & -39.996 & 13.9478 & 929.634 & 0.033 \\
\hline & -39.996 & 13.9488 & 929.634 & 0.033 \\
\hline & -39.997 & 13.9484 & 929.637 & 0.033 \\
\hline & -39.997 & 6.3753 & 925.740 & 0.032 \\
\hline & -39.997 & 6.3740 & 925.742 & 0.032 \\
\hline & -39.997 & 6.3777 & 925.743 & 0.032 \\
\hline & -39.997 & 6.3782 & 925.743 & 0.032 \\
\hline & - 39.998 & 1.1573 & 922.970 & 0.031 \\
\hline & -39.997 & 1.1615 & 922.973 & 0.031 \\
\hline & - 39.998 & 1.1611 & 922.974 & 0.031 \\
\hline & -39.998 & 1.1655 & 922.974 & 0.031 \\
\hline & -20.010 & 29.3904 & 920.233 & 0.032 \\
\hline & -20.008 & 29.3994 & 920.235 & 0.032 \\
\hline & -20.007 & 29.4014 & 920.236 & 0.032 \\
\hline & -20.007 & 29.4054 & 920.237 & 0.032 \\
\hline & -20.008 & 11.9975 & 910.865 & 0.028 \\
\hline & -20.005 & 11.9997 & 910.863 & 0.028 \\
\hline & -20.005 & 11.9982 & 910.864 & 0.028 \\
\hline & -20.005 & 12.0003 & 910.864 & 0.028 \\
\hline & 79.991 & 12.0733 & 822.481 & 0.035 \\
\hline & 79.997 & 12.0692 & 822.469 & 0.035 \\
\hline & 79.998 & 12.0665 & 822.465 & 0.035 \\
\hline & 79.998 & 12.0637 & 822.464 & 0.035 \\
\hline & 79.998 & 12.0523 & 822.452 & 0.035 \\
\hline & 79.999 & 12.0521 & 822.450 & 0.035 \\
\hline & 79.999 & 12.0486 & 822.448 & 0.035 \\
\hline & 79.999 & 12.0459 & 822.445 & 0.035 \\
\hline & 79.997 & 7.9338 & 818.319 & 0.035 \\
\hline & 79.999 & 7.9354 & 818.319 & 0.035 \\
\hline & 79.999 & 7.9349 & 818.320 & 0.035 \\
\hline & 79.998 & 7.9341 & 818.318 & 0.035 \\
\hline & 79.998 & 4.0220 & 814.197 & 0.034 \\
\hline & 79.999 & 4.0232 & 814.197 & 0.034 \\
\hline & 79.998 & 4.0190 & 814.197 & 0.034 \\
\hline & 79.998 & 4.0175 & 814.190 & 0.034 \\
\hline & 79.998 & 1.0563 & 810.930 & 0.034 \\
\hline & 79.997 & 1.0556 & 810.927 & 0.034 \\
\hline & 79.999 & 1.0567 & 810.927 & 0.034 \\
\hline & 79.999 & 1.0546 & 810.925 & 0.034 \\
\hline
\end{tabular}

Table A3. Experimentally measured temperatures $t$, pressures $p$, and densities $\rho_{\text {exp }}$ for the air saturated toluene with the the standard uncertainty $u$ ( $\left.\rho_{\text {fluid }}\right)$; measurements carried out in 2007

\begin{tabular}{|c|c|c|c|c|}
\hline & $\begin{array}{c}t \\
\left({ }^{\circ} \mathrm{C}\right)\end{array}$ & $\begin{array}{c}p \\
(\mathrm{MPa})\end{array}$ & $\begin{array}{c}\rho_{\exp } \\
\left(\mathrm{kg} \mathrm{m}^{-3}\right)\end{array}$ & $\begin{array}{l}u\left(\rho_{\text {fluid }}\right) \\
\left(\mathrm{kg} \mathrm{m}^{-3}\right)\end{array}$ \\
\hline \multicolumn{5}{|l|}{ Filling 1} \\
\hline & -39.999 & 18.8499 & 932.043 & 0.033 \\
\hline & - 39.999 & 18.8446 & 932.041 & 0.033 \\
\hline & -39.999 & 18.8418 & 932.040 & 0.033 \\
\hline & - 39.999 & 18.8402 & 932.037 & 0.033 \\
\hline & -40.000 & 6.4334 & 925.734 & 0.032 \\
\hline & -39.999 & 6.4368 & 925.734 & 0.032 \\
\hline & -39.999 & 6.4361 & 925.733 & 0.032 \\
\hline & -39.999 & 6.4336 & 925.731 & 0.032 \\
\hline & -40.001 & 0.8799 & 922.777 & 0.031 \\
\hline & -39.999 & 0.8807 & 922.777 & 0.031 \\
\hline & -40.000 & 0.8839 & 922.780 & 0.031 \\
\hline & -40.000 & 0.8852 & 922.779 & 0.031 \\
\hline & -20.003 & 29.0999 & 920.032 & 0.031 \\
\hline & -20.003 & 29.0956 & 920.034 & 0.031 \\
\hline & -20.002 & 29.1042 & 920.035 & 0.031 \\
\hline & -20.002 & 29.1055 & 920.036 & 0.031 \\
\hline & -20.002 & 21.5364 & 916.057 & 0.030 \\
\hline & -20.002 & 21.5273 & 916.050 & 0.030 \\
\hline & -20.001 & 21.5342 & 916.055 & 0.030 \\
\hline & -20.001 & 21.5294 & 916.050 & 0.030 \\
\hline & -20.001 & 15.6096 & 912.828 & 0.029 \\
\hline & -20.001 & 15.6120 & 912.830 & 0.029 \\
\hline & -20.002 & 15.6091 & 912.828 & 0.029 \\
\hline & -20.001 & 15.6124 & 912.830 & 0.029 \\
\hline & -20.002 & 7.7837 & 908.401 & 0.028 \\
\hline & -20.002 & 7.7850 & 908.402 & 0.028 \\
\hline & -20.001 & 7.7883 & 908.402 & 0.028 \\
\hline & -20.001 & 7.7888 & 908.401 & 0.028 \\
\hline & -20.003 & 1.8406 & 904.900 & 0.027 \\
\hline & -20.001 & 1.8377 & 904.898 & 0.027 \\
\hline & -20.001 & 1.8457 & 904.902 & 0.027 \\
\hline & -20.002 & 1.8459 & 904.903 & 0.027 \\
\hline & -0.005 & 27.3479 & 902.327 & 0.030 \\
\hline & -0.004 & 27.3536 & 902.328 & 0.030 \\
\hline & -0.004 & 27.3524 & 902.328 & 0.030 \\
\hline & -0.004 & 27.3522 & 902.329 & 0.030 \\
\hline & -0.004 & 16.1949 & 895.743 & 0.028 \\
\hline & -0.003 & 16.1946 & 895.739 & 0.028 \\
\hline & -0.003 & 16.1963 & 895.743 & 0.028 \\
\hline & -0.003 & 16.1913 & 895.741 & 0.028 \\
\hline & -0.005 & 7.1952 & 890.086 & 0.027 \\
\hline & -0.002 & 7.1967 & 890.085 & 0.027 \\
\hline & -0.003 & 7.1956 & 890.086 & 0.027 \\
\hline & -0.004 & 7.1966 & 890.086 & 0.027 \\
\hline & 19.997 & 30.5609 & 887.684 & 0.031 \\
\hline & 19.998 & 30.5565 & 887.681 & 0.031 \\
\hline & 19.998 & 30.5587 & 887.682 & 0.031 \\
\hline
\end{tabular}


Volume 113, Number 1, January-February 2008

Journal of Research of the National Institute of Standards and Technology

Table A3 (continued)

Table A3 (continued)

$\begin{array}{lrll}19.998 & 30.5568 & 887.681 & 0.031 \\ 19.998 & 27.3354 & 885.675 & 0.031 \\ 19.998 & 27.3308 & 885.671 & 0.031 \\ 19.998 & 27.3307 & 885.672 & 0.031 \\ 19.999 & 27.3330 & 885.674 & 0.031 \\ 19.997 & 20.3391 & 881.181 & 0.029 \\ 19.999 & 20.3376 & 881.176 & 0.029 \\ 19.998 & 20.3372 & 881.180 & 0.029 \\ 19.998 & 20.3362 & 881.179 & 0.029 \\ 19.997 & 11.9792 & 875.520 & 0.028 \\ 19.999 & 11.9806 & 875.519 & 0.028 \\ 19.998 & 11.9781 & 875.520 & 0.028 \\ 19.998 & 11.9771 & 875.519 & 0.028 \\ 19.997 & 6.1452 & 871.356 & 0.027 \\ 19.998 & 6.1447 & 871.353 & 0.027 \\ 19.998 & 6.1441 & 871.355 & 0.027 \\ 19.998 & 6.1451 & 871.356 & 0.027 \\ 19.997 & 2.0015 & 868.280 & 0.027 \\ 19.998 & 2.0056 & 868.281 & 0.027 \\ 19.998 & 2.0063 & 868.281 & 0.027 \\ 19.998 & 2.0078 & 868.281 & 0.027 \\ 20.000 & 1.9983 & 868.276 & 0.027 \\ 20.000 & 1.9973 & 868.274 & 0.027 \\ 19.999 & 1.9996 & 868.277 & 0.027 \\ 20.000 & 1.9994 & 868.274 & 0.027 \\ 19.999 & 1.9992 & 868.274 & 0.027 \\ 20.000 & 2.0000 & 868.275 & 0.027 \\ 19.999 & 1.9993 & 868.276 & 0.027 \\ 19.999 & 2.0022 & 868.278 & 0.027 \\ 20.000 & 2.0004 & 868.277 & 0.027 \\ 20.000 & 2.0025 & 868.277 & 0.027 \\ 19.999 & 2.0039 & 868.280 & 0.027 \\ 20.000 & 2.0029 & 868.278 & 0.027 \\ 49.996 & 32.9841 & 864.927 & 0.035 \\ 49.997 & 32.9820 & 864.927 & 0.035 \\ 49.998 & 32.9772 & 864.920 & 0.035 \\ 49.999 & 32.9801 & 864.922 & 0.035 \\ 49.999 & 27.8278 & 861.270 & 0.034 \\ 50.001 & 27.8253 & 861.266 & 0.034 \\ 50.000 & 27.8228 & 861.265 & 0.034 \\ 50.000 & 27.8218 & 861.265 & 0.034 \\ 50.000 & 19.9628 & 855.405 & 0.032 \\ 50.000 & 19.9585 & 855.403 & 0.032 \\ 50.000 & 19.9575 & 855.399 & 0.032 \\ 50.001 & 19.9590 & 855.400 & 0.032 \\ 50.000 & 11.0857 & 848.311 & 0.031 \\ 49.999 & 11.0829 & 848.309 & 0.031 \\ 50.000 & 11.0831 & 848.307 & 0.031 \\ 50.000 & 11.0782 & 848.304 & 0.031 \\ 49.998 & 5.8874 & 843.881 & 0.030 \\ 50.000 & 5.8869 & 843.880 & 0.030 \\ 50.000 & 5.8849 & 843.882 & 0.030 \\ 49.999 & 5.8838 & 843.879 & 0.030 \\ 49.998 & 1.5804 & 840.035 & 0.030 \\ 50.000 & 1.5816 & 840.036 & 0.030 \\ 50.000 & 1.5807 & 840.035 & 0.030 \\ 49.999 & 1.5819 & 840.036 & 0.030\end{array}$

\begin{tabular}{|c|c|c|c|}
\hline 79.995 & 28.2844 & 837.014 & 0.038 \\
\hline 79.996 & 28.2827 & 837.012 & 0.038 \\
\hline 79.996 & 28.2826 & 837.010 & 0.038 \\
\hline 79.997 & 28.2848 & 837.011 & 0.038 \\
\hline 79.996 & 19.4690 & 829.354 & 0.036 \\
\hline 79.998 & 19.4694 & 829.352 & 0.036 \\
\hline 79.999 & 19.4665 & 829.347 & 0.036 \\
\hline 79.998 & 19.4640 & 829.347 & 0.036 \\
\hline 79.998 & 11.3224 & 821.647 & 0.035 \\
\hline 79.997 & 11.3192 & 821.639 & 0.035 \\
\hline 79.998 & 11.3200 & 821.643 & 0.035 \\
\hline 79.998 & 11.3199 & 821.640 & 0.035 \\
\hline 79.997 & 5.9936 & 816.209 & 0.034 \\
\hline 79.999 & 5.9937 & 816.206 & 0.034 \\
\hline 79.998 & 5.9954 & 816.207 & 0.034 \\
\hline 79.997 & 5.9945 & 816.208 & 0.034 \\
\hline 79.997 & 2.1535 & 812.055 & 0.034 \\
\hline 79.998 & 2.1546 & 812.057 & 0.034 \\
\hline 79.998 & 2.1556 & 812.055 & 0.034 \\
\hline 79.998 & 2.1525 & 812.052 & 0.034 \\
\hline 99.992 & 17.6003 & 810.191 & 0.038 \\
\hline 99.995 & 17.6029 & 810.195 & 0.038 \\
\hline 99.996 & 17.5995 & 810.189 & 0.038 \\
\hline 99.996 & 17.5996 & 810.188 & 0.038 \\
\hline 119.996 & 32.5440 & 808.391 & 0.043 \\
\hline 119.996 & 32.5433 & 808.393 & 0.043 \\
\hline 119.996 & 32.5427 & 808.389 & 0.043 \\
\hline 119.996 & 32.5412 & 808.385 & 0.043 \\
\hline 119.996 & 28.1025 & 803.966 & 0.042 \\
\hline 119.995 & 28.0980 & 803.961 & 0.042 \\
\hline 119.996 & 28.0996 & 803.959 & 0.042 \\
\hline 119.997 & 28.1017 & 803.961 & 0.042 \\
\hline 119.995 & 19.1983 & 794.384 & 0.040 \\
\hline 119.997 & 19.1966 & 794.381 & 0.040 \\
\hline 119.997 & 19.1978 & 794.382 & 0.040 \\
\hline 119.997 & 19.1966 & 794.381 & 0.040 \\
\hline 119.997 & 11.5355 & 785.196 & 0.039 \\
\hline 119.997 & 11.5347 & 785.196 & 0.039 \\
\hline 119.997 & 11.5340 & 785.194 & 0.039 \\
\hline 119.997 & 11.5360 & 785.198 & 0.039 \\
\hline 119.996 & 5.8395 & 777.639 & 0.039 \\
\hline 119.997 & 5.8405 & 777.643 & 0.039 \\
\hline 119.997 & 5.8384 & 777.636 & 0.039 \\
\hline 119.997 & 5.8373 & 777.637 & 0.039 \\
\hline 119.995 & 1.9513 & 772.036 & 0.038 \\
\hline 119.997 & 1.9553 & 772.039 & 0.038 \\
\hline 119.997 & 1.9557 & 772.039 & 0.038 \\
\hline 119.997 & 1.9562 & 772.040 & 0.038 \\
\hline 149.995 & 20.6286 & 769.625 & 0.043 \\
\hline 149.996 & 20.6304 & 769.627 & 0.043 \\
\hline 149.996 & 20.6320 & 769.629 & 0.043 \\
\hline 149.998 & 20.6329 & 769.629 & 0.043 \\
\hline 149.998 & 12.0061 & 757.332 & 0.042 \\
\hline 149.997 & 12.0055 & 757.335 & 0.042 \\
\hline 149.997 & 12.0043 & 757.331 & 0.042 \\
\hline 149.998 & 12.0047 & 757.331 & 0.042 \\
\hline
\end{tabular}


Table A3 (concluded)

$\begin{array}{llll}149.998 & 6.1527 & 747.768 & 0.041 \\ 149.998 & 6.1525 & 747.773 & 0.041 \\ 149.997 & 6.1517 & 747.772 & 0.041 \\ 149.998 & 6.1511 & 747.767 & 0.041 \\ 149.998 & 1.4862 & 739.185 & 0.041 \\ 149.998 & 1.4859 & 739.185 & 0.041 \\ 149.998 & 1.4858 & 739.186 & 0.041 \\ 149.998 & 1.4858 & 739.184 & 0.041\end{array}$

Filling 1a

$\begin{array}{llll}50.002 & 2.0528 & 840.504 & 0.030 \\ 50.001 & 2.0540 & 840.506 & 0.030 \\ 50.000 & 2.0528 & 840.506 & 0.030 \\ 50.000 & 2.0523 & 840.507 & 0.030 \\ 50.000 & 2.0493 & 840.503 & 0.030 \\ 50.001 & 2.0499 & 840.502 & 0.030 \\ 50.000 & 2.0474 & 840.501 & 0.030 \\ 50.000 & 2.0467 & 840.499 & 0.030 \\ 50.000 & 2.0469 & 840.500 & 0.030 \\ 50.000 & 2.0441 & 840.498 & 0.030 \\ 50.000 & 2.0472 & 840.500 & 0.030 \\ 50.000 & 2.0436 & 840.497 & 0.030\end{array}$

\section{Acknowledgments}

We thank our NIST colleagues T. Bruno and J. Widegren for the chemical analysis of the toluene samples. R. Gomez calibrated the pressure transducer, and $\mathrm{M}$. Yetzbacher created the drawing of the hydrostatic apparatus. J. Wright provided the sample of SRM 211d used in this work. We acknowledge helpful discussions with R. Perkins and J. Wang on the experiments and statistical analysis, respectively.

\section{References}

[1] M. O. McLinden and C. Lösch-Will, Apparatus for wide-ranging, high-accuracy fluid ( $p-\rho-T)$ measurements based on a compact two-sinker densimeter, J. Chem. Thermodynamics 39, 507-530 (2007).

[2] W. Wagner and R. Kleinrahm, Densimeters for very accurate density measurements of fluids over large ranges of temperature, pressure, and density, Metrologia 41, S24-S39 (2004).

[3] M. O. McLinden, R. Kleinrahm, and W. Wagner, Force transmission errors in magnetic suspension densimeters, Int. J. Thermophysics 28, 429-448 (2007).

[4] V. E. Bean and J. F. Houser, Report of Analysis, Characterization of Toluene as a Liquid Density Standard, SRM 211d, Report to the NIST Standard Reference Materials Program (2000).

[5] G. L. Harris and J. A. Torres, Selected laboratory and measurement practices and procedures, to support basic mass calibrations, National Institute of Standards and Technology NISTIR 6969, Gaithersburg, MD (2003).

[6] R. S. Davis, Equation for the determination of the density of moist air (1981/91), Metrologia 29, 67-70 (1992).
[7] H. A. Bowman, R. M. Schoonover, and C. L. Carroll, A density scale based on solid objects, J. Res. NBS 78A, 13-40 (1973).

[8] H. A. Bowman, R. M. Schoonover, and C. L. Carroll, The utilization of solid objects as reference standards in density measurements, Metrologia 10, 117-121 (1974).

[9] Z. J. Jabbour, Report of Calibration, NIST Test Number 822/6654-00, National Institute of Standards and Technology, Gaithersburg, MD (2000).

[10] C. A. Swenson, Recommended values for the thermal expansivity of silicon from 0 to $1000 \mathrm{~K}$, J. Phys. Chem. Ref. Data 12, 179-182 (1983).

[11] Y. S. Touloukian, R. K. Kirby, R. E. Taylor, and P. D. Desai, Thermophysical Properties of Matter, Volume 12, Part 1, Thermal Expansion: Metallic Elements and Alloys, IFI/Plenum, New York (1975).

[12] S. J. Ashcroft and M. B. Isa, Effect of dissolved gases on the densities of hydrocarbons, J. Chem. Eng. Data 42, 1244-1248 (1997).

[13] International Organization for Standardization, Guide to the Expression of Uncertainty in Measurement, International Organization for Standardization, Geneva Switzerland, (corrected and reprinted 1995).

[14] C. J. Smithells, Smithells Metals Reference Book, 7th edition, Butterworth-Heinemann, Boston (1997).

[15] M. O. McLinden, Densimetry for primary temperature metrology and a method for the in-situ determination of densimeter sinker volumes. Measurement Science and Technology 17, 2597-2612 (2006).

[16] R. Span, E. W. Lemmon, R. T Jacobsen, W. Wagner, and A. Yokozeki, A reference equation of state for the thermodynamic properties of nitrogen for temperatures from 63.151 to $1000 \mathrm{~K}$ and pressures to $2200 \mathrm{MPa}$, J. Phys. Chem. Ref. Data 29, 13611433 (2000).

About the authors: Mark O. McLinden is a chemical engineer in the Physical and Chemical Properties Division of the NIST Chemical Science and Technology Laboratory. Jolene D. Splett is a statistician in the Statistical Engineering Division of the NIST Information Technology Laboratory. The National Institute of Standards and Technology is an agency of the U.S. Department of Commerce. 